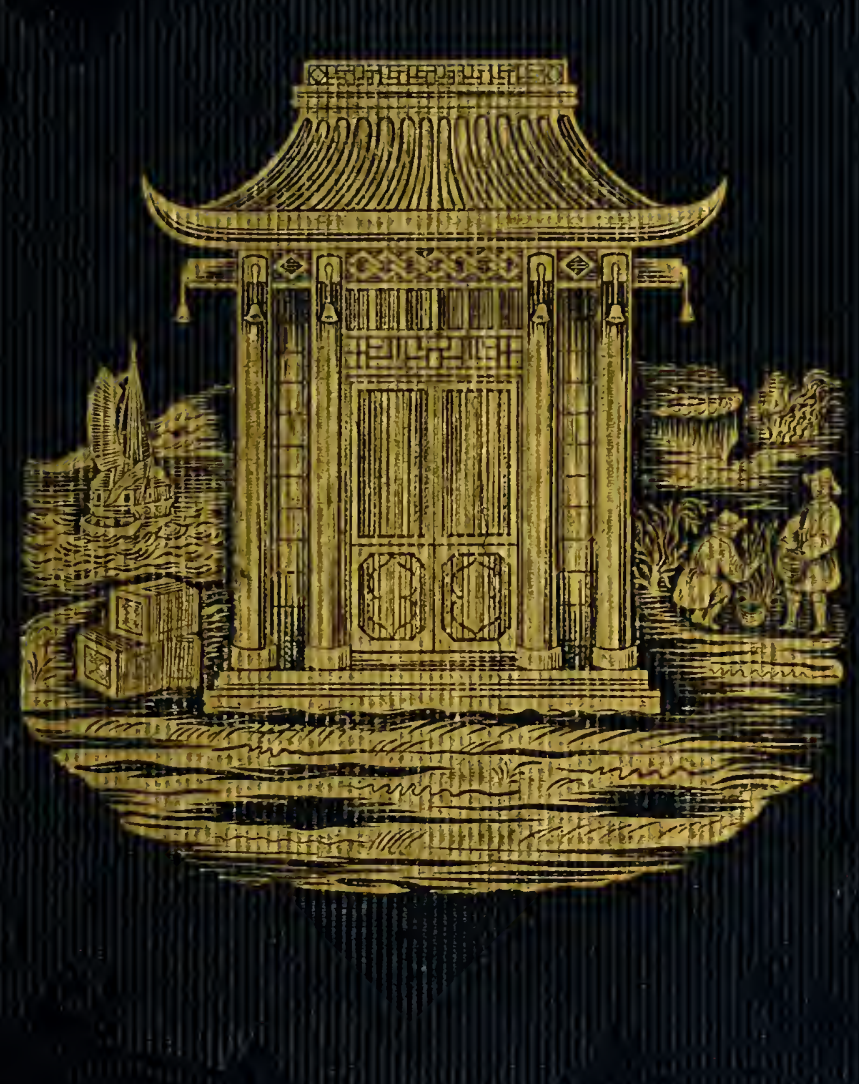



Digitized by the Internet Archive in 2010 with funding from University of Ottawa 


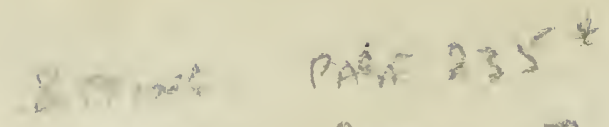

Veation Ano 447 
MONOGRAPHIE

DU TIIE 



\section{MONOGRAPIIIE}

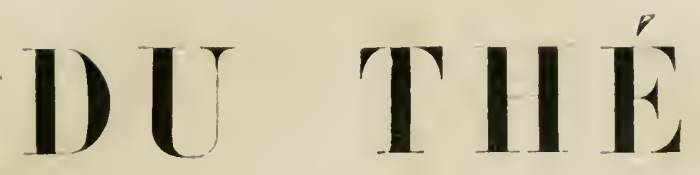

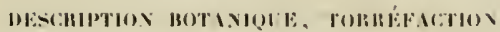

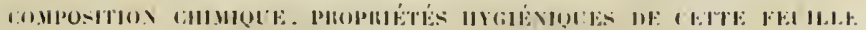

\section{PAR J.-G. HOUSSAYE}

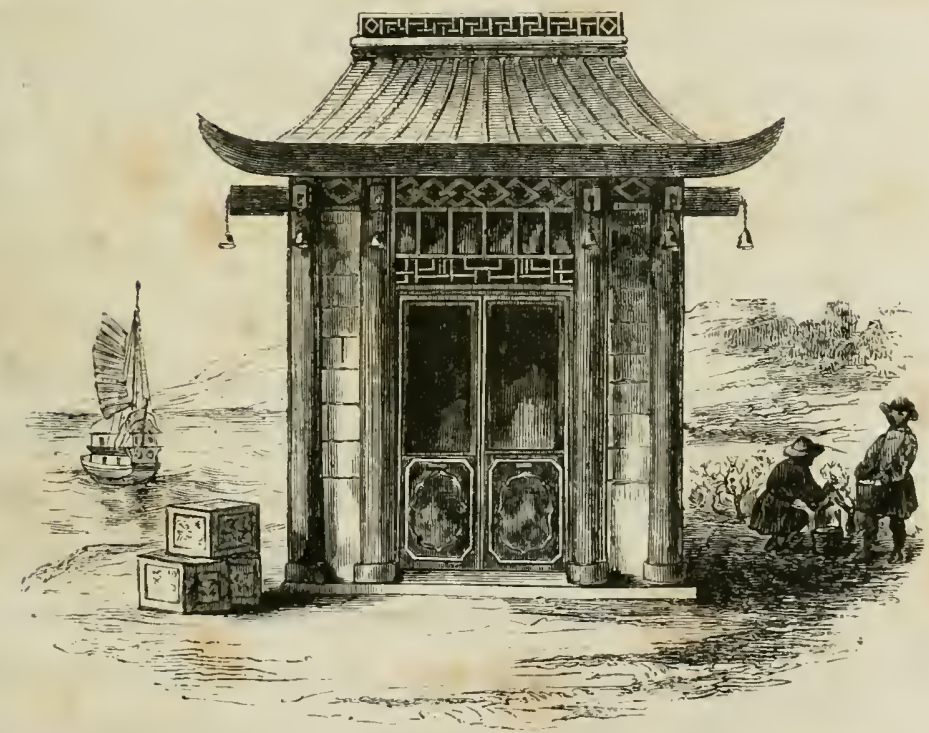

\section{PARIS}

CHEZ L'AUTEUR, 3 RUE DE IA BOURSE

$18 \%: 3$ 



\section{INTRODUCTION.}

Parmi les produits végétaux que les peuples européens reçoivent des autres parties du monde, et dont la consonmation est devenue pour plusieurs d'entre eux une nécessité de premier ordre, le thé doit occuper un rang a part; ses propriétés à la fois alimentaires, hygiéniques et médicales, lui confèrent des droits légitimes à cette distinction. On peut affirmer, sans crainte de tomber dans l'exagération, qu'aucune des substances exotiques les plus justement estimées, et dont l'usage est depuis longtemps passé dans nos habitudes, ne réunit autant de qualités précieuses que la feuille du thé. Elle n'a pas seulement enrichi l'hygiène d'une boisson nutritive, toujours suave, toujours salubre, qui ne redoute aucune comparaison sous ce rapport avec le café ou le chocolat; elle n'a pas seulement accru la somme de nos jouissances domestiques, de nos plaisirs de famille et de société, elle a fait mieux, elle nous a procuré un moyen simple, économique, et presque toujours souverain, de maintenir dans leur état 
normal et régulier nos organes et même nos facultés intellectuelles; elle a enfin fourni un puissant spécifique pour prérenir ou combattre une foule d'affections plus ou moins légères auxquelles le corps humain est si souvent sujet.

Il n'entre pas dans mes rues d'attribuer à ce végétal toutes les propriétés merveilleuses que quelques auteurs enthousiastes se sont plu à lui reconnaître; mais on ue peut voir sans intérêt la marche ascendante que cette feuille a prise en Europe depuis son introduction, le mouvement commercial auquel elle a donné lien dans toute l'Europe et même dans le Noureau Monde, et l'amélioration que cette boisson a apportée dans les habitudes des divers peuples qui en font un usage journalier.

Depuis vingt ans, je me suis spécialement occupé de ce commerce; j’ai fait les recherches les plus consciencieuses sur la nature de cette plante; j'ai lu tous les auteurs anciens et modernes qui ont écrit sur le thé ; j’ai comparé les diverses analyses qui en ont été faites; j’ai moi-mıême, en dégustant des thés, fait des expériences sur les différences de goùt et la nature de leurs effets; et pour m'entourer de renseignements plus suirs, j’ai, non-seulement puisé mes documents dans les ouvrages de Short et de Lettsom, qu'on a longtemps considérés comme elassiq̣ues dans le genre; dans ceux plus nouveaux des docteurs Abel, Newnham, Signnond; consulté les récits des hommes dignes de foi qui ont séjourné en Chine, tels que les Pères 
de Phodes, du Halde, monseigneur Carpena, actuellement vicaire apostolique au Fo-Kien; le révérend ministre anglican Nedhurst; analysé les travaux récemment publiés de MM. Davis et Bruce, dont le caractère officiel domne une grande autorité à ce cu'ils ont écrit relativement au thé; mais encore, je me suis appuyé de l'autorité et des lumières de plusieurs savants distingués de notre époque. Cumme les notions qu'on possède sur la nature chimique du thé sont anciennes, incomplètes, et le plus sourent contradictoires, je me suis adressé à MI. Peligot, professeur de chimic au Conservatoire royal des arts et métiers, bien commu par les nombreux travaux scientifiques qu'il a publiés, pour qu'il reuille bien coordouner les faits acquis à la science sur la composition du thé, et compléter, par l'analyse comparative des échantillons authentiques de tous les thés commerciaux qu'on consomme en France, les documents que nous avons déjil sur ce sujet. J'ai eu recours au savoir et à l'expérience d'un de nos praticiens les plus célèbres, M. le docteur Troussean, médecin de l'hôpital Necker, professeur de thérapeutique à la Faculté de médecine de Paris, qui a bien voulu faire de nombreuses expériences avec des thés que j'avais mis à sa disposition, et qui a pu apprécier par luimême et vérifier ce qui avait été déjà publié par les auteurs dont j’ai parlé plus baut.

Les rapports de ces deux savants professeurs forment les septième et buitième chapitres de cet ouvrage. 
J'ai tâché en classant les thés, de les désigner d'une manière assez claire pour mettre le public à même de distinguer les espèces.

Et j'ai terminé cette esquisse par la manière de préparer cette boisson èn indiquant les mélanges de thésqui peurent flatter le goùt sans nuire à la santé. Mais j'ai dủ rester à cet égard dans des limites très-circonscrites, en raison de la variété des tempéraments, de la différence des goûts et des habitudes qu'il eût été trop long d'énumérer ici, et auxquels une longue expérience peut seule servir de guide. 


\section{DU THÉ.}

\section{CHAPITRE PREMIER.}

Histoire du Thé et son introduction en Europe.

L'usage du thé, établi depuis un temps immémorial, en Chine et au Japon, d'où il s'était répandu dans l'Inde, l'Arabie, la Tartarie et même la Perse, resta inconnu en Europe juscque vers le milieu du xviI ${ }^{\mathrm{e}}$ siècle, c'est-à-dire jusqu'à l'époque où la découverte du cap de Bonne-Espérance, faite un siècle et demi auparavant par Barthélemy de Dias, eut rouvert aux principales nations maritimes de l'Occident la route des Indes fermée à l'Europe depuis l'apparition de l'islamisme. Une spéculation de la compagnie des Indes-Hollandaises, constituée en 1602, amena la première importation du thé dans nos contrées. Sachant vaguement que les Chinois et les Japonais, avec qui ils entretenaient des relations de commerce, tiraient leur boisson ordinaire d'un arbuste de leur climat, des armateurs hollandais voulurent essayer si ces peuples feraient cas d'une plante européenne que l'école de Salerne van- 
tait alors comme un spécifique infaillible contre un grand nombre d'affections morbides. Ils leur expédièrent une grande quantité de sauge qui leur fut payée en thé, daus la proportion de trois livres de cette dernière substance contre une de la première. Ils vendirent à Paris ce thé, qui ne leur revenait qu'à huit ou dix sous la livre, jusqu'ì 30 et même 100 franes. Ils approvisionnèrent pendant plusieurs ammées notre pays du peu de thé qui s'y consommait. On comprend que le goût de la plante enropéenne ne dura que peu de temps en Chine, tandis que celui de la feuille chinoise alla croissant en Europe. En 1655; il était déjà si bien répandı dans la haute société de notre capitale que le $\mathrm{P}$. Alexandre de Rhodes, qui arail habité la Chine pendant trente-cing ans, de 1618 à 1653, termine ainsi un chapitre de l'bistoire de ses voyages : “ Je " me suis un peu étendu sur le discours du thé, parce " que depuis que je suis arrivé en France, j’ai eu l'hon" neur de roir un grand nombre de personnes d'illustre " condition et d'excellent mérite qui s'en servent avec " profit et qui ont eu la bonté de vouloir que je leur disse " ce que mon expérience de trente-cing ans m'arait " appris de cette plante. " - Le même Père dit quelques lignes plus haut: "On comnence à connaitre le thé en “France, par le moyen de messieurs les Hollandais qui “ l'apportent de la Chine et le rendent à Paris 30 francs la " livre qu'ils ont achetée en ce pays-là huit ou dix sous, " et encore, vois-je ordinairement qu'il est vieux et gâté. “C'est ainsi que nos Français laissent enrichir les étran" gers dans le négoce des Indes-Orientales d'où ils pour"raient tirer les plus belles richesses du monde, s'ils " avaient le courage de l'entreprendre aussi bien que leurs 
"roisins qui ont moins de moyens d'y réussir qu'enx." Cette réflexion, encore anjourd'hui pleine d'à-propos, fait honneur au jugement et au patriotisme du pieux écrivain. Du reste, il n'est pas lo seul de son ordre qui ait donné cet excellent avis. Le recueil des Lettres ćdifiantes des jésuites abonde en citations de ce genre, attestant le zèle des missionnaires de la Chine pour les intérêts de la France (qu'ils identifiaient en quelque sorte arec ceux de la religion. Leurs instances à ce sujet auprès du grand roi et de ses ministres ne furent pas toujours sans succès. Au commencement du xrure siècle, existaient à Canton plusieurs établissements français, qui déclinèrent et disparurent à mesure que le crédit dont les jésuites jouissaient en Chine s'affaiblissant eùt fait place à des persécutions d'abord indirectes, puis tout-à-fait déclarées.

On doit croire que ces Pìres ne furent point étrangers à l'introduction du thé dans les sálons de la capitale, pendlant le xrmi siècle; mais l'initiative que prirent quelques savants, tant français qu'étrangers, pour recommander ceite boisson fut encore plus efficace. Nicolas Tulpius, médecin hollandais, fut presque le premier qui, en 1640, écrivit sur les propriétés médicinales du thé : ses observations n'étaient pas toutes de lui; il les avait puisées en grande partie auprès de marins instruits qui avaient fréquenté les mers de Chine. Avant lui, en 1600 , l'Espagnol Hereira avait vu à Malacca des feuilles sèches de thé avec lesquelles on lui dit que les Chinois faisaient une boisson. En 1633, le voyageur hollandais Oléarius avait vu cette habitude en vigueur chez les Persans, qui se procuraient cette denrée par l'intermédiaire des Tartares d'Usbeck. En 1639 , Starkoff, ambassadeur moscovite à la cour du 
grand mogol Schah-Ali, prit part à une infusion de thé, et à son départ le sultan lui en offrit plusicurs caisses pour être offertes en présent au czar Michel Romanoff, mais l'ambassadeur refusa en alléguant que son maître n'en faisait point usage.

En 1648, Morisset, médecin français, publia une apologie du thé; en 1657, Jonquet, autre médecin français, fit paraître un petit traité sur cette plante dans lequel il l'appelait une herbe divine et la comparait à l'ambroisie. En 1678, parut sur le mème sujet un ouvrage plus complet qui eut un si grand retentissement que trois éditious en furent épuisées aussitôt qu'imprimées. Il était intitulé : T'raité sur l'excellente boisson du thé, par Cornelius Bentekoë. L'auteur, Hollandais de naissance, et médecin ordinaire de l'électeur de Brandebourg, l'un des princes les plus éclairés de l'Europe, se déclarait le champion dı thé contre le café et le chocolat. Quoique son livre ait été l'objet de critiques sévères et en partie fondées, en raison des louanges exagérées qu'il donne à la feuille chinoise, il est hors de doute qu'au moment où il parut, il lui conquit un grand nombre de partisans. Il fut traduit dans toutes les langues. Orercamp, biographe de Bentekoë, dit que ce dernier ne se montra si passionné admirateur du thé que pour se concilier les bonnes grâces de la compagnie des Indes-Hollandaises qui le récompensa généreusement, et en même temps pour faire de l'opposition à ceux de ses confrères qui ne partageaient pas ses opinions sur les vertus de cette plante. Cependant, d'autres médecins, à l'exemple de Bentekoë, embrassèrent la cause du thé, tels qu'en Angleterre, Sydenham; en Allemagne, Etmüller qui célébra ses propriétés céphaliques et stoma- 
chiques; en France, Geoffroy, Lémery, dans son Traité des aliments; Andry (le Thé d Europe, 1712).

On n'est pas certain lequel du thé ou du café a été le premier introduit en Angleterre. Andrew Ellis, Haugthon et plusieurs autres autorités archéologiques se prononcent en faveur du café. Dans tous les cas, l'usage de ce dernier ne précéda celui du thé que d'un espace de temps presque imperceptible. On a prétendu que e'est Daniel Edwards, membre de la compagnie de Turquie, qui sous le protectorat de Cromwell, en 1652, apporta le premier café à Londres; ct que ce fut son domestique Pasque, Grec de naissance, qui ourrit le premier établissement public où l'on apprêtât cette boisson à la manière turque. Mais cette opinion est contredite par l'imposant témoignage de l'antiquaire Anthony Wood, qui affirme qu'un café était ouvert à Oxford dès 1650 .

Quant au thé, les lords Ossory et Arlington passent à tort pour en avoir amené de Chine le premier chargement, en 1666. Des manuscrits échappés au récent incendie de la Tour de Londres, constatent qu'un navire anglais débarqua, en 1661, une certaine quantité de cette substance; ils en donnent même les noms; le bohea pour les thés noirs; le hyson et le songlo pour les thés verts. Un autre manuscrit de 1660, donné au Nuséum britannique par Georges IV, porte ce titre curieux : “ Description exacte de la culture, des qualités et des vertus de la feuille de thé, par Thomas Garway, marchand de tabac, débitant de thé et de café en gros et en détail, dans $\mathbf{E x}-$ change-Alley, près la Bourse, à Londres. " Ce Garway ou Garraway par altération, parait avoir été le fondateur du café Garraway, l'un des plus connus et des plus fréquen- 
tés de Londres, jusque dans ces derniers temps qu'il a été enveloppé dans l'incendie de la Bourse.

Ce qui dénontre d'ailleurs que la première importation de thé est antérieure ì 1666 , c'est le bill adopté par le parlement en 1660 et qui frappe d'un droit de 8 pence (80 c.) chaque gallon (4 litres $1 / 2$ ) de thé vendu daus les cafés et les tavernes. Par ce bill, ces deux sortes d'étab)lissemeuts juscuu'alors distincts avaient désormais à supporter les mêmes charges fiscales. Les maîtres de café étaient également obligés de se pourvoir d'une licenee, et de donner caution pour le paiement des taxes d'accise. En cas de contravention, ils étaient passibles d'une amende de einq livres sterling par mois. Leurs maisons, de même que les tavernes, étaient visitées deux fois par jour par des employés chargés spécialement de s'assurer de la quantité de thé, de café, de chocolat et de sorbets qui s'y consomnait, afin d'établir les droits du fisc en conséquence. Ce mode vexatoire d'inspection et de perception eût arrêté l'essor de la consommation de tout autre produit moins bien approprié au goût de la nation que le thé. Il subsista néanmoins pendant 29 ans, c'est-à-dire jusqu'en 1689, où il fut supprimé par un acte de Guillaume III et de Marie Stuart, sa fernme; acte dans lequel il est dit : "que l'expérience, ayant démontré l'imper"fection du mode d'impôts qui grevait les boissons ven" dues dans les cafés, telles que thé, café, chocolat; ayant " établi qu'il était onéreux aux débitants comme aux con" sommateurs; qu'il nécessitait l'entretien d'un nombreux " personnel d’employés, il était aboli et remplacé par un "droit additionnel de cinq schellings de plus par gallon." Depuis cette époque, la taxe sur le thé a été un revenu 
héréditaire de la couronne, il en est aujourd'hui le plus productif '

Ainsi; d'après les recherches consciencieuses des sitvants, il est ì peu près généralement recomnu que l'usage du thé remonte dans la Grande-Bretigne ì l'annće 1652; mais il n'existe aucun document authentique qui fasse connaître la quantité importée depuis cette amnée $\mathbf{1 6 5 2}$ jusqu'en 1669, ditte précise de l'arrivée it Londres du premier chargement de thé effectué par la Compagnie des Indes ${ }^{2}$. Cette quantité au surplus doit être très-minime, car les registres de l'accise n'en font aucune mention; le prix du thé était alors si éleré que les grandes maisons seules pouvaient y atteindre. La livre en gros ne contait pas moins de 50 ì 60 schellings, somme bien plus considérable que celle qu'elle représente aujourd'hui, si on tient compte de la supériorité de valeur intrinsèque de l'or et de l'argent, à cette époque. La petite cargaison de thé de 1661 se vendit à 56 schellings la livre; il est vai que ce cours exagéré ne se soutint pas. En 1668, les directeurs écrivirent ì leur factorerie de Bantam à Java pour ordonner qu'on leur envoyât par un de leurs vais-

' Les annales chinoises font remonter le premier impôt du thé, dans le Céleste Empire, à l'année 78. de notre ère, sons le règue du garand enıpereut' de la treizieme dynastie, Içuel port.it le nom de Tang. Pour mettre fiu à linsolente prépondérance des eunnques qui fomenterent des gnerres civiles, cн prince fut obligé d'entretenir de nombreuses armées; l'impôl llu thé l’aida à faire face aux dépenses extraordinaires que nécessita la rébellion d'une partie de ses sujets.

2 La Compagnie des Indes, fondée en 1599 par la grande reine Élisabeth, ne commença réellement à fonctionner que sous le roi Jaçues Ier qui la dota de: nombreux priviléges. Dès 163 , le capitaine Wessel, commandant un des naviles de la Compagnie, était parvenu, après plusieurs difficultés suscitées par les [lollandais, à pénétrer à Canton, où il avait été anicalement accueilli par les chinois; c'est depuis celte époque que datent les relations commerciales des deux peuples. 
seaux cent livres pesant du meilleur thé qu'on pourrait se procurer. La factorerie en expédia, l'annće suivante 1669 , 143 livres 8 onces. Les directeurs de la Compagnie en offrirent 22 livres ì la reine Catherine de Portugal, femme de Charles II. C'est à l'occasion de ce cadeau présentė à la princesse, le jour de sa naissance, que IValler, le poètecourtisan, le joyeux ami des Rochester et des Buckingham, fit une pièce de vers qui peint fidèlement les mœurs relâchées de la cour de Charles II. Cette boisson devait y étre déjà fort estimée, car on lit dans les mémoires de lord Clarendon, le célébre chancelier Hyde, beau-père du duc d'York, depuis Jacques II : "Le R. père Couplet "soupa avec moi, et après le dessert, nous primes du " thé; il m'assura qu'il était réellement aussi bon que " celui qu'il avait pris en Chine où il avait été mission" naire. " L'un de ses contemporains, sir Pepys, secrétaire de l'amiranté, écrivait dans ses mémoires, à la date de 1662 : "J'ai envoyé chercher une tasse de thé; c'est une " boisson chinoise dont je n'ai pas encore goutté. "

La factorerie de Bantam expédia en 1670 à la Compagnie 79 liv. 6 onc., ce qui ajouté aux 143 liv. 8 onc. de l'année précédente, fait daus l'espace de deux ans 222 liv. 14 onc., dont 132 avariées furent vendues aux enchères au prix de 3 schellings 2 pence ( 3 fr. 95 .c.). La Compagnie se réserva le surplus pour ses menibres. En 1671, elle reçut 264 livres de thé de Bantam; en 1672, 1673 et 1674, elle en acheta 50 liv. 10 onc. de divers particuliers, parmi lesquels on remarque M. Thomas Garraway. En 1675,1676 et 1677, la Compagnie n'en importa point ni ne fit aucun achat. Ainsi, dans l'espace de neuf ans, de 1669 à 1677 inclusivement, il ne fut importé en Angle- 
terre que 542 liv. 8 onc. sur lesquelles $\mathbf{1 3 2}$ liv. d'avariées. - On a calculé que de 1652 à 1700 le chiffre des importations n'excéda pas 181,145 liv., total qui représente à peine la $180^{\circ}$ partie de ce qui se consommait un sic̀cle plus tard, en 1800 , et la $200^{\circ}$ de ce qui se consomme aujourd'hui.

Tels furent les lents et humbles débuts dı thé, qui devait jouer plus tard un si grand rôle dans l'histoire politique, commerciale et économique de la Grande-Bretagne. Enrichie en grande partie par ce commerce dont elle avait le monopole, la compagnie des Indes allait moins d'un siècle après doter la métropole d'un empire vingt fois plus vaste et dix fois plus peuplé qu'elle, d'une fertilité extraordinaire, et dont le sol, sans cesse couvert de précieux produits agricoles, recelait dans son sein des mines d'or et de diamants. Cette immense conquete, œuvre à la fois de la politique, des armes et de la civilisation, fut accomplic presque tout entière dans l'espace d'un demi-siècle par une simple association de marchands, exemple inoui dans les fastes de l'antiquité grecque et romaine. $0 \mathrm{r}$, il est permis de croire que sans les énormes bénéfices que lui procurait le monopole du thé, jamais la Compagnie ne se fût trouvée en état de concourir si efficacement aux vues ambitieuses de la mère-patrie. Développement de sa marine marchande, affermissement de sa domination dans l'Hindoustan, débouché de la Chine, si longtemps fructueux pour ses manufactures, roila les bienfaits dont l'Angleterre est redevable à une simple feuille exotique. Faut-il s'étonner ensuite qu'elle lui ait roué une prédilection si constante et si universelle ! que plusieurs de ses 
poëtes en aient fait le sujet de leurs chants ${ }^{\mathbf{1}}$; que ses écrivains et ses savants les plus illustres aient célébré les vertus de cette boisson vraiment nationale?

Les expéditions de thé pour l'Angleterre et la Họllande s'élevèrent sensiblement à partir de 1685 , parce que la dynastie tartare régnante à Pékin acheva de soumeltre les provinces chinoises qui obéissaient à son compétiteur Tching-lie-san, et que pour témoigner sa reconnaissance aux Européens qui l'araient aidé dans cette entreprise, l'empereur permit par un édit, à ses sujets, de coinmercer arec les barbares. Toutefois, à cette époyue, la minière de préparer le thé n’était guère connue en Angleterre que dans quelques grandes maisons de la capitale; les chroniques du temps rapportent que la veuve de l'infortuné duc de Montriouth ayant envoyé une livre de thé à un de ses parents en Écosse, sạns indiquer la métliode de l'apprèter, le cuisinier fit bouillir la plante, jeta la liqueur, et servit les feuilles comme un plat d'épinards. $11 \mathrm{y}$ a lieu de croire que l'étrangeté de ce mets ne fut pas tout-i-fait du goùt des convires.

L'homme qui contribua le plus à populariser le thé en

1 Parmi eux, il faut ranger Waller Henrich, le poëte lauréat Tales; Peters Francius, qui composa sur ce divin hreurage deux dillyrambes; Peuchlin, qui publia également sur ce sujet un dialogue iıtitulé: Theophilus Bibaculus; Petit, à qui le thè inspira un poëme latin commençant par ces distiques charmants :

\footnotetext{
I, puer, $i$, theam eonfestim in pocula misce, Urget non solitus lumina nostra sopor ;

Mens stupet, obtusie languent in corpore rires, Languorem solvet virida thea norum.
}

"Allons, allons, garçon, verse le thé dans ma lasse; mes yeux succombent à un assoupissement inexplicahle: je sens mon esprit engourdi, mes forces abattues; l'action virifiante du the dissipera cette langueur. » 
Europe et ì appeler sur' lui l'attention des savants, fut le docte voyageur Kœmpfer. Le premier il en donna des notions exactes. Avant lui, les botanistes n'en avaient pas même fait mention. Leinschotten, a venturier du xvi ${ }^{\mathrm{e}}$ siècle, qui prit une part active aux événements dont les IndesOrientales furent alors le théâtre, avait parlé de ce végétal comme d'une herbe; Tournefort ne l'avait pas jugé digne d'être compris dans sa nouvelle classification; Bauhin l'avait bien fait entrer dans son P'inax, mais sous le nom méconnaissable de Chiro.

A partir de la publication du grand onvrage de Kœmpfer, Amanitates exoticà, dont la traduction francaise ne parut qu'en 1726 , e'est-à-dire, plus de trente ans après le retour de l'auteur en Europe, le sucçès du thé alla croissant en Angleterre, en Hollande et daus quelques états de l'Allemagne. Vainement Bocrhaave, qui tenait alors le sceptre de la médecine, Van Swieten, et d'autres médecins, cherchèrent à arrêter cet élan, ils ne purent résister à l'entrainnement de l'opinion; on dit même qu'ils rendirent des hommages particuliers à la boisson qu'ils dénigraient dans leurs écrits. En France, le thé eut pour défenseurs l'abbé Jacquin, aumònier des princesses, filles de Louis XV ; Buchoz, médecin du hon roi Stanislas Lecziuski, due de Lorraine; Fougeroux, qui présenta un mémoire sur le thé en 1775, à l'Académie des Sciences; le naturaliste Valmont de Bomare; en Angleterre, Schort; en Suède, le grand Liinée, qui composa exprès un traité sur cette matière (Dissertatio potüs thece), et dont les conclusions furent d'un grand poids daus la balance de la discussion; le botaniste Thumberg, élève et ani de Linnée; etc., etc. Pour combattre tant d'illustres suffrages, 
il n'y eut guère qu'un médecin français, Le Bègue de Presles, moins connu aujourd'hui par ses ouvrages que par la part qu'il prit à l'autopsie du corps de J.-J. Rousseau. Encore son opinion ne concerne-t-elle que le the vert, et ne l'a-t-il émise qu'avec beaucoup de restrictions, puisqu'il le recommande comme médicament et ne l'interdit que comme boisson habituelle.

Après ce résumé analytique des faits qui se rapportent au thé dans le courant des xvil et xvIII ${ }^{e}$ siècle, il convient de rappeler succinctement les premiers essais qui furent tentés pour transplanter l'arbuste lui-même sous notre climat.

Les feuilles de thé étaient encore si rares et si peu connues en Europe, vers le milieu du xvire. siècle, que plusieurs naturalistes crurent avoir retrouvé dans nos contrées ce qu'on allait chercher si loin et à si grands frais. Simon Pauli, professeur de botanique à Copenhague, présenta le piment royal (Myria-Galle) de Limnée pour le véritable arbrisseau chinois; il fut tiré de son erreur par les échantillons que le docteur Cleyer lui envoya des Indes. Le jésuite Labat porta de la Chine à la Martinique des graines qu'il avait prises pour celles du thé; quand elles poussèrent et qu'elles fleurirent, on reconinut que l'arbuste n'était autre que le Camellia sesanqua avec lequel l'arbrisseau à thé a une parfaite ressemblance.

Linnée fit tous ses efforts pour l'acclimater en Europe; il en sema vingt fois des graines sans succès. Comme ces graines renferment une amende huileuse sujette à se rancir promptement, elles demandent, pour lever, a etre mises en terre presque aussitôt qu'elles ont été cueillies. Il faut qu'elles puissent arriver dans nos climats fraîches, 
saines et mures; ce que l'on reconnait it la couleur lruneviolette de leur tégument. Pour remplir cette condition indispensable, on imagina d'abord deux procédés difféerents qui ne réussirent qu'imparfaitement. Le premier fint d'enduire les graines de cire après les avoir bien fait séeher au soleil; le second fut de les laisser dans leurs capsules et de les renfermer dans des boites de fer-blanc ou de toutenague closes hermétiquement; ees deux méthodes sont aujourd'hui abandonnées.

Osbeck, au retour d'un voyage en Chine, rapporta it Linnée un jeune plant de thé; qui, placé sur le gaillard d'arrière, fut emporté en mer d'un coup de vent. Lagerstrom donna au jardin botanique d'Upsal, pour des arbres à thé, deux plants qui, à leur floraison, au bout de deux ans, furent reconnus pour des camellias. Quelque temps après, on était parvenu, avec de grandes précautions, a apporter un arbrisseau à thé à Gothembourg; mais pendant la nuit qui suivit le débarquement, et par suite de la négligence des matelots, les rats du navire le maltraitèrent tellement, qu'il en mourut. Enfin, Linnée engagea le capitaine Eckberg à mettre des semences fraîches dans des pots remplis de terre légère et argileuse, au moment où il appareillerait de Canton, ce qui réussit fort bien; pendant que le bâtiment était mouillé dans la rade de Gothembourg, toutes les graines levèrent; la moitié fut de suite envoyée à Upsal et périt dans le transport; le eapitaine y porta l'autre moitié le 3 octobre 1763. Les cotylédons ou lobes séminaux étaient encore adhérents à chacun des pieds; ainsi la Suède a la gloire d'avoir fait comnaitre la première cet arbuste à l'Europe.

Les Anglais s'emparèrent de cette méthode, qu'ils per- 
fectionnèrent. A leur départ de Canton, ils mirent à bord des caisses couvertes d'un vitrean de fil d'archal et remplies de bome terre, dans lesquelles avaient été semées d'excellentes graines de thé. Pendant la traversée, on eut soin de les arroser fréquemment avec de l'eau douce, et de ne pas trop les exposer à l'air ni à la rosée d'eau salée que jette la brise en rasant les lames. C'est grâce à ces précautions minutieuses qu'on est parvenu à introduire en Angleterre les premiers pieds de cet arbrisseau, qui vient aujourd'hui parfaitement dans les pépinières et les jardins de cette île. Il y supporte même le plein air pendant l'êté.

Le premier arbrisseau a thé qui ait paru en Franice est celui que Gordon, fameux pépiniériste de Londres, fit passer à M. le chevalier de Jaussen, et qu'on voyait à Chaillot quelques ammées avant la révolution. Depuis, plusieurs individus furent cultivés au Jardin des Plantes de Paris; deux fleurirent abondamment sous l'empire, au témoignage de M. Desfontaines. En 1838, M. Guillemin, aide de botanique au Muséum d'histoire naturelle, enlevé récenment à la science par une mort prématurée, fut chargé par M. le ministre de l'agriculture et du commerce d'une mission au Brésil, ayant pour objet principal des recherches sur les cultures et la préparation du thé, et le transport de cet arbuste en France. Ce naturaliste parvint à se procurer environ 3,000 plants de jeunes thés, qu'il plaça dans dix-huit caisses pouvant s'ouvrir et se fermer à volonté au moyen de panonceaux mobiles, en ayant soin que la lumière pénétrât par un conduit, condition indispensable de salut pour tous les végétaux exotiques que l'on transporte par mer. Entre les plants il sema plus de $\mathbf{2 , 0 0 0}$ graines bien mûres; nais malgré l'extrême sollicitude 
qu'il eut pour ses plantes pendant la traversée, le voyage de mer en tua plus des deux tiers; de sorte qu'il ne puten rapporter que 12 ou 1,500. L'auteur de cet ouvrage a vu dans les orangeries du Museum deux arbustes à thé dont l'air chétif et rabougri contraste avec l'aspect d'un magnifique camellia leur voisin. On voit à la pépinière de M. Cels, barrière du Maine, un grand nombre de ces arbrisseaux très-beaux et très-vigoureux. Plusieurs de ses confrères élèvent également des arbustes à thé d'une excellente venue et qui ont figuré dans les expositions trimestrielles de la société d'horticulture de Paris, it l'orangerie du Luxembourg. 


\section{CHAPITRE·II.}

Tableaux statistiques des importations du TLé dans les divers états de l'Europe el de l'Amérique.

Pour compléter l'aperçu historique contenu dans notre premier chapitre, nous allons retracer sommairement les phases qu'a suivies la consommation du thé dans les principaux états de l'Europe.

\section{ANGLETERRE.}

L'Angleterre doit naturellement occuper la première place dans cette revue. Il n'est pas inutile d'avertir nos lecteurs que les chiffres que nous allons reproduire sont tirés, de 1669 à 1696, des registres de l'ancienne Compagnie des Indes; que de 1697 à 1708, ils ont été relevés sur celui de l'administration des douanes; et depuis $\mathbf{1 7 0 8}$ jusqu'à 1834, sur les livres de la Compagnie actuelle des Indes; car la réunion de l'ancienine à la nouvelle ne s'effectua que cette année-là. Depuis 1834, époque où la Compagnie a perdu son privilége et où tous les négociants anglais ont été admis aux bénéfices du trafic du thé, les chiffres que nous publions sont empruntés aux renduscomptes officiels de la douane anglaise.

Comme nous l'avons vu dans le précédent chapitre, le 
total des importations de thé de 1652 à 1700 ne s'élève qu'à 181,545 liv. De 1700 à 1750 il fut d'environ 40 millions. A partir de 1751, il prit un accroissement remarquable. En 1772, il atteignait déjà 22,119,844 liv.; la guerre de l'indépendance américaine fit descendre ce chiffre à $16,735,116$ liv.; mais il se releva rapidement après la paix de 1781 , et se trouvait de 23 millions en 1793, à l'époque de la célèbre et infructueuse ambassade de lord Macartney à Pékin. En 1787, pour mettre un terme à la contrebande qui se faisait sur cet article, on vota une loi, dite bill de commutation, qui prescrivait l'importation directe et conférait exclusivement ce droit à la Compagnie, avec redoublement de peines contre les contrevenants. En 1822, la quantité rendue aux marchés de la Compagnie s'élevait à $\mathbf{2 5 , 8 7 4 , 5 4 6}$, non compris 2,091,019 vendues aux mêmes marchés pour le compte des capitaines et subrécargues. Le tableau suivant montre combien il a monté dans les années subséquentes. Depuis trois ans, il a fléchi par suite de la guerre de la Grande-Bretagne avec le céleste empire.

\begin{tabular}{|c|c|c|}
\hline ANNÉES. & PROVENANCES. & $\begin{array}{l}\text { QUANTITE. } \\
\text { D E LIVRES. }\end{array}$ \\
\hline $\begin{array}{l}1669 \\
1670 \\
1671 \\
1672 \\
1673 \\
1674\end{array}$ & $\begin{array}{l}\text { Bantam. } \\
\text { Id. } \\
I d . \\
\text { Par différentes personnes. }\end{array}$ & $\begin{array}{rr}\text { liv. } & \text { on } \\
143 & 8 \\
79 & 6 \\
264 & \\
& \\
55 & 10\end{array}$ \\
\hline
\end{tabular}




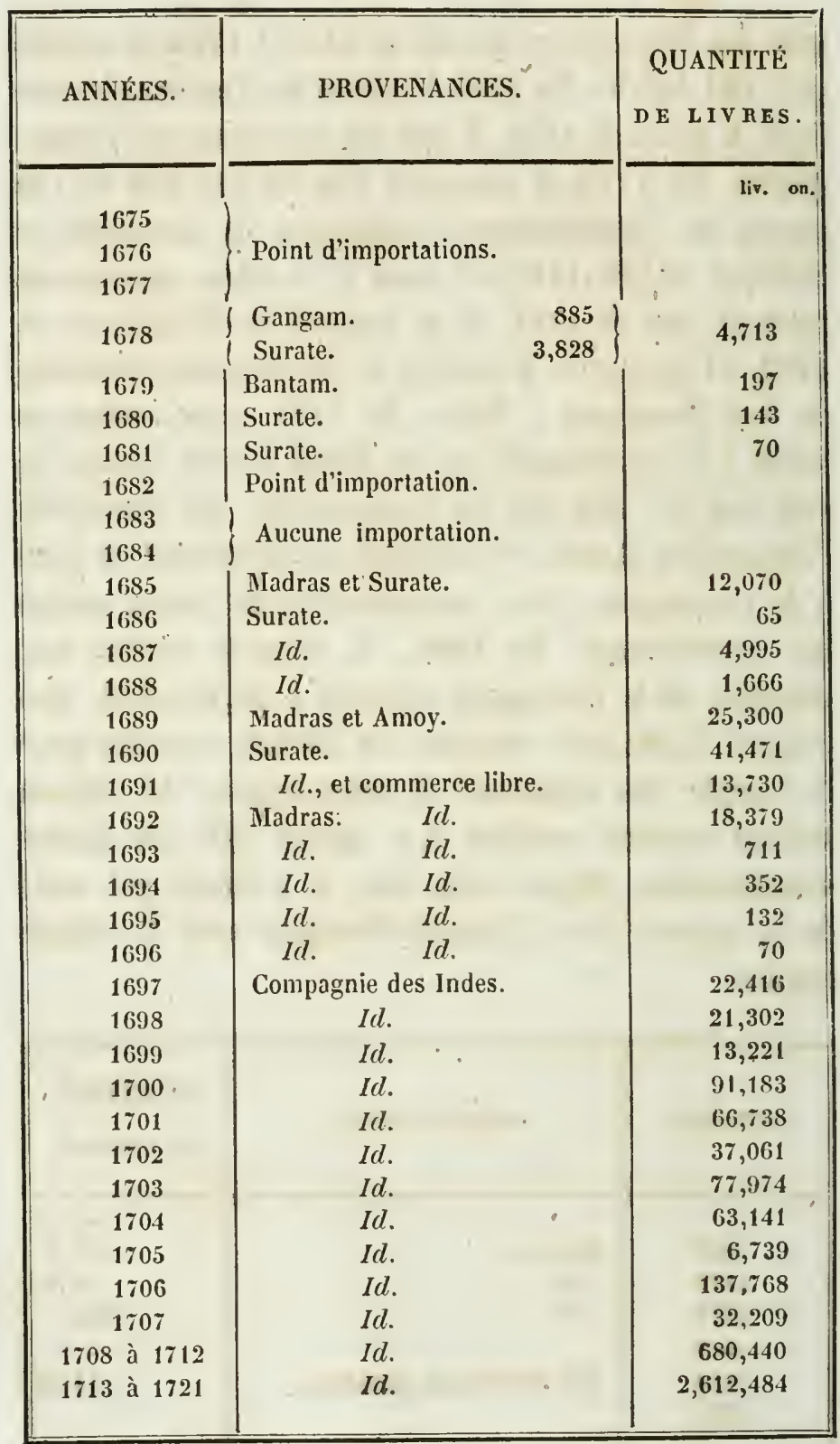




\begin{tabular}{|c|c|c|}
\hline ANNEES. & PROVENANCES. & $\begin{array}{l}\text { QUANTITĹ: } \\
\text { DE LIVRES. }\end{array}$ \\
\hline 1722 à 1723 & Compagnie des Indes. & ${ }_{1,839,256}^{\text {liv. on. }}$ \\
\hline 1724 à 1733 & $I d$. & $6,518,484$ \\
\hline 1734 à 1744 & $I d$. & $16,712,201$ \\
\hline 1745 à 1747 & $I d$. & $5,267,779$ \\
\hline 1748 à 1750 & $I d$. & $6,123,843^{\circ}$ \\
\hline 1751 à 1759 & Id. & $24,573,129$ \\
\hline 1760 à 1767 & $I d$. . & $34,666,136$ \\
\hline 1768 à 1772 & $I d$. & $40,378,770$ \\
\hline 1773 à 1783 & $I d$. & $64,027,963$ \\
\hline 1784 & Id. & $10,148,257$ \\
\hline 1785 & Id . & $-15,081,737$ \\
\hline 1786 à 1794 & Id. & $152,684,613$ \\
\hline 1795 à 1796 & $I d$. & $39,858,516$ \\
\hline 1797 & $I d$. & $18,076,106$ \\
\hline 1798 & $I d$. & $22,849,451$ \\
\hline 1799 & $1+$ & $24,077,422$ \\
\hline . 1800 & Id. & $25,378,816$ \\
\hline 1801 à 1826 & $\begin{array}{l}\text { Importations évaluées à } 29 \text { mil- } \\
\text { lions par an, ensemble. . . }\end{array}$ & $754,000,000$ \\
\hline 1827 & Compagnie des Indes. & $32,000,000$ \\
\hline 1828 & $I d$. & $29,000,000$ \\
\hline 1829 & Id & $\begin{array}{l}\text { kilogramines. } \\
13,376,080\end{array}$ \\
\hline 1830 & $I d$. & $13,720,778$ \\
\hline 1831 & Id. & $13,899,026$ \\
\hline 1832 & $I d$. & $14,307,203$ \\
\hline 1833 & $I d$. & $14,434,732$ \\
\hline 1834 & $I d$. & $15,858,737$ \\
\hline 1835 & $I d$. & 16,586311 \\
\hline 1836 & Id. & $22,286,004$ \\
\hline 1837 & $I d$. & $13,888,531$ \\
\hline 1838 & $I d$. & $14,671,447$ \\
\hline 1839 & $I d$. & $15,930,225$ \\
\hline 1840 & $I d$. & $14,380,344$ \\
\hline 1841 & $I d$. & $16,690,107$ \\
\hline 1842 & Id. & $18,026,698$ \\
\hline
\end{tabular}


Nous ne nous arrêterons pas à faire ici le relevé total de ces chiffres, parce qu'il est humainement impossible de garantir l'exactitude d'un pareil calcul. Il semble au premier abord représenter, du moins très-approximatirement, l'ensemble des importations de la Grande-Bretagne depuis 1669; mais il ne tient pas compte des thés importés en fraude pendant ce long intervalle, et comment apprécier l'ẹnorme excédant occasionné dans la première évaluation par cette contrebande permanente? Nous arons dù ne point fixer de chiffre rigonreux: cette prétention ne peut sourire qu'à un mathématicien curieux de déterminer combien de milliards de livres ${ }^{\text {x de }}$ thés la Grande-Bretagne a reçues dans l'espace de deux siècles; combien il faudrait de navires et de marins pour transporter un pareil chargement; et d'évaluer la quantité de numéraire auquel est censé correspondre le total des chiffres que nous venons de donner; mais de pareilles recherches spéculatives sont interdites à un écrivain qui a un but sérieux et généralement utile.

Il n'est pas besoin de faire remarquer que les chiffres du tableau ci-dessus représentent les thés importés et non ceux consommés. Ce n'est seulement que depuis 1836 que l'administration des douanes anglaises donne les tableaux officiels de la consommation de cette substance. Ils sont généralement à ceux de l'importation dans le rapport de 1 à 7 ; c'est-à-dire que l'Angleterre en exporte pour ses innombrables colonies cnviron un septième.

' La livre anglaise, inférieure à notre ancienne lirre française (celle-ci valant 16 onces, èt celle-lả sculement 1 i), équivaut à 0 kilog. 453. 


\section{ETATS-UNIS.}

Le commerce de l'Amérique arec la Chine prit naissance vers la fin de la guerre de l'indépendance, et depuis il n'a cessé de s'accroître. Leur pavillon parut pour la premiere fois dans le port de Canton en 1784. Ce commerce a pris une extension énorme, et il aurait encore fait plus de progrès depuis 1818 si les Hollandais n'avaient repris leur concurrence, et si la Compagnie anglaise des Indes n'avait accaparé aux dépens des Américains la fourniture des thés du Canada. Voici le tableau de leurs importations depuis 1829: (La livre américaine est la mème que la livre anglaise valant 0 kil. 453.)

\begin{tabular}{|c|c|}
\hline ANNÉES. & POIDS. \\
\hline 1829 & $\begin{array}{l}\text { liv. } \\
6,636,790\end{array}$ \\
\hline 1830 & $8,609,415$ \\
\hline$\therefore 1831$ & $5,182,867$ \\
\hline 1832 & $9,906,606$ \\
\hline 1833 & $12,588,640$ \\
\hline 1834 & $16,274,679$ \\
\hline 1835 & $14,414,380$ \\
\hline 1836 & $16,381,126$ \\
\hline 1837 & $16,973,742$ \\
\hline 1838 & $14,414,046$ \\
\hline 1839 & $9,340,061$ \\
\hline 1840 & $19,981,476$ \\
\hline
\end{tabular}




\section{RUSSIE.}

Les Russes cultivent depuis le $\mathrm{xvI}^{\mathrm{e}}$ siècle des relations amicales avec la Chine. Pierre-le-Grand envoya deux ambassadeurs à Pékin, Isłrands-Ides en 1693, et Ismaïlof en 1719. Ils obtinrent pour leur nation des priviléges que jamais les Chinois n'ont accordés à aucun autre peuple, tels que l'établissement d'un collége de jeunes Russes à Pékin même. Ce collége subsista jusqu’au commencement de ce siècle, où il fut supprimé à la snite d'un différend entre les deux empires; mais leur rapprochement dans ces dernières années a pris un caractère d'intimité. Il est impossible de préciser exactement le chiffre des importations de thés en Russie, attendu que ce commerce se fait par échanges à Kiakhta ${ }^{\mathrm{I}}$ et que de là il est transporté à la foire de Nijni-Nowogorod ${ }^{2}$, rendez-vous

- Kỉakhta, situé sur les frontières limitrophes de la Russie asiatique et de la Tartarie chinoise, est éloigné de lloscon de 5,807 verstes (de 10 3/10 all degré ), équivalant à environ 1,500 lieues de Frauce. C'est une petite ville de 5,000 âmes qui a, dans le mois de décenibre, une foire fameuse on se fiit la plus grande partie du commerce de la Russie avee la Chine. Le Iransport des marehandises de Kiakthta a la foire de Nijni-Nowogorod s’effeetue par terre et lar eau ; dans le premier cas, il exige deux ans et dans le second trois ans, nu plutôt trois été fort eourts, attendu que les rivières et canaux sont gelés pendant tout le reste de l'année.

2 Nijni-Nowogorod est la capitale d'un gouvernement du même nom, situé entre ceux de Walidimir et de Kasan, dont la eapitate vient d'ètre entièrement dévorée par les flammes. Nijni-Nowogorod doit égralement son importance â la fameuse foire qui y a été transportẻe en 1817 et qui se tenait alors à Marliarieff. On porte á plus de 150,000 le nombre des marehands des divers pays de l'Europe et de l'Asie qui s'y rendent tous les ans. Cette foire commence le 29 juin et dure jusqu'à la fin de juillet. Il s'y est fait en 1836 un nouvement d'affaires éralué, par le Journal de Saint-Pétersbourg, à $\mathbf{1 1 4 , 1 6 5 , 0 0 0}$ roubles $(114,165,000$ francs.) 
annuel, aux mois de juillet et d'août, du commerce de l'Asie orientale et de l'Europe septentrionale. Le mouvement d'affiaires rui s'y opère s'élève ì des sommes considérables. Les négociants de Moscou ont le monopole de cette foire; toutefois le gouvernement y admet d'autres marchands, pourvu qu'ils paient au fise un droit égal à celui que paient les premiers. Les thés qui se vendent sur ces marchés sont réputés d'une qualité supérieure à ceux qui viennent par mer de Canton. - Un article remarquable inséré dans la Revue des Deux-Mondes de 1841, sous le titre de Progrès de la Russie dass l'Asie gentrale, dit que, d'après le rèlevé des dounes de Frortz-Kossawkaya, le thé acheté ì Kiakhta des Chinois par les Russes, en $\mathbf{1 8 2 3}$, a été de 130,256 pudds de 40 livres russes, correspondant à 16 kil. 375 ; en tout 2,132,942 kil., pour la somme de.

En 1837 , on en acheta 213,063 pudds, faisant $3,488,966$ kil. ' 1 [2, pour . . . $8,277,204$

Ce qui fait environ, terme moyen, 2 fr. 41 c. par lilog. Nais ce prix n'est que le taux d'achat sur les lieux; celui de la revente est toujours quatre ou cing fois plus éleré; car il faut compter en sus les droits de douanes, les frais de transport, etc. En effet, à la foire de Nijni-Nowogorod, l'article seul des thés provenant de Kiakhta donne lieu à un mouvement d'affaires de 35 millions de roubles-assignations $(35,000,000 \mathrm{fr}$.). La Russie exporte des thés pour la Suède, le Danemarck et le nord de l'Allemagne. Voici le tableau de ses importations depuis 1829 par Kiakhta, et depuis 1836 par Odessa; les pudds y sont réduits en kil. 
DU THÉ.

\begin{tabular}{|c|c|c|c|}
\hline ANNÉES. & $\begin{array}{c}\text { Par } \\
\text { KIAKHTA. }\end{array}$ & $\begin{array}{c}\text { Par } \\
\text { ODESSA. }\end{array}$ & $\begin{array}{c}\text { VALEURS } \\
\text { en } \\
\text { kilogrammes. }\end{array}$ \\
\hline 1829 & $\begin{array}{l}\text { prids. } \\
153,520\end{array}$ & & $\begin{array}{c}\text { hilog. } \\
5,584,289000\end{array}$ \\
\hline 1830 & 154,554 & - & $5,621,901 \quad 250$ \\
\hline 1831 & 142,055 & & $5,166,950 \quad 625$ \\
\hline 1832 & 179,474 & & $6,528,367750$ \\
\hline 1833 & 166,097 & & $6,031,788 \quad 375$ \\
\hline 1834 & 174,119 & & $6,333,578 \quad 625$ \\
\hline 1835 & 200,480 & en tout: & $7,292,460 \quad 0(10$ \\
\hline 1836 & $215,648 \quad 1 / 2$ & $263,093 \quad 1 / 2$ & $9,570,026 \quad 062$ \\
\hline 1837 & 193,970 & 204,469 & $7,437,232500$ \\
\hline 1838 & $201,153 \quad 1 / 2$ & $206,338 \quad 1 / 2$ & $7,505,564937$ \\
\hline
\end{tabular}

Il est à présumer que la quantité réelle des importations de thé en Russie, dépasse cette moyemne de 8,000,000 de kilogrammes, qui ne représente que les quantités acquittant des droits de douanes.

\section{HOLLANDE.}

A la fin du $\mathrm{xvl}^{\mathrm{e}}$ siecle, les Hollandais parvinrent à supplanter les Portugais et les Espagnols dans leur commerce avec la Chine et le Japon. Leur Compagnie des Indes, créée en 1602, fonda un comptoir à Ferandao, au Japon, en 1609, et s'empara de l'íle Formose en 1620. Elle seule approvisionnait alors les autres états européens de la petite quantité de thé qui s'y consommait. Les Chinois ne tardèrent pas à manifester leurs préventions contre ces étrangers. Le gouverneur de Batavia, en 1653, expédia en vain une frégate à Canton pour y fairè des échanges; elle re- 
vint vide. En 1655, il envoya Keyser et Neuhoff en ambassade à Pékin; l'empereur refusa de les recevoir; les Chinois chassèrent même les Hollandais de Formose en 1662 ; depuis cette époque, il y eut froideur entre les deux nations jusqu'en 1683, 'fu'elles renouc̀rent leurs rapports commerciaux, qui ne furent interrompus que pendant la durée de l'incorporation de la Hollande à l'empire français, de 1795 a 1814. En 1795, le gouverneur de. Batavia, d'après les conseils de M. Van Braam, envoya M. Titzing en ambassade à la cour de Pékin; cette mission quoique mieux accueillie de l'empereur que celle de lord Macartney, n'eut cependant que des résultats précaires et que les événements de la révolution française achevèrent d'annihiler. La restauration de la maison de Nassan, en rendant à la Hollande sa belle colonie de Java, lui rouvrit le débouché de la Chine; mais elle ne s'en laissa pas moins expulser des marchés de Canton par les Anglais et les Américains. Elle tire une grande partie du thé qu'elle consomme de sa propre colonie, et elle s'approvisiome du surplus auprès des Américains. Au reste, la consommation de cet article y a subi peu de variations depuis 1830 , malgré l'augmentation de sa population. Cette immobilité est attribuée, par le ministre des finances de la Néerlande, à la concurrence du café et à la cherté du thé, par suite de la guerre récemment terminée de la GrandeBretagne avec le céleste empire. Dans un document émané de cet homme d'état et qui a été mis à notre disposition, la consommation de cet article est portée pour 1840 , a 450,000 kil. Le tableau suivant donne le nombre des quarts de caisse de thé débarqués dans les principaux ports du royaume néerlandais pendant les amnées $\mathbf{1 8 3 6}$, 
1837, 1838 et 1839. Il n'est pas possible de les évaluer exactement en kilog.

\begin{tabular}{|c|cc|}
\hline \multirow{2}{*}{ ANNÉES. } & \multicolumn{2}{|c|}{ QUANTITES. } \\
\hline & & \\
\hline & & \\
1836 & 23,982 & quarts de caisse. \\
1837 & 35,143 & $I d$. \\
1838 & 32,171 & $I d$. \\
1839 & 20,292 & $I d$. \\
1840 & 450,000 & kilogrammes. \\
& & \\
\hline
\end{tabular}

\section{FRANCE.}

La France n'occupe que le cinquième rang dans cette revue statistique. L'usage du thé, longtemps circonscrit chez elle aux tables de quelques grandes maisons, ne commence à pénétrer parmi les classes aisées que depuis un petit nombre d'années. L'époque fatale du choléra a déterminé un progrès sensible dans cette consommation. Anparavant on ne connaissait guère que les thés verts; aujourd'hui on commence à apprécier les thés noirs, et à coniprendre qu'ils peuvent avantageusement soutenir la concurrence du chocolat et du café. Mais il n'en est pas moins vrai, qu'en dehors d'un petit cercle d'amateurs indigènes, ce salutaire produit de la Chine n'est point généralement estimé dans notre pays autant qu'il le mérite. Dans nos petites villes et dans nos campagnes, on continue de le reléguer comme médicamment au fond des pharmacies. L'état longtemps stationnaire de cette consommation chez nous tient à diverses causes. On n'a jusqu'à présent rien fait pour appeler l'àttention publique sur cette 
substance alimentaire; elle n'a obtenu ni la même protection ni les memes encouragements que tant d'autres den'ées exotiques qui sont bien loin de la valoir. L'usage du café, que nos colonies nous fomrnissent en abondance, est trop enraciné parmi nos populations pour qu'il puisse de longtemps céder une modeste place à une denrée originaire d'une contrée lointaine avec layuelle nous n'arons entretenu jusqu’à présent que de rares et faibles relations de commerce. Ajoutons que notre infériorité sous ce rapport tient encore à ce que la manière de préparer le thé est très-peu répandue parmi les classes laborieuses qui ignorent tout ce que ce mode d'alimentation possède de savoureux, d'hygiénique et de reconfortant. Du reste, il n'est pas inutile de faire observer que l'usagre du thé est encore tout nouveau parmi nous; et que l'Angleterre, pendant les cinquante premières années de l'introduction de cette substance, n'en a cousommé que 121,545 liv., représentant à peine la moitié de ce que nous consommons aujourd'hui par an !... Ce rapprochement doit nous rassurer pour l'avenir. Sans prétendre que le thé soit appelé un jour à opérer une révolution dans nos habitudes nütritives, il est permis d'espérer que le temps et l'expérience dissiperont beaucoup d'erreurs et de préjugés accrédités sur ce précieux régétal, et qu'alors, en présence des prosélytes qu'il gagnera chaque jour, l'administration. sera amenée à entrer dans une voie qui intéresse à la fois notre marine et notre commerce extérieur ${ }^{\mathrm{I}}$; c'est-à-dire

${ }^{I}$ Et l'importante question des sucres, pouvons-nous ajouter aujourd'hui, en eomparant la consonimation de la Franee a vee celle de la Grande Bretagne: On voit, d'après des relevés officiels, que eette dernière s'élève à plus du double de la nòtre, relativement à la population; et que cette différence provient, au dire mème dés économistes, de l'usage quotidien de la boisson du thé 
à lier des rapports plus intimes avec le riche et populeux empire de l'Indo-Chine. Le temps n'est peut-être pas éloigné où elle sentira la nécessité de ressusciter la vieille influence du pavillon français dans ces lointains parages!...

Le tableau suivant de uos importations de thé est officiel; il émane du ministère du commerce et de l'agriculture :

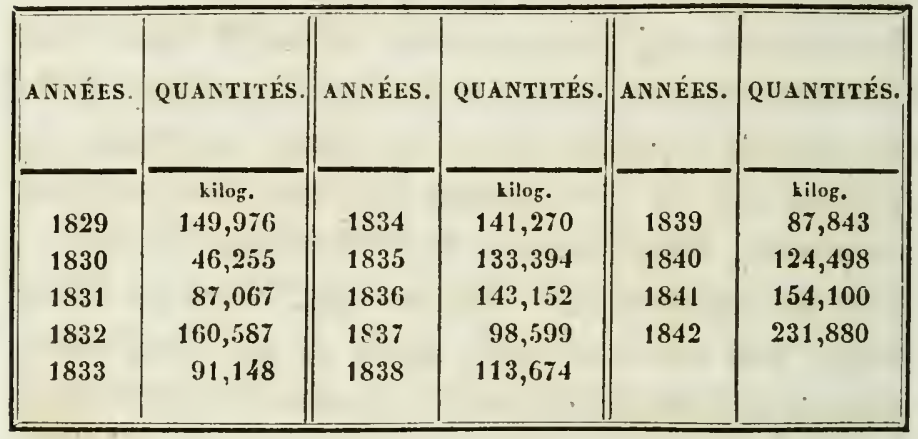

\section{BELGIQUE.}

Les états brabançons, sous la domination de la maison d'Autriche, enroyaient quelques navires en Chine. Charles II, roi d'Espagne, créa deux ans avant sa mort, en 1698, la Compagnie d'Ostende, qui ne put entrer en activité qu'en 1717; mais contrecarrée par la jalousie des Hollandais, elle fut obligée de se dissoudre en 1727, malgré la protection déclar ée de la cour de Vienie.

La consommation du thé en Belgique ne date guère que de son incorporation à la Hollande; le tableau suivant atteste qu'elle a fait de sensibles progrès dans ce pays, depuis qu'il a conquis son indépendance. 


\begin{tabular}{|c|c|}
\hline & \\
ANNEES. & 1mpontarions total.s. \\
& de lia Belgique. \\
\hline & \\
\hline 1831 & kilog. \\
1832 & 27,404 \\
1833 & 110,555 \\
1834 & 136,489 \\
1835 & 84,465 \\
1836 & 58,021 \\
1837 & 47,119 \\
1838 & 91,381 \\
1839 & 69,224 \\
& 51,620 \\
\hline
\end{tabular}

\section{PRUSSE.}

Sous les auspices du grand Fréléric; une compagnie se forma à Embden pour exploiter le commerce spécial des Indes et de la Chine; mais cet établissement ne subsista que jusqu'au commencement de la révolution francaise. La Prusse tire en partie le peu de thé qu'elle consomme de la Russie par la voie de Stettin; en partie des Chinois eux-mêmes par l'intermédiaire de quelques armateurs de Dantzick. En 1831, elle a reçu par la voie de Stettin 6 canistères de thé (mesure chinoise dont le poids est variable); en 1835, 2 ; en 1837, 7 ; en 1838 , elle a reçu par la voie de Dantzick, 121 canistères, et en 1839, 174.

\section{ZOLWEREIN GERMANIQUEE}

et la ville libRe DE HAMBOURG.

On comprend sous cette dénomination tous les états 
allemands de premier, de second et de troisième ordre (qui se sont ralliés à la ligue des douanes prussiennes. Il a été constaté qu'en 1837, il avait été importé dans ces divers états 5,987 livres anglaises de thé sur lesquelles 3,349 araient été consommées, 868 exportées, et $\mathbf{1 , 8 4 1}$ passées en transit pour la Prusse. Voici le tableau des importations et exportations de thé à Hambourg pendant les années $1836,1837,1838$. Cette ville tient son thé de la Grande-Bretagne.

\begin{tabular}{|c|c|c|}
\hline ANXÉES. & IMPORTÉ. & EXPORTÉ. \\
\hline & & \\
\hline 1836 & $1,503,400$ & 44,300 \\
1837 & $1,344,000$ & 100,000 \\
1838 & $1,301,000$ & 69,200 \\
& & \\
\hline
\end{tabular}

\section{SUÈDE, NORWĖGE ET DANEMARCK.}

Jadis la Suède avait aussi sa Compagnie des Indes fondée en 1727 par un négociant appelé Koning; ses vaisseaux fréquentaient les mers de Chine, et apportaient en retour des thés; anjourd'hui elle reçoit cet article d'autres puissances maritimes de l'Europe. En 1836, il a été importé dans ce royaume 33,144 livres anglaises de thé; en 1939, seulement dans la capitale Stockholm, 13,665. On a constaté que la Norwége, en 1835, arait reçu 59,205 liv. anglaises de thé. Le Danemarck, qui autrefois arait aussi une Compagnie des Indes, reconstituée en 1728, est au- 
jourd'hui it cet égard dans la méme position que la Suède. Sa consommation a la méme importance ${ }^{\mathrm{I}}$.

Maintenant si on passe à une récapitulation générale, on trouve qu'il se consomme approximativement par année, en adoptant pour terme moyen 1838, savoir :

\begin{tabular}{|c|c|c|}
\hline ETATS. & POPULATION. & $\begin{array}{c}\text { THÉ: } \\
\text { CoNSOMMÉ. }\end{array}$ \\
\hline 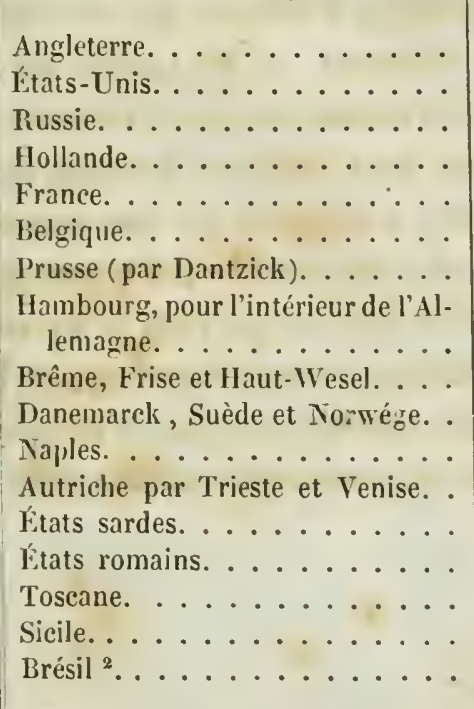 & $\begin{array}{r}27,000,000 \\
14,500,000 \\
64,000,000 \\
2,600,000 \\
33,500,000 \\
4,200,000 \\
12,000,000 \\
\\
125,000 \\
1,000,000 \\
8,000,000 \\
4,000,000 \\
33,000,000 \\
2,500,000 \\
3,500,000 \\
1,500,000 \\
2,000,000 \\
3,500,000\end{array}$ & $\begin{array}{r}\text { kilog. } \\
14,671,417 \\
7,207,023 \\
7,505,564,937 \\
450,000 \\
113,674 \\
69,224 \\
15,000 \\
\\
800,000 \\
215,500 \\
65,000 \\
4,650 \\
3,500 \\
2,800 \\
2,100 \\
2,000 \\
850 \\
100,000\end{array}$ \\
\hline
\end{tabular}

Nous ne donnons ces aperçus qu'à titre de simples renseignements et sans en garantir la rigoureuse exactitude.

1 Nous ne faisons pas entrer dans cette revuè statistique la consommation extrêmement minime de l'Espagne, du Portugal, de la Suisse et de l'Italie, tributaires, pour ce produit, de la France et de l'Angleterre.

2 Qnoique le Brésil ait de nọmbreuses plantations de thés, le commerce des thès chinois y est encore très-actif; il s'y fuit en partie par l'eutremise des États-Unis, et en antre partie par des navires brésiliens qui vont s'approvisionner à Canton. 
Il nous suffit de faire apprécier par-là le haut degré de faveur dont jouit le thé chez les principales nations du globe. Si d'un côté l'on fait figurer dans ce compte-rendu les exportations de thé qui se font aux Philippines, au Tonquin, d̀ la Cochinchine, à Siam, dans le Lahore, dans l'Afghanistan, et dans d'autres contrées de l'Asie centrale, il n'y a pas d'exagération à porter à 150 , et mème 200 millions le revenu annuel que ce seul article procure au Céleste Empire. Si d'un autre côté on tient compte de l'immense nouvement d'affaires que ce trafic alimente, du nombre de vaisseaux et de marins qu'il entretient, des échanges et des transactions qu'il nécessite, des sommes qu'il fait verser dans le trésor des états qui l'exploitent; si, en se plaçant à un point de vue encore plus élevé, on considère quelle influence le thé a exercée sur les mœurs et l'hygiène des peuples quil'ont pris pour base de leur régime alimentaire, on sera convaincu qu'il n'est peut-être aucun produit exotique qui pèse d'un plus grand poids dans la balance du commerce et de la civilisation moderne. 


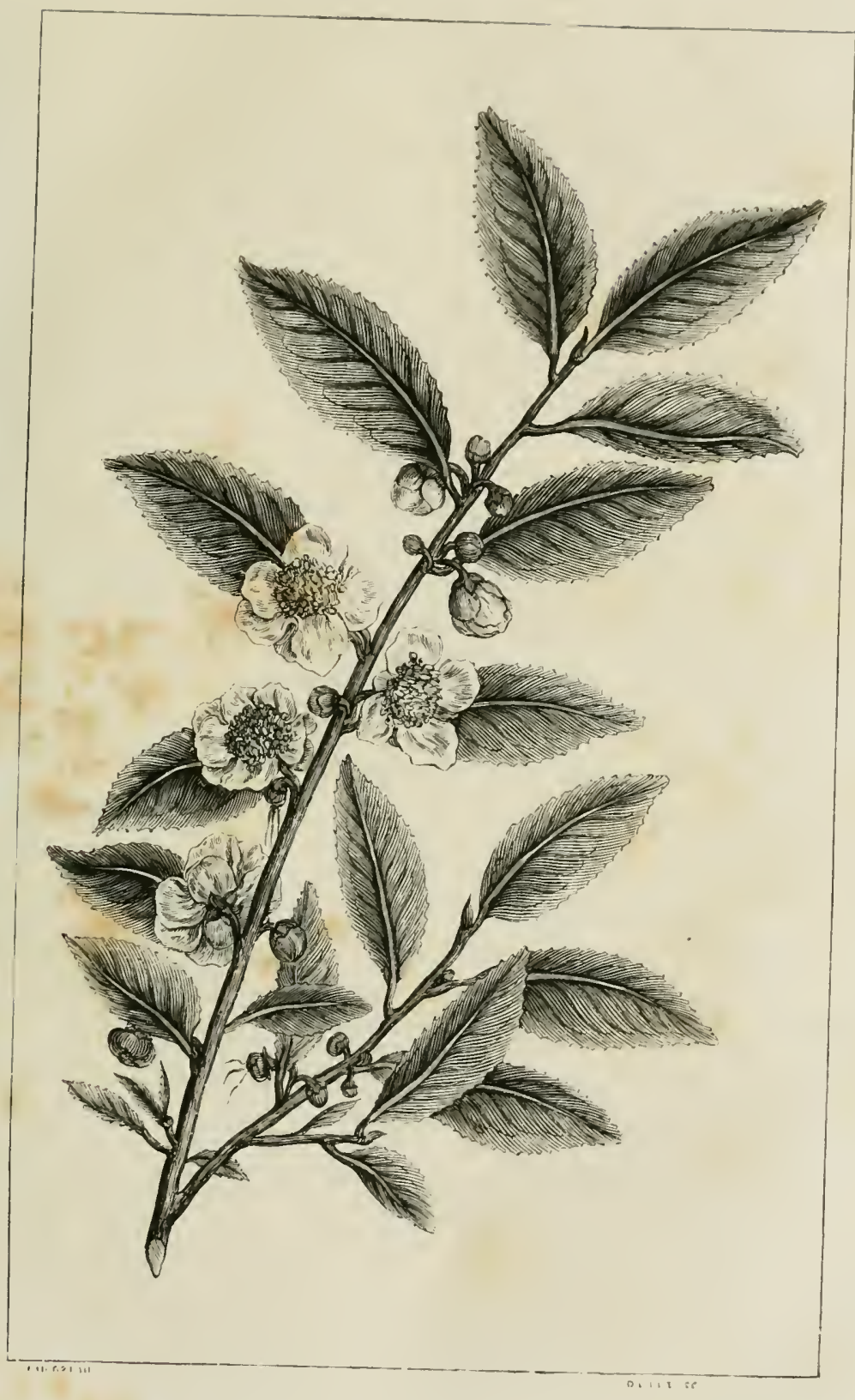

Branche du thé. 



\section{CHAPITRE III.}

Origine du Thé. - Sa description botanique.

L'arbuste qui produit le thé, de l'avis de tous les naturalistes, est indigène à la Chine, où il croît spontanément dans plusieurs provinces. Il paraît qu'il a été transplanté de bonne heure au Japon, où il a fini par s'acclimater comme dans son pays natal. Le nom de thé (en langue mandarine $t c h a$, en japonais $t s j a a$, ) vient du dialecte populaire usité dans la province du Fo-Kien, où il est cultivé en abondance.

"Le thé, dit M. Desfontaines (Flore médicale), est un " genre de plantes dycotélydones à fleurs complètes, po"lypétalées, de la famille des auriontacées, offrant pour " caractère distinctif un calice à cinq ou six folioles, cinq "à neuf pétales, trois styles connivens, une capsule supé"rieure à trois coques. Chaque fleur offre $: 1^{\circ}$ un calice " à cinq ou six divisions profondes, courtes, planes, ar"rondies, obtuses; $2^{\circ}$ une corolle composée de cinq à " neuf pétales, assez grands, arrondis, concaves; trois "pétales extérieurs dans les fleurs à neuf pétales; $3^{\circ}$ des "étamines nombreuses insérées sur le réceptacle dont les " filaments sont filiformes, plus courts que la corolle, ter" minées par des anthères à deux lobes arrondis; $4^{\circ}$ un 
" ovaire supérieur, globuleux, à trois côtés, surmonté de " trois styles rapprochés et connivens en un seul corps " subalé, de la lougcueur des étamines, terminées par trois " stigmates simples. Le fruit est une capsule globuleuse à " trois coques réunies à une partie inférieure à trois loges, "renfermant clıacuue une semence glọbuleuse, anguleuse “ à unc de ses faces. - Les feuilles sont alternes, dures, " ovales, lancéolées ou elliptiques, entières près la base, " dentées en scie dans le reste de leur longueur, et por" tées sur un pétiole court et demi-cylindrique. Les bour"geons sont aigus et accompagnés d'une écaille qui se " détache et tombe à l'époque de leur développement. "Les fleurs naissent deux à deux dans les aisselles des " feuilles, sur des pédoncules courts et un peu épars. Le " calice est petit, persistant et à cing divisions obtuses. La " corolle a le plus communément six pétales, blanes, ar" rondis et ouverts; les deux extérieurs sont plus petits et " inégaux; sa largeur est d'environ trois centimètres. Les "étamines, au nombre de plus de deux cents, sont plus " courtes que la corolle et attachées sous l'ovaire. Chatque " anthère a deux loges. I'ovaire, qui est d'une forme " triangulaire, arrondi et surmonté d'un style partagé " en trois stigmates filiformes, devient une capsule à trois " loges rondes, monospermes, réunies par la base et s'ou" vrant longitudinalement d'un seul côté. - Les graines " sont sphériques, anguleuses intérieurement, de la gros" seur d'une aveline, revêtues d'une peau mince, luisante, " un peu dure et de couleur marron. Le noyau est hui"leux, d'une saveur amère et désagréable, qui excite la " salivation et occasionne des nausées. "

Rapprochons de cette description, celles qui ont été 
faites par MII. de Mirbel, membre de l'Institut, et Achille Richard, professeur de botanique à la Faculté de médecine de Paris. (Diclionnaire de médecine.)

"La hauteur de l'arbuste à thé, dit le premier, varie " de 4 à 30 pieds. Ses tiges se divisent en un grand nom" bre de rameaux diffus; ses feuilles sont alternes courte" ment pétiolées, très-glabres, coriacées, d'un rert foncé, " ou ovales oblongues ou orales elliptiques, pointues " aux deux bouts, entières inférieurement, dentelées " ver's le sommet, longues de deux à trois pouces sur um " pouce de largeur. Les fleurs, de couleur blanche, ont à " peu près un ponce de diamètre. Elles naissent dans les " aisselles des feuilles, tantôt solitaires, tantôt réunies “ plusieurs ensemble; leurs pédoncules sont plus ou moins " allongés. Leur calice, petit et persistant, se compose de " cinq pétales ovales, arrondis et se recouvrant par les " bords; la corolle se compose de huit à neuf pétales ar“ rondis, un peu étalés, un peu inégaux. Les étamines, au " nombre d'une ceistaine, sont resserrées à la base des " péta!es et plus courtes qu'eux. Le pistil offre un ovaire " inadbérent, arrondi, à trois loges, contenant chacune " deux orales. Son style se divise au sommet en trois " branches à stigmates peu apparents. Le fruit est une " capsule à trois coques arrondies et de la grosseur d'une " noisette. Chacune de ces coques renferme une graine " huileuse, d'une saveur amère et désagréable, qui excite " la salivation et occasionne des nausées.

“. Celte espèce de plante, dit M. Richard, est un arbris" seau toujour's vert, communément de cinq à six pieds " d'élévation, parce (qu'on le taille ou même qu'on le ré" cèpe fréquemment pour que ses feuilles acquièrent un 
" plus grand développement; cảr, abandonné à lui-mème, “ il peut s'élerer jusqu’à vingt-cinq et même trente pieds " de hauteur. Ses feuilles, alternes et portées sur des pé" tioles trop courts, sont elliptiques, aiguës, dentées et " assez fermes, glabres, luisantes, d'un vert assez intense, "longues communément de denx ou trois pouces sur un " pouce de largeur. Les fleurs sont blanches, assez grandes, " courtement pédonculées, solitaires ou réunies en petit " nombre à l'aisselle des feuilles supérieures. Leur calice " Inonopétale à cinq divisions obtuses. La corolle se cons"pose de trois, six à neuf pétales arrondis et étalés. Les " étamines sont fort nombreuses; le fruit est formé géné" ralement de trois coques globuleuses, adhérentes entre " elles par leur axe commun à une seule loge, s'ourrant " par une fente longitudinale et contenant une seule graine " globuleuse. Quelquefois le fruit se compose de deux ou " mème d'une seule coque, renfermant une amande qui "donne de l'huile. '»

De ces définitions scientifiques passons à d'autres détails explicatifs sur l'arbuste à thé.

Sa racine est noire, irrégulière, ligneuse et divisée; elle a quelque ressemblance avec celle du pêcher; son écorce est mince, sèche, coulcur marron, cendrée sur la tige et nuancée de vert aux extrémités des branches; elle est dure, très-adhérente au hois et couverte d'une légère pellicule qui s'en détache quand l'écorce devicnt sèche; lorsque cette dernière est dépouillée de cette peau, elle parait être verdàtre et son odeur a quelque rapport avec celle du coudrier et du noisetier, excepté qu'elle est un

\footnotetext{
' Les Chinois s'en servent pour la cuisine et l'éclairage.
} 
peu plus forte. "Pour mieux eomnaitre la nature de cet " arbre, dit le père Lecomte dans ses Mémoires sur la "Chine, j'eus la curiosité de goutter l'écorce du trone et "des branches, je mâchai aussi du bois et des fibres; l'un " et l'autre me parurent sans aucune amertume, et mème " sur li fin j’y trourai un goùt de réglisse assez agréable "mais tiès-peu sensible. "

Le bois est dur et fibreux, d'un vert très-pâle, exhalant une mauvaise odeur quand il est frais. La moelle en est petite et adhérente au bois. Les branches sont très-nombreuses, irrégulières, différentes de formes, de grosseur et de longueur; quoique la plupart soient d'un jet eourt, elles n'ont pas cependant d'annélites, comme en ont ordinairement les arbustes qui croissent de bonne heure; les tiges de ces branches sont feuillues, courtes, épaisses, vertes, assez rondes, lisses d'un côté, mais creuses et rétrécies : " Les feuilles, dit le père Lecomte, sont allongées " et terminées en pointe; clles sont assez droites, dentelées " tout autour. Les plus rieilles sont dures, cassantes et " amères; clles ressemblent par leur forme et leur cou" leur au cerisier-griottier (hortensis cerasus). Les nou" velles, au contraire, ont plus de rapport avec le fusain " commun à graines rouges; elles sont molles, flexibles, " rougeâtres, lisses, transparentes, et assez douces au " goût, surtout après qu'on les a un peu mâchées. "

Les fleurs ont quelque analogie avec nos roses sauvages; elles continuent de pousser très-tard dans l'hiver; " elles "piquent vivement la langue, dit Kœmpfer, et ne peu" vent être prises ni en infusion ni autrement. "

Linnée rangea le genre TuÉ dans la famille des plantes qu'il appela Polyandrie Monagynie. MM. de Jussieu et 
Ventenat le placèrent dans la famille des orangers ou hespérides (classe 13, ordre 10). MM. Poiret et Desfontaines adoptèrent cette classification et en firent un genre de plantes dicotélydones ì fleurs complètes, polypétales et régulières. M. Decanćoulle, que la mort a enlevé à la science il y a à peine deux ans, créa la famille camellices dans laquelle il fit entrer le thé. Cette classification, plus rigourcusement exacte que les précédentes, conduisit ì celle qui est aujourd'hui adoptée par tous les botanistes français et dont M. de Mirbel a l'honneur de l'invention. Ce savant a détaché l'arbuste chinois de la famille des auriontacées ou hespérides, et a composé avec lui et quelcures autres genres une famille distincte sous le nom de THéAcÉes.

L'arbuste à thé a une ressemblance frappante arec le Camellia sesanqua; l'œil le plus exercé a même de la peine à les distinguer l'un de l'autre quand ils ne sont pas en fleur. Les botanistes ont même discuté la question si le thé n'était pas un sous-geure du camellia. Le docteur Wallich, surintendant du jardin botanique de Calcutta, a trouvé une différence entre les deux plantes, marquée surtout par la forme de leurs fruits. Un autre naturaliste anglais, II. Griffith, qui a fait une longue résidence dans le Hant-Assam, dont nous parlerous plus loin, dit qu'après avoir attentivement examiné l'arbuste à thé et deux espèces de camellia des montagnes de Khasiya, il fut convaincu de leur identité, et donna mème des dessins à l'appui de son opinion. Néanmoins le sentiment contraire prévaut aujourd'hui. Il est reconnu que le thé diffère du Camellia sesanqua par ses fleurs axillaires, au nombre de deux, qui ont les pétales moindres, non 


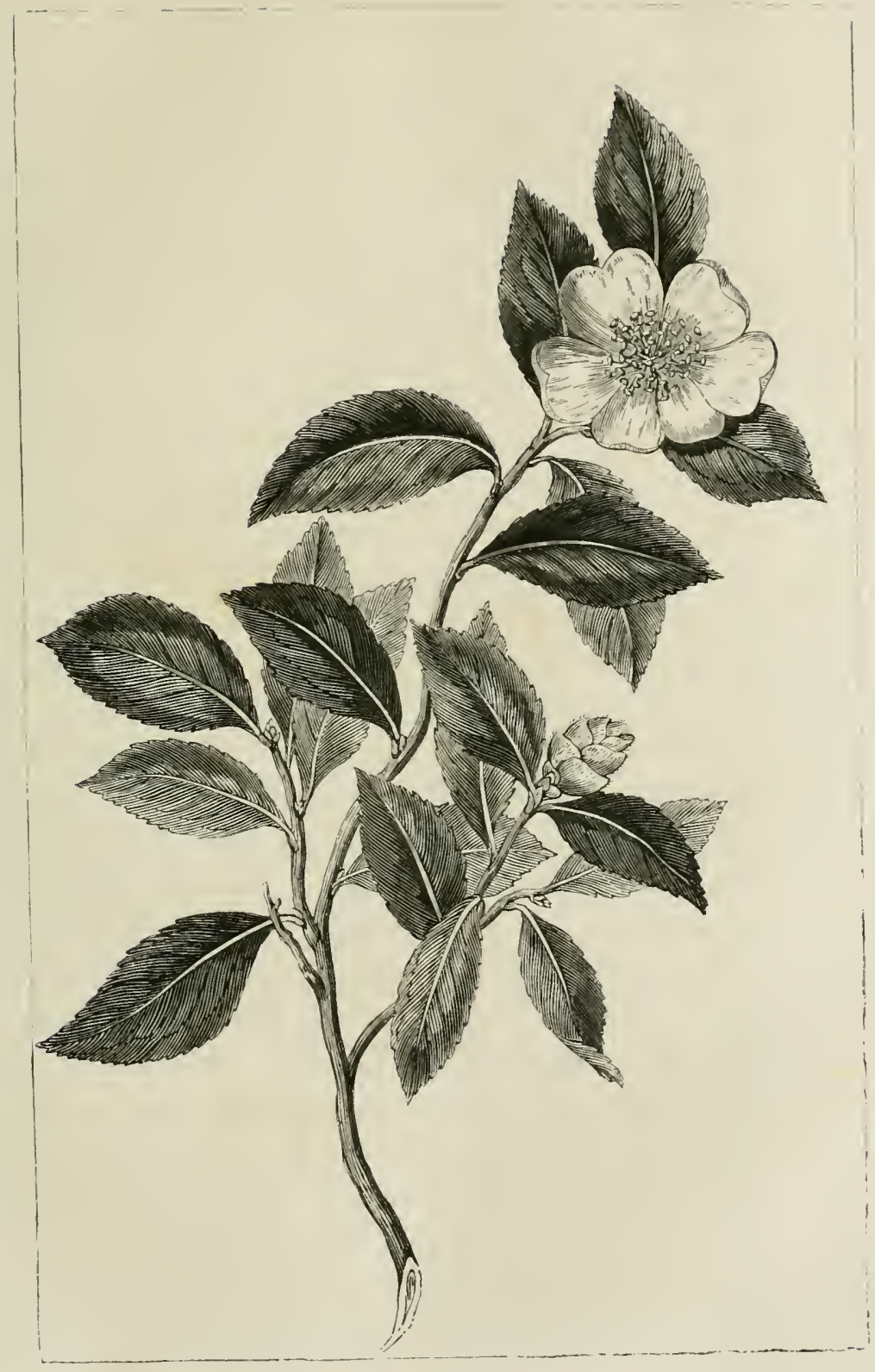

Camelia Sesanqua. 
carinées sous leur sommet, ainsi que par ses feuilles épaisses et non recourbées.

Une autre question u'a pas moins divisé les botanistes et les voyageurs, c'est celle de savoir s'il y a deux especes de thé, l'une dont on tire le thé vert et l'autre le thé noir; ou bien si la distinction à établir entre ces deux classes distinctes de the du commerce, repose tout entière sur un mode différent de prépariation. 'Lettsom s'exprime ainsi sur ce point épineux : "Les arbres à thé noir qui " ont été élevés dans plusieurș pépinières autour de I.on" dres présentent à l'ceil quelques légères différences avec " ceux qui produisent le thé vert en Chine, ef que j’ai re" présentés dans mes gravures. Les feuilles en sont d'un " vert plus foncé; elles ne sont point aussi profondément "dentelées; la tige est d'une couleur plus sombre et "l'arbre enticr paraît plus petit, mais les caractères bo" taniques sont les mêmes. J'ai infusé toutes les sortes de " thé noir et de thé vert que j’ai pu me procurer, et j’ai "étendu les feuilles du premier sur les feuilles du se" cond, afin de comparer leur grandenr et leur forme. Je "voulais par ce moyen découvrir leur îgé. J'ai trouvé " les feuilles du thé vert aussi larges et aussi fibreuses que " celles du thé noir; cette identité m'a fait soupconnei" " que la différence de ces deux thés ne tient pas à l'àge " des feuilles, mais à d'autres circonstances. Nous savons “ qu’en Europe, le sol, la culture, l'exposition dı terrain, " ont une grande influence sur tous les végétaux; la même " espece varic non-seulement d'une province à une autre, " mais d'un canton à celui qui l'avoisine. Cette diversité " dans la même plante doit ètre bien plus considérable " dans un pays aussi vaste que la Chine et dont les pro- 
" vinces ont une climature fortement tranchée : ici règne * une chaleur tropicale, là un froid liyperboréen, ailleurs " une température moyenue. »- Lettsom conclut formellement en ces termes : "Il n'y a, à mon avis, qu'une seule " sorte d'arbre à thé; la différence qui existe entre le thé " rert et le thé noir dépend des circonstances que j'ai rap"pelées plus haut. On a remarqué que l'arbre à thé vert, " planté dans les pays où vient le thé noir, produit du thé " noir, et réciproquement. »

Cette opinion, conforme à celle de tous les voyageurs, est également celle de tous les botanistes modernes. Linnée et d'autres sarants à sa suite distinguaient deux espèces de thé : le thé vert (thea viridis) et le thé noir (thea bohea). Mais cette distinction n'est plus admise aujourd'hui. Déja Kœmpfer', Loureiro (Flore de la Cochinchine); 'Thumberg, disciple de Linnée (Flora Japonica), le père du Halde, avaient reconnu qu'il n'existait qu'une seule espèce d'arbuste. MIM. Pigou, Crawfurd et Marjoribanck, agents de la Compagnie des Indes, qui ont exploré la Chine dans ces dernières années, MII. Medhurst et de Carpéna, sont de cet avis, qui est partagé par le docteur Sigmond, professeur de botanique à la société royale de Londres. Ce dernier dit, à la vérité, que les feuilles du thé vert sont longues et pointues, tandis que celles du thé noir sont plus larges et plus arrondies; mais il n'hésite pas à affirmer que l'arbre est le même. Un des hanistes de Canton, Chowqua, bien connu sur les marchés de Londres, du Hâvre et de Bordeaux, dans un ouvrage qu'il a publié sur le thé en 1838, dit qu'il a visité au moins huit fois le Fo-Kien, et qu'il y a résidé chaque fois au moins quatre ou. six mois; il certifie également que le bohea peut 
servir à faire de l'hyson et vice versä; convenant toutefois que lés thés préparés suivant la nature du sol qui les produit valent toujours mieux.

Pour nous résumer, le doute n'est plus possible sur l'identité de l'arbuste à thé vert et à thé noir. Deux écrivains anglais vivants, M. Davis, qui a exercé jusqu'à l'avènement de la reine Victoria les fonctions élevées de surintendant du commerce britannique en Chine, et M. Bruce, directeur des plantations de thé d'Assam, se prononcent de la manière la plus affirmative en fareur de cette identité. Le premier, au chapitre xix de son Histoire naturelle de la Chine, dit à l'article T’Hé : "Les échantillons " qu'on apporte des provinces où se récoltent le thé vert et "le thé noir ont une légère différence dans la feuille; " celles du premier sont plus minces, d'une couleur un " peu moins foncée et d'une forme plus allongée que les " autres. Mais cette différence provient entièrement d'une " préparation diverse. Les Chinois avouent eux-mêmes " qu'on peut faire indistinctement du thé noir ou du thé " vert avec les feuilles du même arbre. "

Nous verrons au chapitre vi en quoi consiste la différence de manipulation des deux thés.

II. Bruce n'est pas moins explicite dans le rapport qưil a publié à Calcutta en 1838, et qui a été reproduit dans le Journal Asiatique de janvier 1839. - Il dit dans un passage :

"Les feuilles de thé vert ne se récoltent pas de la même " manière que celles dı thé noir, quoique l'arbre soit " exactement le même; ce qui ne saurait prêter sujet au " moindre doute, car, en ce moment même, je cueille " des feuilles pour faire du thé noir et du thé vert dans la 
“ même plantation et sur le même arbre. La différence se "réduit seulement au mode de fabrication et à rien de "plus. " (V. le ch. vi.)

On voit donc que l'expérience a pleinement confirmé l'opinion des plus célèbres botanistes contemporains. Ventenat, de Jussieu, Poiret, Decandolle, A. de Saint-Hilaire, Richard, de Mirbel, guidés par les seules lumières de la science, araient déjà décidé à l'unanimité que dans le genre thé il n'existait qu'une seule espèce qui, de mème que celles cultivées depuis longtemps, est susceptille d'un grand nombre de variétés. Leur vénérable maître, M. Desfontaines, s'était, il y a longtemps, exprimé formellement dans ce sens : "Les observations que j’ai faites, dit-il, " sur quelques individus cultivés au Muséum, et dont cleux " ont fleuri abondamment, ont servi à me convaincre de " la rigoureuse exactitude de celles de Kiompfer, de Thum" berg et de Lettsom, qui n'ont recomnu qu'une seule es"pèce d'arbre à thé. » 


\title{
CHAPI'TRE IV.
}

\author{
Des cultures dı The.
}

Bien que l'introduction du thé en Europe datât de plus d'un demi-siècle, un voile impénétrable couvrait encore tout ce qui était relatif à sa culture et à sa manipulation, lorsque Kœmpfer publia son célèbre ouvrage, qui n'a rien perdu de la haute estime quil'accueillit à son apparition. Ce sarant royageur, qui arait résidé au Japon, n'a parlé que de ce qui s'y pratiquait, mais les détails qu'il doune. ¿̀ ce sujet, outre qu'ils peurent se rapporter à ce qui se passe en Chine, ont été reconnus si exacts, que nous pensons devoir en reproduire ici l'analyse, pour servir de préambule à l'exposé des méthodes usitées en Chine, au Brésil et à Assam.

Au Japon, on n'affecte aux plantations de thé -ni jardins ni enclos particuliers; on les fait sur la lisière des champs de riz et de blé pour que l'ombre projetée par les arbres ne nuise point aux moissons. On n'ensemence pas non plus les graines dans un ordre régulier et symétrique. De distance en distance, on creuse des trous dans lesquels on met six graines au moins et douze au plus, c'est-à-dire autant qu'en contiennent les capsules. Ce nombre est nécessaire, parce que l'huile que renferment 
les graines les rend sujettes à se rancir promptement; il . en lève à peine un cinquième. "Il arrive souvent, dit Kœmpfer, que deux ou trois arbustes poussent ensemble et sont si étroitement entrelacés qu'on croirait, au premier abord, qu'ils sortent de la même tige. ")

On ne donne généralement aucun soin aux jemes plants; seulement, quelques cultivateurs, plus industrieux, ont le hon sens d'extirper les mauvaises herbes qui croissent autour, de labourer la terre, et même de la fumer avec divers engrais. Les feuilles ne sont hounes à cueillir que la troisième année, époque où elles sont abondantes et dans toute leur beauté. Au bout de sept ans environ, l'arbuste a alteint la hauteur d'un homme; comme il croit ensuite très-lentement et qu'il porte peu de feuilles, on le recèpe jusqu'au tronc. A la suite de cette opération, il pousse des rejetons plus vigoureux et en plus grand nombre. On la diffère quelquefois jusqu'à ce que l'arbuste ait atteint l'àge de dix ans, mais toujours le cultivateur est largement indemnisé de ce sacrifice temporaire. Quant à la récolte et à la manipulation des feuilles, elles se pratiquent comme en Chine.

L'agriculture a été portée depuis des siècles, dans ce dernier empire, à un degré de perfection qui a émerveillé tous les Européens qui en ont visité l'intérieur. A chaque pas, ils ont eu occasion d'admirer avec quel art, quelle persévérance les Chinois savaient tirer parti du sol et du climat. Il n'est presque point de landes, point de bruyères sur leur vaste territoire qu'ils n'aicnt su utiliser. Le docteur Abel, attaché à l'ambassade de lord Amherst, en 1818, a publié une description des provinces qu'il traversa, et ce récit s'accorde parfaitement arec celui des persomnes qui 



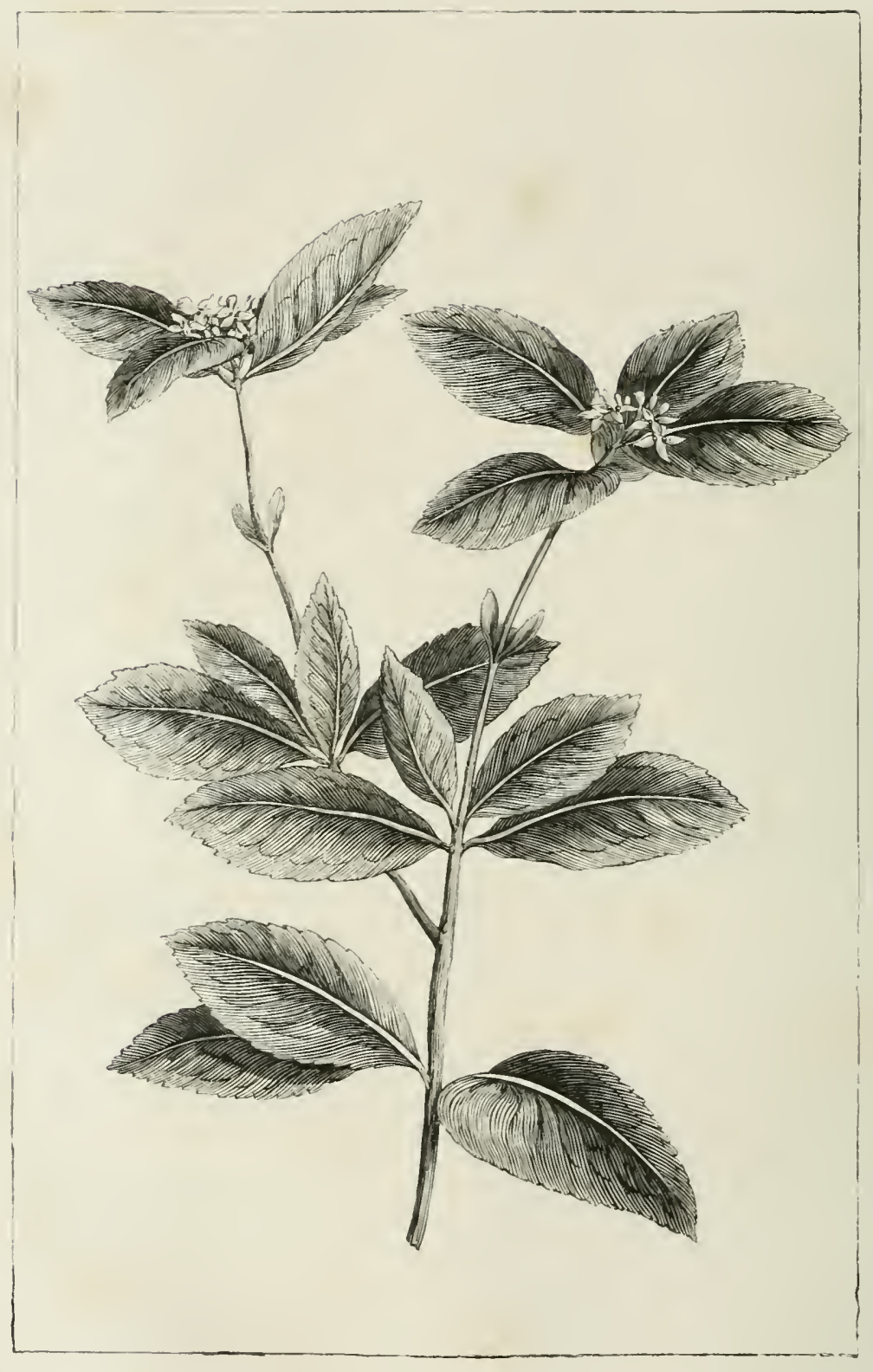

Olea Fragrans. 
nut pénétré plus tard dans cette contrée. Il dit que partout il ent sous les yeux le magnifique spectacle de la puissance de l'homme sur la nature; qu'à chanue pas se déronlèrent devant lui les preuves multipliées du caractère industrieux, tenace et laborieux des Chinois. Il vit sur sa route tantôt des champs couverts de céréales et de plantes légunineuses; telles que riz, orge, millet, haricots, füves, navets, pommes de terre; tantût des vergers de cotonniers, de mûriers, de cannes à sucre, de camellia sesanqua, d'olea fragrans, d'arbres à suif (croton subiferum), le lauricrs-camplure (laureus cumphora); de citronniers, d'orangers, etc., etc. Dans les intervalles des arbres étaient ensemencées des plantes utiles en nédecine comme dans l'usage domestique. A coup sûr, rien ne doit être plus pittoresque qu'un paysage dont les productions sont si variées et offrent un si riche assortiment de couleurs bigarrées. Il suffit de l'avoir vu une fois pour être convaineu de la vérité du proverbe qui dit: Qu'un Chinois tient ses champs én meilleur état que sa muison. Ses instruments aratoires, tels que charrue, herse, houe, etc., sont d'une construction aussi simple qu'ingénieuse. Son système d'arrosage et d'irrigation est parfait; les aqueducs, les canaux qui sillonnent lem territoire en tous sens ; les puits artésiens, qui y sont connus depuis les temps les plus reculés, attestent des connaissances hydrauliques très-étendues. Le plus petit cultitivateur chinois a des machines pour distribuer de l'eau à vulonté sur toutes les parties dı territoire qu'il exploite. Un fermier anglais ou flamand ne saurait pas mieux que lui mettre à profil la moindre parcelle de terre et discerner le genre de production qui lui est le plus approprié. Par instinct et par habitude, il sait tenir compte des différences 
géologiques du sol, des diversités de climat et de température, des influences atmosphériques, etc.

Chez un peuple aussi arancé dans la pratique des arts agricoles, la culture du thé a dù être et a été effectivement portée à un degré incomparable de perfection. Quoique l'arbuste croisse spontanément dans plusieurs endroits et que dans d'autres il serve de haie pour les champs, comme au Japon, il est des provinces de l'empire où l'on n'a épargné ni soins ni dépenses pour l'aeclimater et en tirer les produits les plus exquis et les plus abondants. Les sortes de thés les plus connus des Européens viemnent des prorinces centrales et maritimes de la Chine, les plus belles et les plus fertiles de tont l'empire.

L'affluence de plus en plus grande des acheteurs étrangers a eu pour consézuence nécessaire d'en propager considérablement la culture en Chine. On l'élève anjourd'hui dans des localités où, il y a une trentaine d'années, il était inconnu ou complétement négligé. Les provinces de FoKien, de Kéeang-Nan, de Che-Keang, de Keang-Si et de Keang-Soo en produisent la plus grande partie, et les Anglais prétendent que c'est le meilleur. Toutefois, celui qui se récolte aux environs de Pékin est le plus estimé parmi les hautes classes dı pays. Les Russes achètent celui qui se cueille sur les confins de la Tartarie chinoise, et ce thé, d'une qualité réellement supérieure, est préféré dans le nord de l'Europe, et même en France, conme nous le verrons plus loin.

C'est de Fo-Kien (heureux pays) que rient la plus grande partie des thés consonmés en Angleterre, en Hollande, en France et cu Belgique. Fo-Kíen est séparé du reste de l'empire par une chaine de montagnes qui l'en- 
tomrent du côté des terres; le reste est hordé de rochers escarpés dont les eimes ront en diminuant et se prolongent jusyu à la mer comne les gradius d'un amplithéâtre. Quoique tris-montueux, le Fo-Kien produit autant de thé yue les plus fertiles vallées. Dans un district de cette province qu'on appelle Kean-Ming-Foo, sont situées denx fermes qui ont acquis une grande célélnrité par la supériorité de leur's. produits provenant des monts Woo-eSihan qui sont peuplés de temples et de couvents de honzes. Les thés de cet endroit sont fort recherchés, quoique leur transport, qui se fait ì dos d'homme, ì cause de la rareté des bêtes de somme et du manque de routes praticables, entraine de grandes dépenses. Ce district n'est éloigné de Canton que de 18 milles (environ six lieues); mais les fermes à thé sont situées ì 300 milles dans l'jutérieur des terres. Comme l'on a à traverser des montagnes, des ravins, des rivières et des caniux, il en résulle que le transport des thés peut durer des semaines et même des mois entiers. En général, la végétation du Fo-Kien n'est point naturellement lixueuse; le sol en est paurre; lo génie industrienx des habitants est seml parvenu à le rendre produclif. ì un tel point qu'on a réussi à y élever les fruits les plus rares el les plus sayoureux.

Keang-Nan, qui a élé récenment divisé en deux provinces, est une des contrées du globe que la nature s'est plu à combler de ses largesses. On assure que les habitants l'emportent beaucoup sur les autres Chinois, non-seulement sous le rapport de l'agriculture et de l'aptitude manufacturière, mais aussi pour les arts libéraux, les sciences et les lettres. Ce beau pays forme une plaine immense, entrecoupée de quelques collines et arrosée par un des 
plus grands fleuves de l'ancien continent, le Yang-Tse. C'est là où se cultive et se prépare le songlo (roir au chapitre is de la classification des thés.). Che-keang est encore une province très-agricole et une pépinière d'arbustes à thé. Keang-Si et Keang-Soo sont toutes deux renommées par la salubrité de leur climat, et la population y est employée presque exclusivement à élever et à torréfier le thé.

L'arbuste se plaît sur la pente des coteaux et dans le voisinage des eaux courantes. Le père Lecomte assure que le meilleur thé vient dans une terre pierreuse, la qualité moyenne dans un sable léger, et la qualité inférieure dans une terre jaune et glaise. Son confrère, le père Du Halde, affirme que cette plante affectionne une terre légère, blanehâtre, sablonneuse, mais non pierreuse. Tous deux s'accordent à reconnaitre que le meilleur thé vient dans les endroits exposés au midi, opinion qui est entièrement partagée par M. J.-F. Davis et par M. Bruce, déjà cités. Les observations de ces deux écrivains, revêtus l'un et l'autre d'un caractère officiel, qui ont visité plusieurs provinces de la Chine et qui ont expérimenté par euxmêmes les cultures du thé, méritent la plus entière confiance. Dans son rapport, M. Bruce s'exprime en ces termes : "Je fais observer que le soleil exerce une action " extrêmement puissante sur les feuilles de l'arbuste; car "dès que les arbres qui servent à ombrager les jeunes "plants ont été abattus, la fenille, qui alors était d'un " vert foncé, devient rapidement jaunâtre et conserve cette " couleur pendant quolques mois, au bout desquels elle " reprend graduellement son ton vert et rigoureux; les " branches devienuent plus touffues et produisent des 
"feuilles en beancoup plus grand nombre que lorsqu'elles "étaient ì l’ombre.

"Le thé qui se fait avec les feuilles poussées à l'ombre " est notablenent inférieur ì celui dont les feuilles ont "rétléchi les rayons du soleil. Il est reconnu : $\mathbf{1}^{\circ}$ que ces "dernières poussent plus rapidement; $2^{\circ}$ et que celles " des plants ombragés expriment quand elles sont roulées " une liqueur très-fluide, tandis que les autres rendent un " jus beaucoup plus visqueux. "

Ce témoignage est imposant et s'accorde pleinement avec ce que nous savons de l'action vivifiante du soleil sur la plus grande partie du règne végétal. Cependant au premier abord il semble être contredit par d'autres observations dont nous n'apprécions pas moins le caractère de sincérité. Mgr. de Carpena, vicaire apostolique du SaintSiége dans le Fo-Kien, où il réside encore, a écrit une instruction manuscrite, concise mais substantielle, sur la manière dont on cultive le thé dans cette province. "Le " terrain plat et élevé, dit-il, est le plus propice pour les " arbres à thé. Ce terrain doit être humide, mais non pas " trop bourbeux; solide, c'est-à-dire non mouvant. Quand " sa surface serait couverte de sable, cela ne nuirait point " iux arbres; mais il ne doit pas être pierreux, parce que " ces arbres redoutent la sécheresse. La meilleure qualité "de terre est la,rouge ou la paile, comme l'appellent les "Chinois. En un mot, ces arbres aiment les lieux hu“ inides, froids, élevés et exposés aux vents d'est. Il y a " aussi au Fo-Kien beaucoup de plantations dont le ter" rain n’est pas absolument plat, mais parce que ce ter"rain est trop humide, quoique fertile d'ailleurs, les " arbres à thé qui y croissent ne sont ni aussi touffus ni 
"d'une aussi bonne qualité que ceux des liemx plats. "Tous les endroits du Fo-Kien qui rémnissent les qualités " énoncées plus haut sont plantés d'arbres à thé, princi"palement dans le district de King-Ning-Fou, rulgaire-

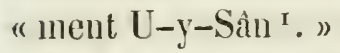

Ce témoignage, émané d'une somrce aussi r’espectable, pour peu qu'on le pèse, riufirme aucunement, au fond, ceux de MM. Davis et Bruce; il donne seulement à comprendre que l'arbre à thé ne se plaît ni dans un sol trop aride, trop exposé à un soleil d'airain, ni dans un terrain trop visqueux et trop marécageux; c'est la conclusion чu’avait déjà déduite le père Du Halde, en déclarant que cet arbuste n'aimait ni le soleil ardent, ni une humidité prulongée, et qu'il était froid de sa nature. On sait, d'après les récits de voyageurs vivants, qu'il prospère en Chine dans des contrées froides et que la neige ne lui fait ancun mal. Les Chinois estiment, suivant M. Bruce, que les sept dixiemes de la production totale de leur empire croissent dans les montagnes, $\in \mathfrak{t}$ les trois autres dixièmes

' Un jeune naturaliste que la mort vient d'enlever, enroyé il y a quatre ans aı Brésil par M. le ministre dı commerce et de l'agriculiure, pour y étudier la culture du thé, M. le doctenr Guillemin, dit dans son rapport que lis plus belles plantations qu'il y ait vues, existent dans la province de Saint-Paul, dont le sol est généralement argilo-fermuinens et uon trop compacte. L'aspect rabougri des thés du jardin botanique de Rio-Janeiro dépend, setuı lui, de la manvaise exposition de ce jasdin dans un bas-fond, all niveau de la neer, frappé directement par les rayons d'un soleil brûlant, ainsi que de la qualité du sul, qui est trés-argileux et fortement cohre par du Iritoxide de ler, ce qui le rend asse\% semblable aus tertes lortes de: France. Lit tempreratme moyeme de Rio-Janciro en de $20^{\circ} 5^{\prime}$ centigrades an nireäl de la mer. Celle dir sol a la surlace est pour te maximum de $45^{\circ}$, pour le minimum de $13^{\circ}$. Jugeant indispensable la condition d'humidite, H. Guillemin consejllait an gourernement d'essayer des plantations de thé dans le département du Finjolere, dont la température assez donce permet d'y cultires le camellia en pleine terre. llituns-nous de dire que cés essais n’ont point rénssi, et que la mission dispenliense de ce jeune naturaliste n'a produit que d'infiuctueux résultats. 



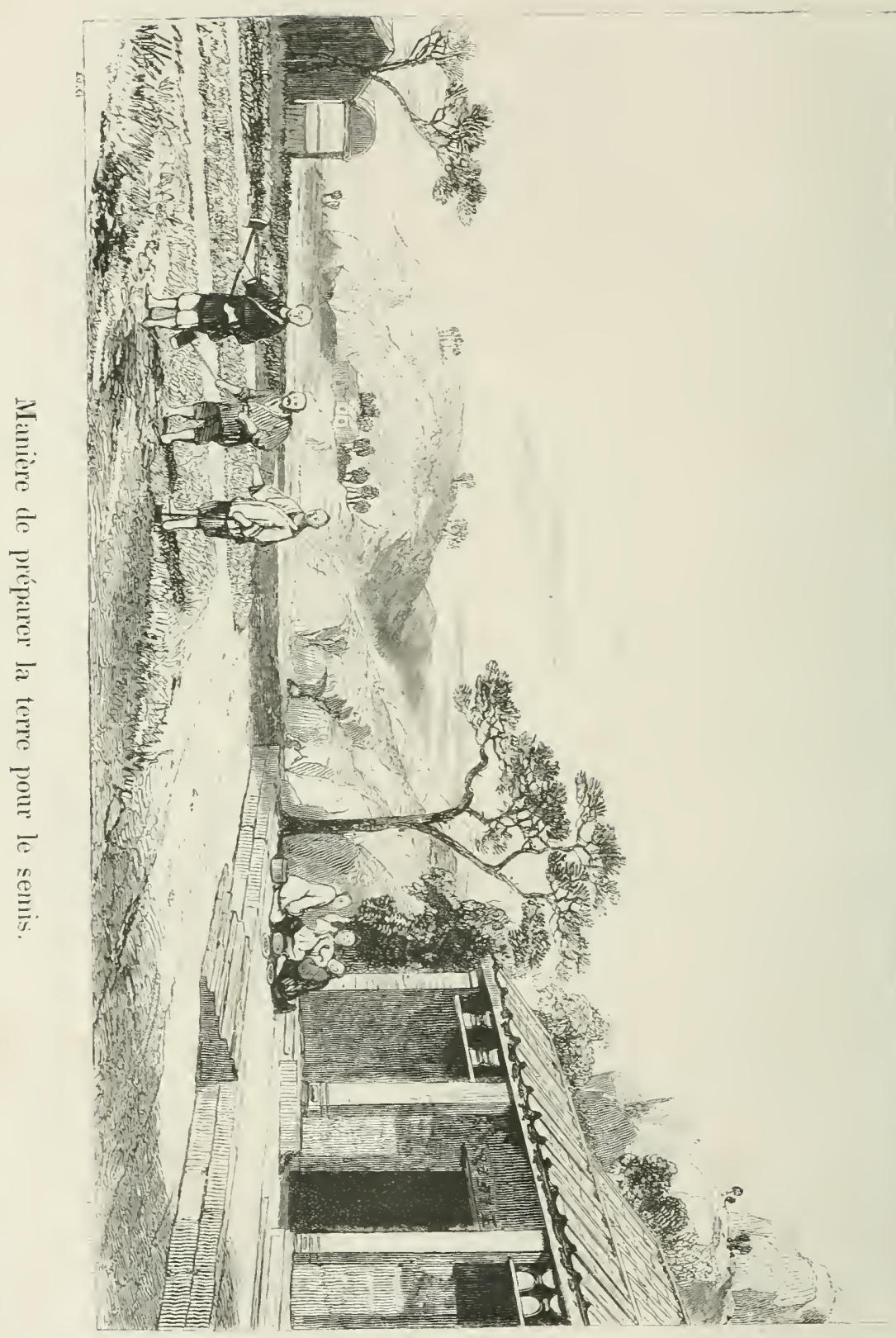




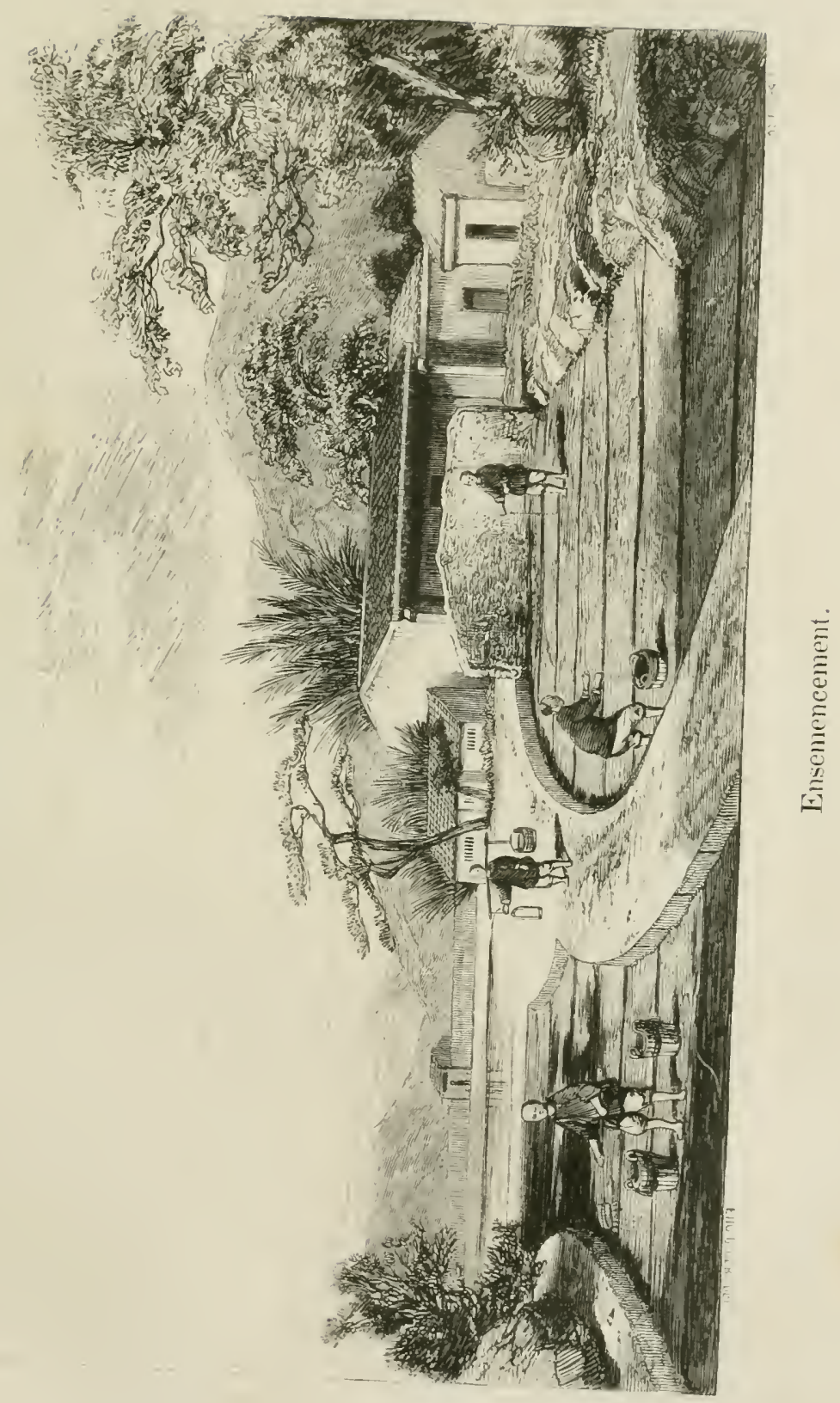



seulement dans les plaines. Ie climat qui lui parait le plus fivorable est situó entre le $25^{\circ}$ et le $33^{\circ}$ de latitude, si on en juge par le succés de sa culture en Chine. Une température moyenue, telle est done la condition indispensable de la bonne venue de cet arbuste. On a pu s'en assurer en France, où il réussit mieux dans le nord que dams le midi.

Suivant monseigneur de Carpena, la province de FoKien, et celle de Kiang-si dans la partie yui y confine, sont celles où existent les plus florissantes plantations de thé. Le terrain est soigneusement préparé; on ne laisse ni herbes, ni hroussailles, ni végétaux parasites. Après qu'il a été bien sarclé (et M. Bruce dit qu'ou répéte cette opération deux fois par an), on y fait des trous à deux mètres environ l'un de l'autre. M. Delamarre, missiomaire en Chine, dans une lettre communiquée an Jorrmal d'Agriculture-pratique par M. l'abbé Voisin, directeur des missions étrangères, prétend que cette distance est seulement de $0^{\mathrm{m}} 65$ : distance évidemment trop faible, et yui anrait des inconvénients pour la croissance et la culture de l'arbuste, non moins que pour la récolte des feuilles. Ces petites fosses doivent avoir, suivant monseigneur de Carpena, 33 centimetres de profondeur; elles n'en ont que 10, d'apres M. Delamarre. Ici encore nous aloptons la première assertion comme la plus rraisemblable, d'autant mienx qu'elle est confirméc par le témoignage de M. Bince. On jette dans chaque tron de six à dix grimes qu'on couvre d'une poignée de funier de brebis, de cheval on de gros bétail, mêlé avec de la cendre et réduit en poussière; puis on comble la fosse avec de la terre sans la fouler. Cette oprération se fait, non dans le 
mois d'octobre, comme le prétend M. Delamarre, mais dans le mois de férrier, après les pluies, afin que le-sol ne soit pas trop sec. Lorsyue l'on sème sur couche pour transplanter ensuite, on a la précaution, en plantant chaque élève, de fouler la terre autour des racines jusqu'à ce que la tige ait atteint la hauteur de $\mathbf{2 3}$ centimètres hors du sol. Quant à l'arbuste planté en pleine terre, on le ferait mourir en foulant la terre qui courre ses racines et en sarclant les herbes qui croissent autour. On entrelace ordinairement des petites baguettes sur les fossés, afin de reconnaitre les endroits ensemencés et en même temps les protéger contre les piétons et les bestiaux.

Les détails que donne M. Bruce, dans son rapport, coïncident parfaitement avec cette description ${ }^{\text {' }}$.

MI. Bruce et de Carpena disent que les cultivateurs chinois u'empêchent pas directement le thé de croître; mais comme ils en cueillent les feuilles trois ou quatre fois l'an, cette opération répétée suffit pour arrêter le développement de l'arbuste. Cette conséquence est rigoureusement conforme aux principes les plus élémentaires de la botanique; cependant il ne faut pas lui donner ici un sens trop absolu. Sans rloute qu'une défoliation

- Au Brésil, on a également soin de bien préparer la terre par des labours à la houe, et d'y mettre un peu de fumier. Les semis de thé se fint ordiuairement dans les mois de janvier, février et mars. Lorsque la graine est suftisamment mûre, on la sème immédiatement, ou très-pen de temps après sa récolte, attendu, comme nous l'avons dit, qu'elle perd promptement sa faculté germinative. Les thés produisent une telle quantite de fleurs et de fruits qu'il s'échappe de ceux-ci heaucoup de graines qui germent sous les vieux pieds, et qui servent à alimenter les plantatious. Celles-ci sont ordinairement disposées en quinconce, les arbustes étant distancés entre eux d'environ un mètre, afin de faciliter la cucillette des fenilles. Quelques agriculteurs plantent en lignes très-espacées, et dans les intervalles ils cultivent du maīs, des plantes légumineuses, ele. 


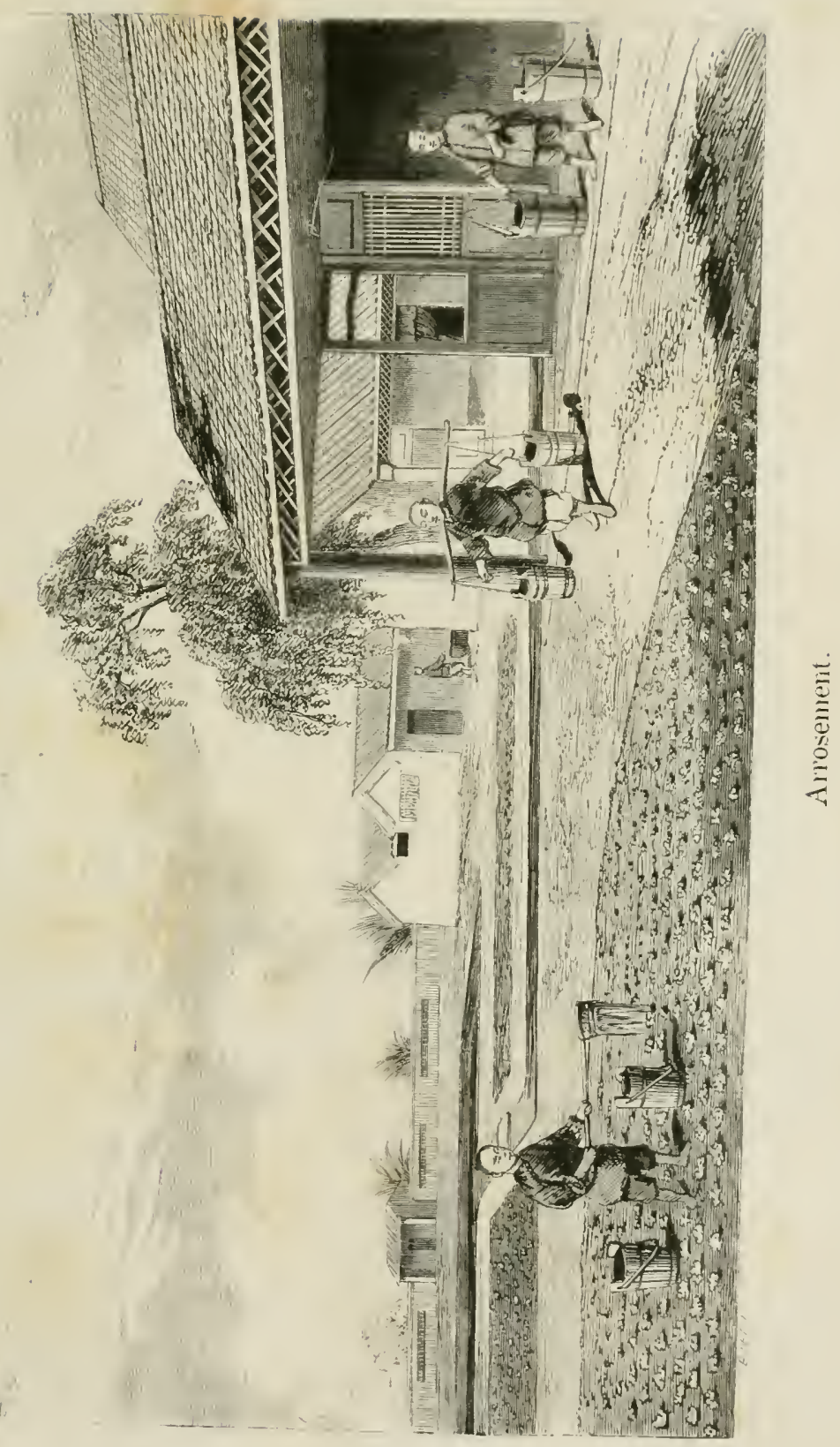


trop répétée est a thé; mais le plus puissant consiste dans l'opération du recépage pratiqué par les Chinois; ils ont mène soin de forcer l'arbuste a se ramifier par la section fréquente des branches supérieures. Suivant les neemes autems, dans le Fo-Kien et le Kiang-Si, ım plant de thé, lorsqu'il est bien entretenu, peut domner des fenilles pendant trente, quarante ans et plus; ensuite on le recoupe au niveau du sol afin que de la sonche il s'élève de noureaux rejetons; ce qui indique clairement que l'opération du recépage, au lien d'être pratiquće dans ces deux provinces, comme aillen's, de sept ans en sept ans ou de dix ans en rlix ans, ne l'est que beaucoup plus tard, en raison probablement d'une plus grande aptitude de terroir ou d'mue culture plus savante.

Les arbres à thé se propagent généralement en transplantant les racines des individus trop vienx ou en employant la méthode de boutures, car les Chinois ignorent l'art de greffer; toutefois, il y a exception pour le Fo-Kien où on ne pratique que le semis.

Dans cette dernière province, la plupart des champs à thé n'ont pas besoin d'être arrosés; leur position inclinée permet d'y creuser facilement des rigoles et des tranchćes; mais dans cette contrée comme dans d'autres, l'arrosage à bras ou par machines est de toute nécessité sur les hauteurs escarpées et les plateaux des moutagnes; il est mêue à présumer qu'on le pratique avec une sollicitude toute particuliere dans les grandes exploitations. La gravure 3, annexée á cet ouvage, ne laisse aucun doute à cet égard.

Ia plupart des royageurs qui ont écrit sur la Chine 
affirment que le fumage des plantations de thé n'est observé que par un petit nombre de cultivateur's. Sans infirmer leur témoignage, que nous croyons impartial, il est permis de ne l'appliquer: $1^{\circ}$ qu'aux ter'ains plats, humides, riches en humus; $2^{\circ}$ yu'aux paurres gens qui exploitent isolément leur's modestes propriétés sans aroir les moyens de l'amender, et qui en Chine, comme partout ailleurs, sont les plus nombreux. Mais le fumagee est indispensable pour les champs situés sur le rersant des montagnes, sur le flanc des collines; car, de l'areu des mêmes écrivains, les inondations fréquentes oceasionnées par les pluies y entrainent les terres végétales, qui y sont quelquefois si rares qu'elles laissent à nu les racines. Aussi les colons, pour réparer ces pertes ou suppléer à l'insuffisance du sol, sont-íls obligés de transporter dans leurs champs un cngrais qu'ils tirent du lieu le plus voisin, et qu'ils ont soin de choisir, autant qu'il leur est possible, analogue au terrain de leurs plantations. C'est à peu près la nème méthode que suivent nos rignerons.

Dans les grandes exploitations, ainsi que le montre la gravure $n^{\circ} 1$, on se garde bien de négliger une partie aussi importante que le fumage.

Le docteur anglais Falconner a conclu, d'après une étude approfondie des diverses localités où le thé se cultive en Chine, qu'il eroit sous une température de $73^{\circ}$ ì $54^{\circ} 5^{\prime}$ Fareuheit $\left(22^{\circ}\right.$ cent. à $\left.12^{\prime \prime}\right)$; qu'en été, la chaleur ne va pas au-dessous de $30^{\circ}\left(26^{\circ}\right.$ cent. $)$ et qu'en hiver, le baromètre descend de $5 y^{\prime}+\dot{a}^{\prime} 6^{\circ}\left(12^{\circ} 7^{\prime}\right.$ à $6^{\circ}$ cent.); que la différence entre l'été et l'hiver sur les frontières du nord était de $59^{\circ}$ ( $14^{\circ}$ cent. ), et sur celles dı sud de $30^{\circ}\left(1^{\circ}\right.$ cent. an-dessous de glace); que les endroits les plus pro- 
pices au the varient de température, année conmune, de 5 '. à $67^{\circ}$ ( $22^{\circ}$ à $28^{\circ}$ cent.); que la pluie tombe également daus tous les mois de l'aunée, et que l'humidité du climat est généralement molérée. Le docteur Abel, que nous avons déjà nommé, a fait un travail curieux sur la structure géologique des terrains ou l'on cultire le thé. Ce travait s'accorde sur tous les points avec les observations de M. Falcomner et celles des royageurs qui ont exploré les provinces à thé de li Chine. 


\section{CHA PIT RE V.}

De la récolte des feuilles.

Lors de l'éponue propre à la cueillette des feuilles de thé, les propriétaires de plantations louent à la journée des ouvriers qui exercent spécialement cette profession et y sont très-habiles; ils ne cueillent pas les feuilles à poignées, mais une à une, en évitant soigneusement d'endommager les hranches et les bourgeons; et si long et si minutieux que paraisse ce travail, ils ramassent par jour de dix à quinze livres de feuilles. Kœmpfer a longuement décrit ce qui est relatif à cette sorte de moisson dans le Japon; il dit que la première cueille commence au milieu de la dernière lune précédant immédiatement l'équinoxe du printemps; c'est le premier mois de l'annće japonnaise, correspondant à la fin de février ou au commencement de mars; on donne alors aux feuilles le nom de Ficki-T'sjaa ou thé en poudre, parce qu'on les pulvérise et qu'on les fait tremper dans l'eau chaude. Les jeunes et les tendres produisent le théImpérial, destiné seulement à l'empereur, aux princes et aux grands seigneurs. Kœmpfer fait la description d'une plantation célèbre qui fournit le thé de la cour. - Udsi, dit-il, est une petite ville voisine de Meaco, capitale de l'empire japonnais. Dans ses environs, 



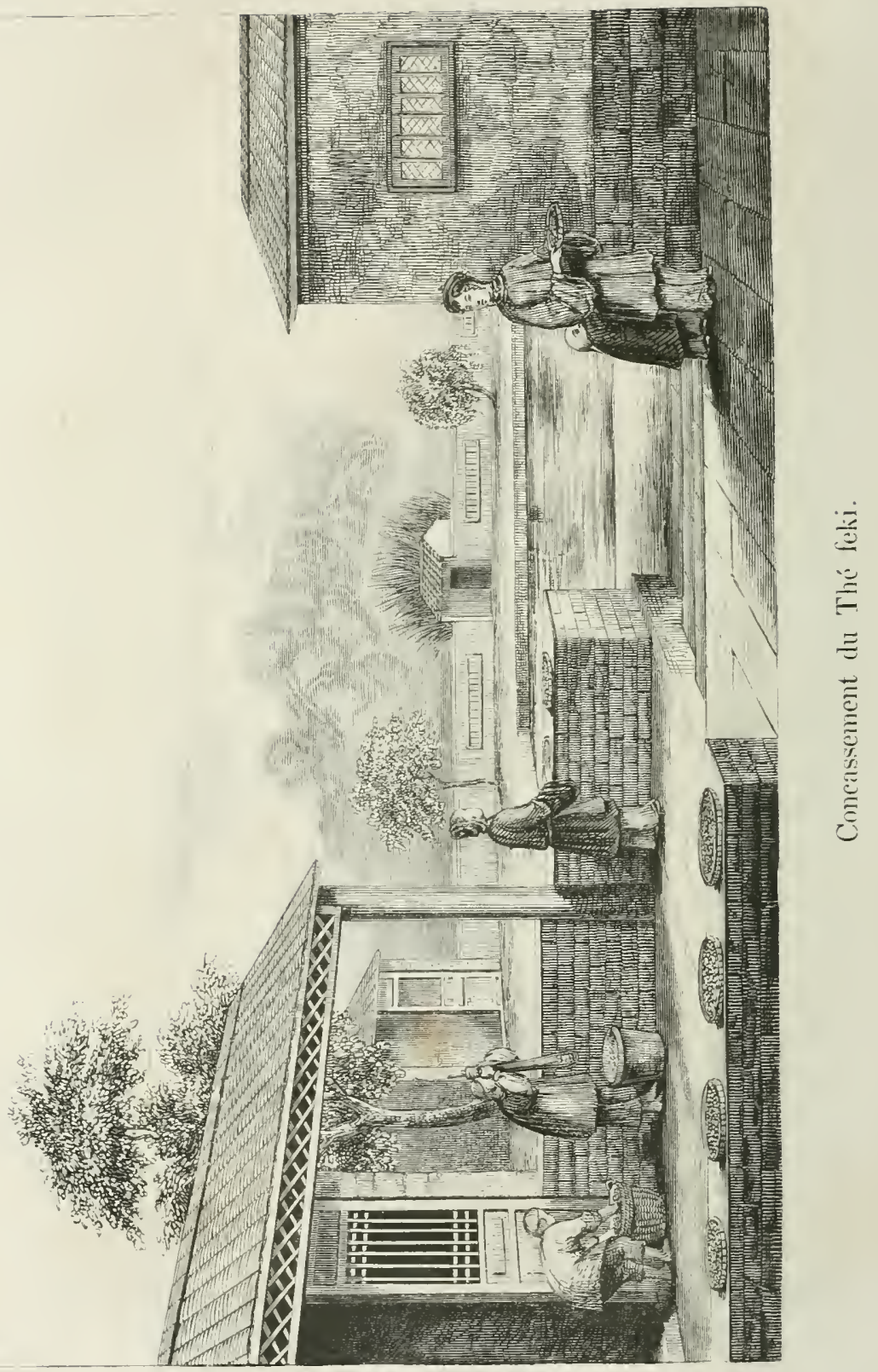


se trouve une montagne de même nom renommée par la qualité dle ses produits. Eille est mutouréc d'une double ceinture de haies et de fossés. Les arbres it thé sont plantés en allées régulières. Il y a des gens qui sont chargés uniquement de veiller sur ces arbres et de les préserver de la poussière, de la boue, des insectes, etc.; de les maintenir, en un mot, dans un état parfait de propreté. Les ouvriers qui doivent en cueillir les feuilles s'abstiennent dès la veille de tout aliment grossier qui pourrait leur domner une haleme susceptible de communiquer une mauraise odeur à ces feuilles. Ils portent même des gants, de peur de les toucher arec les doigts. Les trivaux s'effectuent sous une surveillance sévère, et lorsqu'ils sont achevés, la récolte est portéc au palais impérial, par le surintendant, escorté d'une garde nombreuse.

La deuxième récolte, au Japon, a lieu à la fin de mars ou au commencement d'avril. Quelques-unes des ferilles sont arrivées à leur entière maturité, d'autres ne le sont pas encore; on les cueille toutes indifféremment, et ensuite on les trie, en les assortissant selon leur âge, leur grandeur et leur bonté; on en fait le Too-tsjaa ou thé chinois, parce qu'on l'infuse à la manière chinoise.

La troisième et dernière récolte se fait au mois de juin; les feuilles sont alors très-abondantes et complétement épanouies. On en tire le thé appelé Ban-tsjaa, qui est la sorte la plus commune et réservée au bas peuple.

Quelques-uns se limitent à deux récoltes par an; la première et la seconde répondent alors aux deuxiène et troisième de l'année précédente. D'antres ne font qu'une seule récolte à l'époque de la troisième et dernière cueille. Mais, dans toutes ces méthodes, les feuilles n'en sont pas 
moins chaque fois triées et classées en différentes sortes.

Lettsom, dans son consciencieux ouvrage, lor'squ'il est arrivé à la récolte du thé, se borne à copicr Kœrnpfer. Il ne dit rien sur la manière dont cette opération se pratique à la Chine, avouant arec franchise qu'il n'est pas assez bien renseigné à ce sujct. Plus heureux que cet estimable écrivain, nous pourons donner à cet égard des détails circonstanciés, puisés à des sources dignes de foi. M. de Carpena dit positivement que, dans le Fo-Kien et le Kiang-Si, la première récolte commence clans les premiers jours d’arril. Le 5 de ce mois est un jour renommé parmi les Chinois, qui l'appellent Chin-ming; le thé cueilli dans celte journée a une grande réputation, qu'il justifie d'ailleurs par la finesse de son arôme. Des obserrations météorolngiques expliquent l'origine et le crédit de cette superstition populaire, comme en France celle dont le jour de la Saint-Iédard est l'objet. Les pluies, les vents et les gibonlées qui succìdent alors à l'équinoxe du printemps, en Chine comme en Europe, domnent aux feuilles du the III bonquet extrêmement suare. Ceite remarque n’a point échappé à la perspicacité des colons chinois.

La pluie, comme nons l'avons dit au chapitre IV, est généralement contraire à cette récolte. Il y a même certaines sortes, telles surtout que le Souchong, qui ne peuvent etre cueillies par une température humide. Pour procéder à celte opération, on choisit, antant que possible, un leau jour de soleil et la matinée, alors que les feuilles sont scintillantes des perles de la rosée. Celte règle est applinuée indistinctement à toutes les sortes de thé, Les dégustateurs exercés distinguent même au besoin si telles qualités ont été récoltées par un beau temps ou par la 



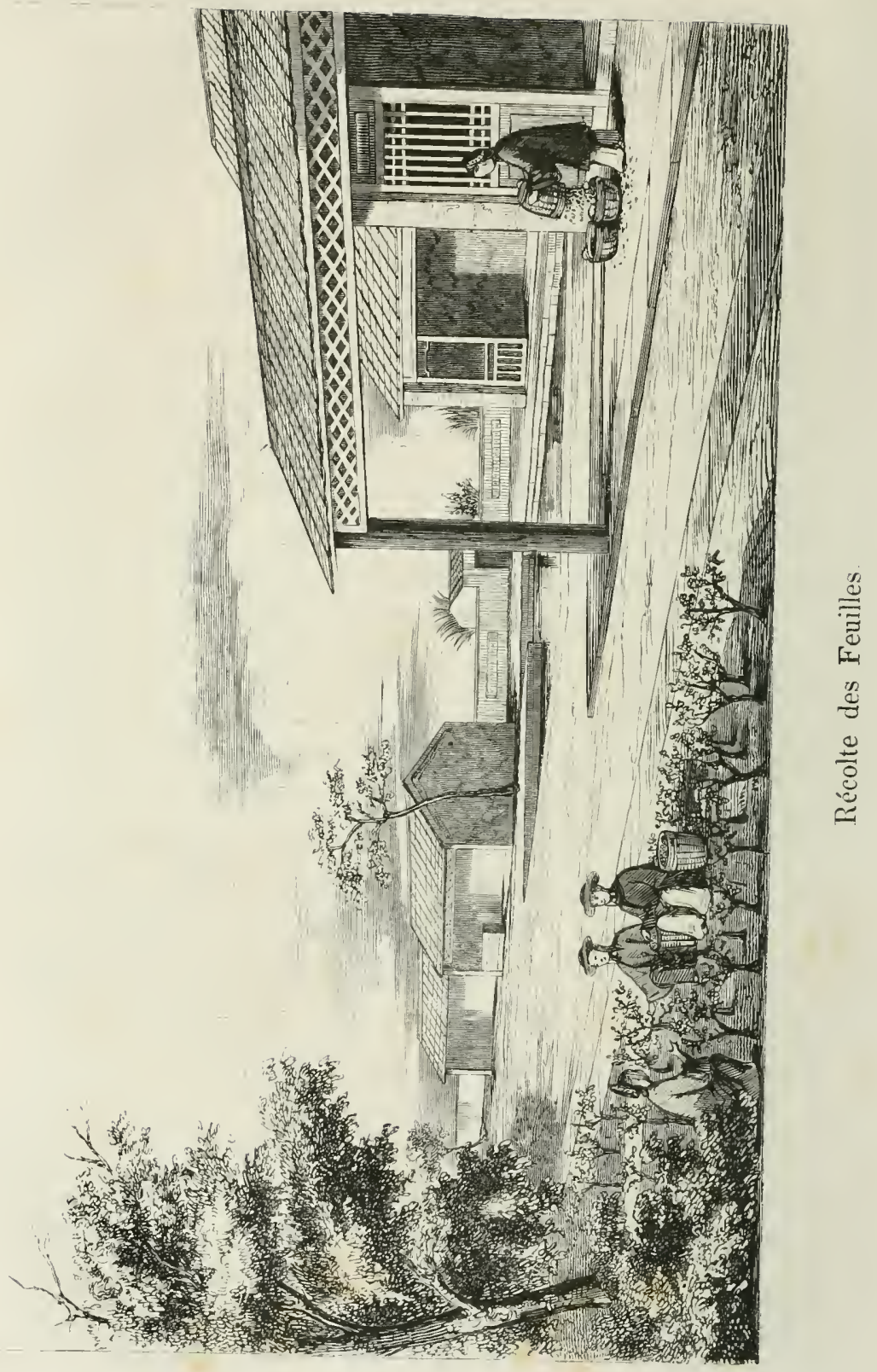


pluie. Les Chinois prétendent que si on cueille les grandes feuilles de thé noir par une température pluvieuse, il en fiudra quator'ze livres pour faire deux livres de thé, tandis que si cette récolte a lieu par un tempssec, huit livres suffiront pour rendre la mème quantité de deux livres. M. Bruce, rui a cu occasion d'interroger ì cet égard un grand nombre de Chinois de diver'ses contrées, s'est assuré, par' sa propre expérience, de la rérité du fait. On conçoit parfaitement que les feuilles détrempées jar la pluie doivent rendre un liquide beanconp moins dense et moins aromatique que celles dont la chaleur a pompé le principe aqueux.

La récolte des fenilles du thé vert diffère quelque pen de celle des feuilles du thé noir.

Les moissonneurs de thé vert ont une petite corbeille suspendue autour du cou par une courroie de deux pieds de longueur, afin que la corbeille soit à la hauteur de la ceinture. D'une main ils tiennent la branche, et de l'autre ils arrachent les fevilles une à une, en ayant soin d'en laisser une légère partie adhérente au pétiole, afin que de nouveaux rejetons puissent pousser. Cette méthode est incontestablement longue et minutieuse.

Quant au thé noir, les moissonneurs cueillent les fenilles arec les deux mains, en se servant du pouce et de l'index; ils les ramassent dans la paume de leurs mains, et quand elle est pleine les jettent dans un panier placé près de l'arbre. Cette besogne se fait aree une agilité si merveilleuse, que l'œil du spectateur a peine ì en suivre la marche, et à distinguer les feuilles cueillies. Tout ce quil voit, ce sont des mains voltigeant de droite et de gauche, se vidant et s'emplissant avec une rapidité incroyable; 
Lnut ce qu'il entend, c'est un fròlement continu qui a quelque chose de la régularité monotone d'une pendule.

La récolte, comme nous l'avous dit, ne s'ouvrant qu'au commencement d'avril, les premières feuilles pour le thé noir ne sont encore qu'en bourgeon; celles couvertes d'un léger duret fournissent le pékoë à pointes blanches; l'arbuste ne les produit que juśqu'ì l'âge de six ans. Quelques jours après, on récolte le pékoë noir. Dans le mois de mai, les feuilles qui ont poussé depuis la première récolte, ont atteint leur croissance; elles forment alors la sorte appelée Sonchong. Cing ou six semaines plus tard, e'està-dire vers la fin de juin, on procède à la troisième récolte qui fournit le Congo; les feuilles choisies du Congo forment le Campo): Quant au Bohea, il n'est pas entièrement produit par le canton de Fo-Kien qui porte ce nom. On dome cette dénomination générique au thé noir tiré des feuilles les plus communes de la derniere cueille.

Pour le thé vert, les premiers bourgeons de l'arl)uste fournissent le Hyson; le Schoulang est un hyson soigneusement trié et préparé différemment; la Pondre à canon est composée des feuilles les plus délicates roulées en globules. La dernière récolte fournit le Tonkay. Comme les feuilles qui le composent sont les phus vieilles et les plus coriaces, on prend pen de soin de leur manipulation.

M. l'abbé Delamarre, qui est ici parfaitement d'aceord avec M. Bruce, rend ainsi conıte de l'opération de la cueille :

"Ce n'est guère que vers la troisième année, aux pre“ miers jours d'arril, qu'on peut cueillir les feuilles de " the. On laisse sur l'arbre celles des années précédentes " qui, étant trop vieilles, ne peurent plus servir, et on ne 
" cueille que les fenilles de l'annéc. A l'aide de l'ongle ', " on casse aree la fenille une partic de son pétiole de lia "longueur de 0 m 02 cent. ou 9 lignes. De cette manière, " les branches poussent de noureaux rejetons et en nombre "d'autint plus grand qu'on a arraché d'ibord plus de "pétioles. Il faut avoir soin de ne jamais cueillir que les " feuilles nouvelles. Ordinairement il y a trois cueilles par " an, de vingt jours en vingt jours, parce qu'aprìs chaque "récolte, l'arbre pousse de nouveaux rejetons et de nou"velles feuilles. Plus les récoltes sont rapprochées ou, en " d'autrestermes, plus les feuilles sont cueillies tendres et " jeunes, plus le thé est estimé. La première caeille printa" nière vaut mieux que la suivante, et ainsi de snite ${ }^{2}$." Le meilleur thé est fourni par les lranches supérieures;

I Il est évident que M. Delamarre n'entend parler ici que de la récolte des feuilles destinces à fitire le thi vert. Lettsom dit que les ouvriers se servent quelquefois d'un bâton croclı pour ramener ì enx les branches trop élevées. Ce procédé, qui n'est point indiqué dalis les gravures chinoises, et qui nous semble inutile, attendu la taille exignë de l'arbre à thẻ cultivé, serait, dans tous les cas, beancoup plus niturel que celni dont parlent quelques anciens auteurs, phus partisans du mervejlleux que de la réalité. Suivant eux, les Chinois dressent des singes pour cneillir les fenilles des arbres à thé qui croissent dans les lieux escarpés. Ce conte ridicule a pourtant èté répété textuellement par quelques écrivains modernes, et notamment dans un opuseule sur le thé, publie il y a quelque temps à Paris, et oi se trouve reproduite par la gravure celte opération fantastique. Sans vouloir réfuter toutes les erreurs dont cet écrit fourmille, il est certain que ce fait est d'alliant plus alsurde, que la Chine ne produit aucun individu de la race simiane. Il faut également reléguer an rang des fables un autre genre de récolte dont parlent de vieux anteurs tels que schort, Stannton, ete. : ils aftirnent gravement que le ché destiné à la boisson impériale: n'est récolté que par de jeunes vierges. Quelques compilaterurs n'ont pas manqué de s'emparer dr cette assertion qui peut hien n'être pas contraire aux mour's orientales, mais que nous croyous dénuée de fondement, attendu que les voyageurs modernes, qui ont pénétré jusqu’à Pékin, n’en parlent pas.

2. Al Brésil, la récolte du thé, fuoique non interrompue pendant toute l'année, est néanmoins plus productive peudant les mois d'aout, septembre et octolore, qui sont le printemps de cette partie de l'Amérique. Elle est faite généralement par des fémmes et des enfants nigres. Ils enlévent avec discernement les feuillestendres, d'un vert pàle, se servant de l'ongle pour couper le 
les moyennes et les inférieures prouluisent des qualités relativement moins honnes.

Un arbre à thé de bonne renue, suivant l'estimation de MII. Bruce, de Carpena et Delamarre, produit, terme moyen, de trois à quatre demi-kilog. de feuilles par an.

jeune lourgeon foliifère un peu au-dessus de la première on deuxième feuille développée. Les feuilles tendres, servant à la confection des thés fins, sont cueillies comme en Chine, avec le pétiole et l'extrémitć terminale de chaque. hourgeon. La récolte peut devenir permanente en la régularisant de manière que les feuilles aient repoussé sur les plants les plus anciennement déponillés au moment oi l'on achève la défoliation des derniers. Chaque nègre peut eneillir environ un demi-arrobe (8 kilog.) par jour. 



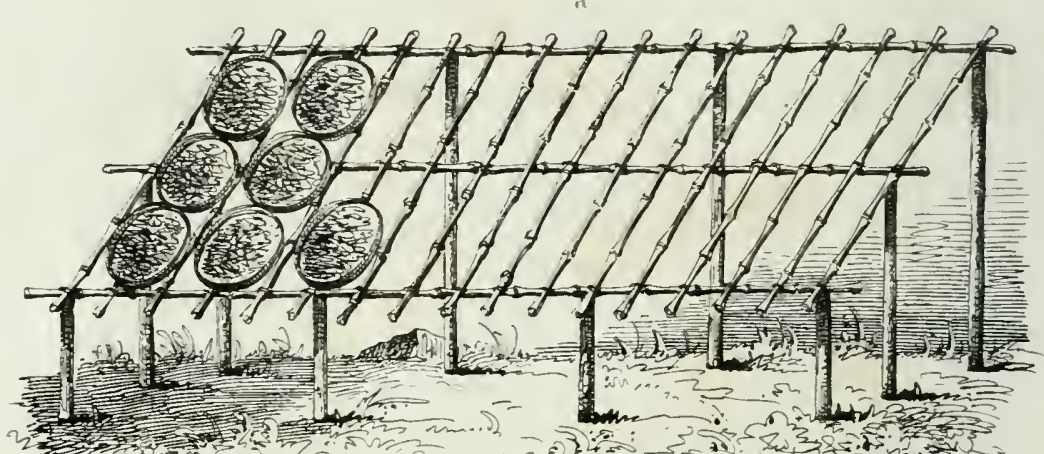

100 की

ton

Chatssw en bumbur sur lequel sont posers les corbeilles remplies de feuilles fruiches exposies aue resleil

(1)

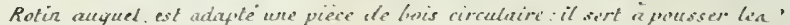
corbeilles sur les chassis et a les relirer.

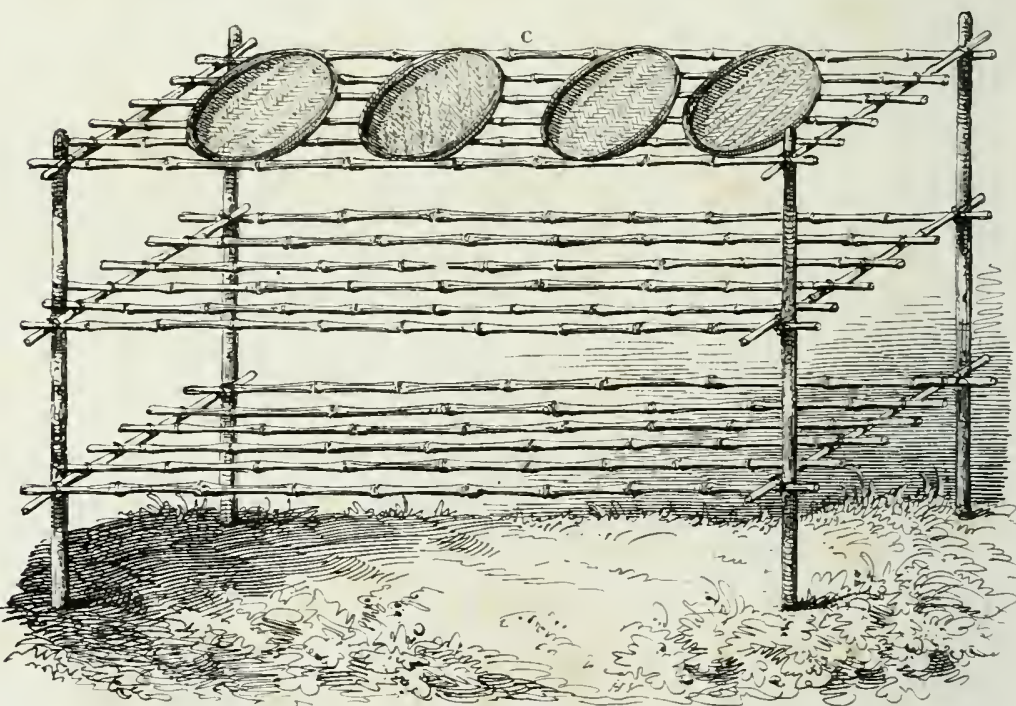

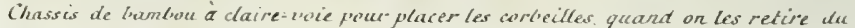
soleil 

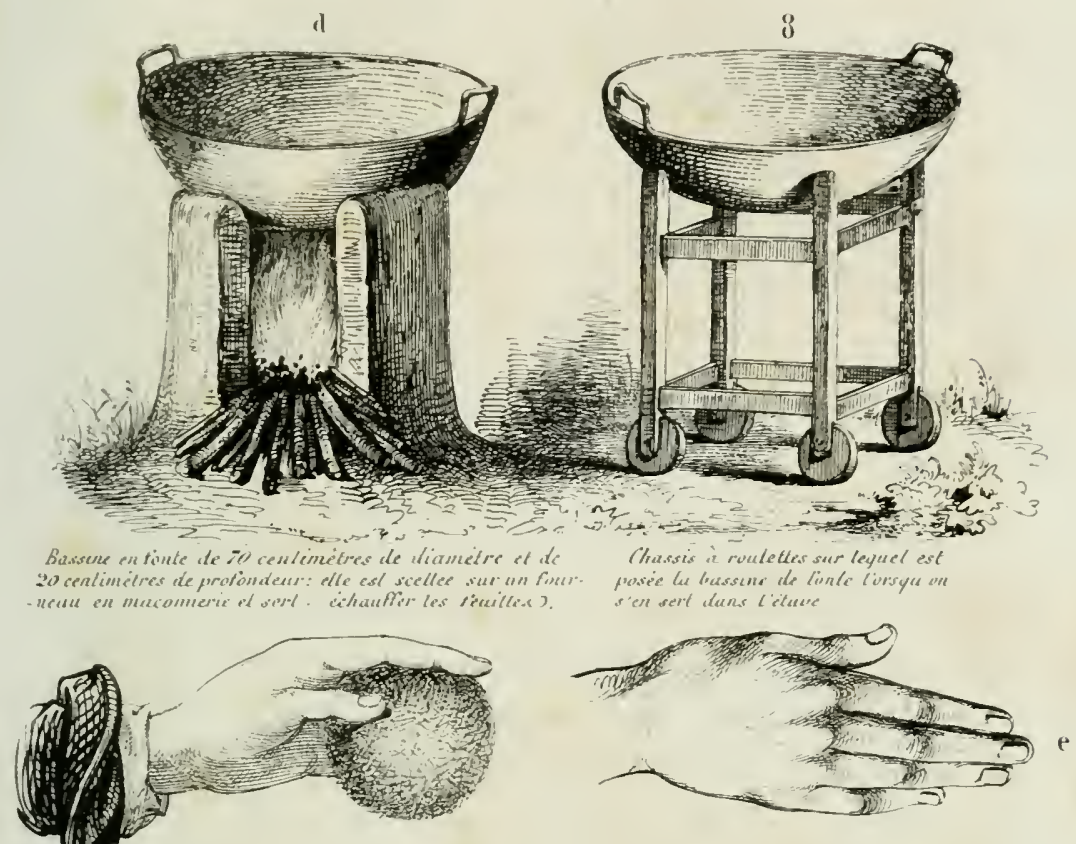

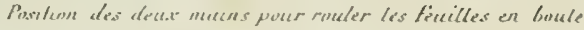

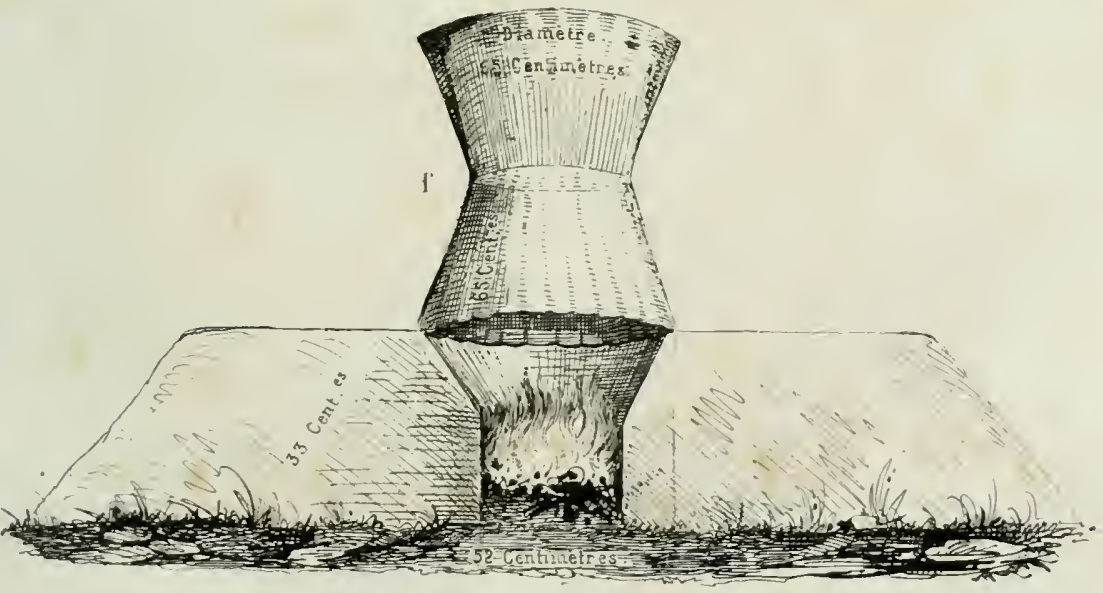

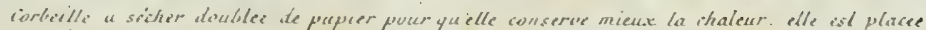

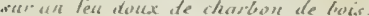





\section{CHAPITRE VI.}

De la torrefiaction du The, et de l'enroulement des fenistes.

La torréfaction constitue incontestablement la partie la plus importante de l'art de préparer le thé et d'olitenir de la mème espèce d'arbuste les nombreuses variétés que nous commaissous en Europe, et yni ont chacune une apparence, un goùt et des propriétés distinctes. Cet art a eté jusque dans ces derniers temps un secret que les Chinois évitaient religiensement de communiquer aux étrangers. Depuis plusieurs amnées, on citait parvenu, dans quelques contrées, telles qu à Java et au Brésil, à créer des plantations de thé, à faire porter ì l'ar'suste la mème quantité de fenilles aussi belles et aussi bonmes qu'en Chine; mais lit s'était borné le succès de ces tentatives; la réritilble méthode usitée dans le céleste enupire était restée un mystère impénétrable. Tous les Européens qui ont visité la Chine depuis deux siècles en itaient revenus aussi peu instruits à cet égard qu'ils y étaient entrés. Le rérérend ministre anglican Medhurst, qui l'a habitée pendant vingt-deux ans, de 1816 ì 1838, dit mème que le procédé de torréfaction y est caché non-senlement aux étrangers, mais encore au plus grand nombre des indigènes. Ce qui donnerait effectivement lieu de présumer que cet art n'est point tout it fait tombé dans le domaine public en Chine, e'est que, 
dans les plantations de Jara et dı Brésil, on fit venir au commencement, et à grands frais, des colons chinois, et que néanmoins les expériences relatives ì la torréfaction ne réussirent jamais que médiocrement. Les produits de ces manufactures sont aussi beaux à l'oeil que ceux de Chine; leur apparence est même souvent plus séduisante; mais à l'infusion ils sont d'une infériorité marquée, et cette différence provient évidemment de la torréfaction.

Les descriptions qui ont été faites jusqu'ici sur la manière dont s'exécute cette opération ont été empruntées aux peintures chinoises qui en représentent les détails. Cés récits donnaient bien sans doute un aperęu du mécanisme de celte manipulation, de la forme architecturale des appartements où elle a lieu, des fonctions distinctes des personnes qui y coopéraient; mais elles ne nous initiaient point complétement à la partie sarante de l'œurre.

Ce n'est que tont récemment qu'a été levé le voile jusqu'alors impénétrable qui enveloppait les méthodes chinoises de torréfaction. Les plantations el les manufactures de thé des Anglais dans le Haut-Assam ont permis de faire commaître l'entière vérité à cet égard. M. Bruce, directeur en chef depuis dix ans de ce noivel et magnifique établissement, a, dans un récent rapport officiel déjà cité, donné les détails les plus minutieux sur les divers modes usités par les Chinois jour fabriquer leur's nombreuses espèces de thé. Les communications qu'il fait à ce sujet sont de la plus grande authenticité, attendı qu'elles sont le résumé de: conversations (quil a eues avec plusieur's Chinois employés sous ses ordres, et dont le témoignage unanime était d'autant moins suspect qu'ils étaient la plupart de diverses contrées, et qu'on les interrogeait séparément. D’ailleurs, 


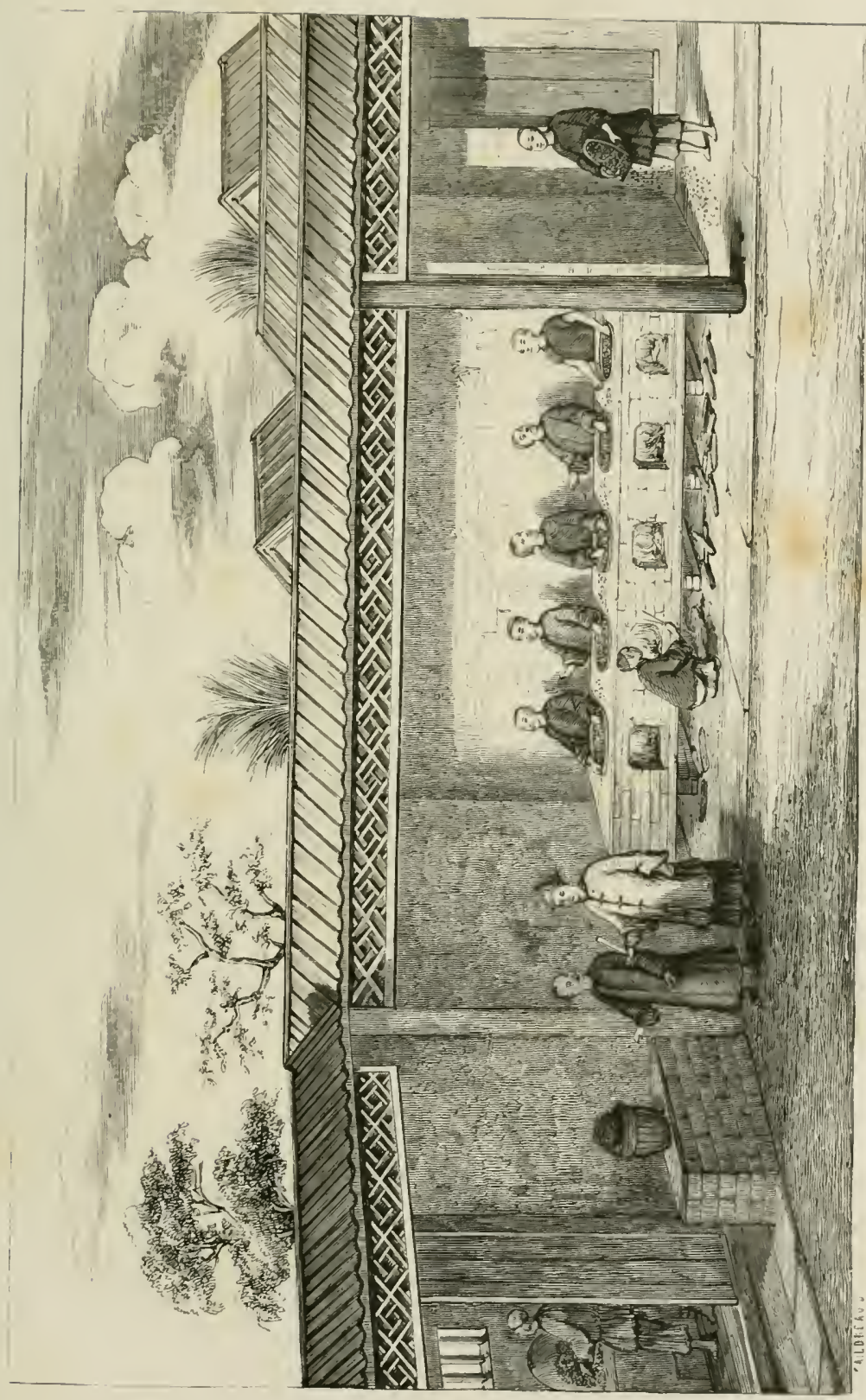

בֶ气 

les expériences joumalières ru’avait oceasion de laire II. Bruce pour s'assurer de l'exaltitude des confidences de ses interlocuteurs, étaient toujour's d'accord avec ces dernières. Nous n’hésitons donc pas ì mettre à profit les renseignements donnés par cet honorable fonctiomaire étranger, et ì déclarer que ce que nous arons écrit de relatif à la torréfaction des thés noirs et des thés verts est extrait en grande partie de son remarquable travail.

L'endroit où se torréfie le thé contient un certain nombre de fourneaux en macomnerie de forme circulaire et d'une hauteur ì mi-corps d'homme; chacun d'eux est surmonté d'une poc̀le ou plutôt d'une bassine de fonte adhérente au fourneau, également de forme circulaire, très-évasée et très-inclinée sur le devant, et ayant les bords relevés, afin que les feuilles ne puissent s'échapper ni sur le derrière ni sur les còtés, et qu'elles retombent naturellement sur le devant où se tient le torréfacteur.

Autant cul'il est possible, les feuilles doivent être enployées le jour même de leur extraction. Si on différait leur cuisson de plus de ringt-quatre heures, elles s'échaufferaient, noirciraient, et perdraient leur parfum.

Pour mettre de l'ordre dans notre travail, nous allons suecessivement exposer les deux méthodes distinctes de torréfier les thés noirs el les thés verts.

\section{\$1. - Torréjuction des Thés noirs.}

Comme nous l'avous dit dans le précédent chapitre, les fenilles qui servent à la fabrication du thé noir sont toujours cueillies avec ure partie de leurs pétioles. Immé- 
diatenınt après leur récolte, elles sont exposées au soleil pendant deux heures, daus de grands paniers de bambou à claire-roie :A); des ourriers les remuent de temps eu temps pour prérenir leur fermentation $(\mathbf{B})$. Au bout de ce temps, on les porte au laboratoire et on les étend sur une claie pendant une demi-heure, afin de les laisser refroilir (C), puis on les replace daus de plus petits pauiers

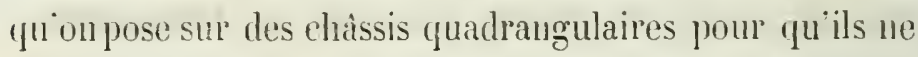
touchent pas à terre. Cela linit, les vuriers malaxent légr̀̀rement les feuilles arec la paume des mains, sans se servir les doights, en les passant d'une main à l'autre, les laissent retomber dans le panier, les reprennent, et contimusut ainsi pendant dix minutes. On les étend de noureau sur la claie pendant une demi-heure. On réitère l'opération trois ou quatre fois, jusqu'a ce que les lenilles soient devenues souples comne de la peau; el'e a pour effet de domner an thé une couleur foncée ${ }^{\mathrm{I}}$. Ators commence la torréfaction. L'onvier qui en est chargé et qui est comnele chef del'atelier, est debout en face du foumean dans leguet brùle un feu bien chair de bambou; à sa ganche un homme tient le pinier daus lequel sont les feuilles farmches; deux autres, à sa droite, jortent des espèces de mammes wn colheilles creuses (clollahs anglais : pour rectroir au fur et à mesure chayue cuisson. Quand la bilssine est chanfiv; au rouge (D), le tor'éfacteur y jette euriron deux lirres de feuilles qu'il étend, bien uniforménent, pour qu'elles

- Tous les ćcrivaius qui ont traite de la torréfaction des thés, y compris même Mu. Davis et IItedhurst, prétendent quavant de livrer les füilles Iraîcles: a l'action da feu, les Chinois les plongent dans l'eati bouillante reudant une demi-minate; que retle immersion a pour objet de les dépuuiller de leurs principes vireux. M. liruce n'en dit mot pour aucune des sorles de thés, d'oú il faut conclure qu'on se contente de faire subir d'abord ans t!ns et aux autres une maluxation manuelle. 


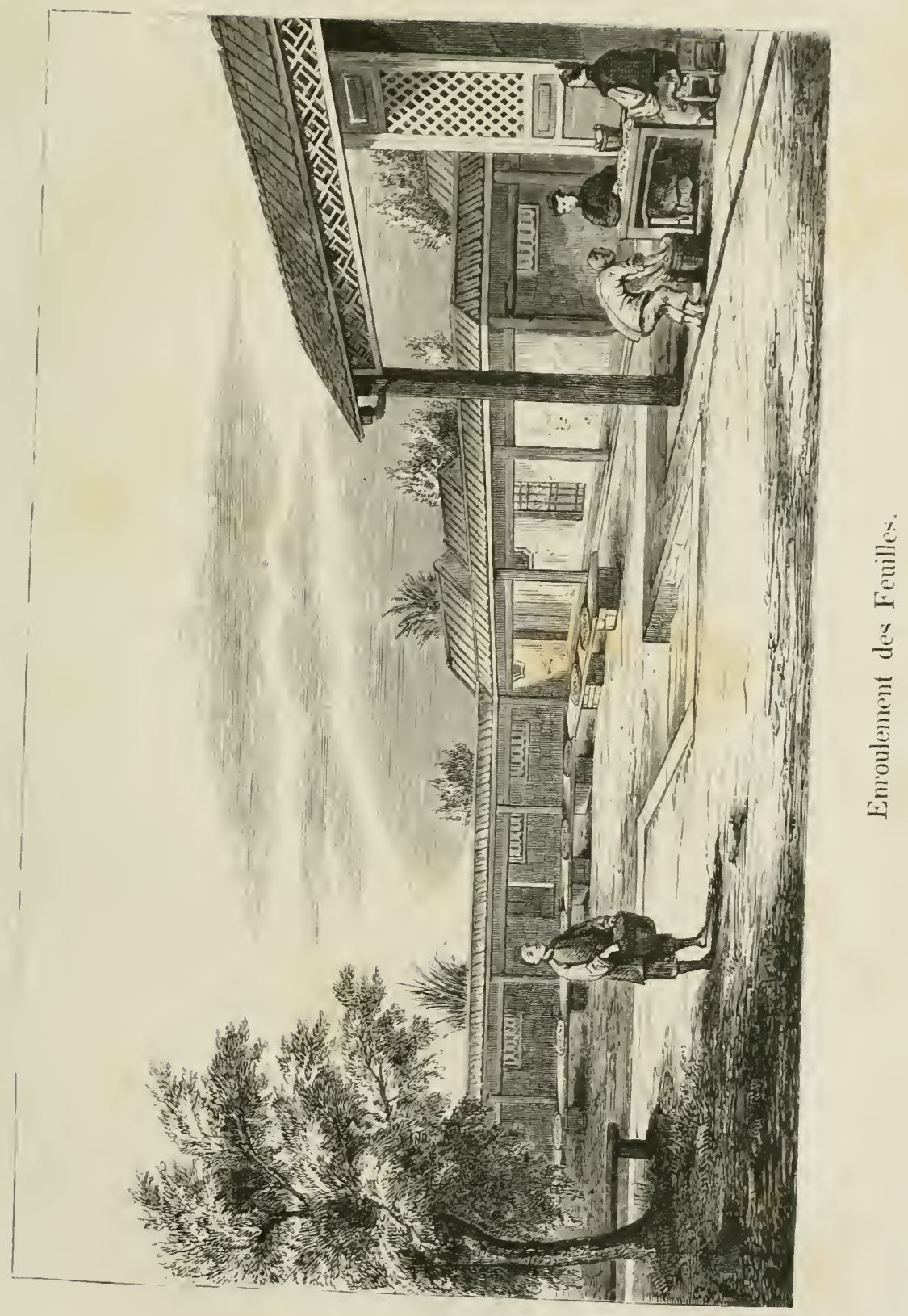



puissent avoir toutes le meme degré de coction. Il les retourne en tous sens avec les mains, jusqu'à ce rqu'elles deviennent si brulantes yn'il ne puisse en supporter la pression; cette opération est excessivement doulonreuse, tant ì cause de la température extrêmement élevée du local, des vapeurs suffocantes dont il est rempli, que du suc cerrosif qui transsude des feuilles pétillantes au contact de la fonte rougie, car ce sue ronge la peau. Il faut cependaut que cette mamipulation contimue sans relàche, les fenilles ne pouvant être roulées que lorsqu'elles sont chaudes. Cette première coction dure à peine une demiminute; dès qu'il s'aperçoit que les feuilles ont pris une certaine consistance molle et qu'elles penrent s'enrouler, le torréfacteur les retire du feu et les remet aux hommes placés à sa droite, puis lave la bassine arec de l'eau froide, tandis qu'un autre la frotte intérieurement arec une verge de bambou pour enlever le duvet cotomeux qui provient de la plante et qui s'attache au fond et aux parois du vase. Si par hasard il reste quuelques feuilles adhérentes à la bassine, le torréfacteur se sert pour les enlever d'une serviette qu'il tient à la bouche, sans doute pour atténuer la force des émanations qu'il respire. Les feuilles torréfiées sont jetées an fur et ì mesure dans les corbeilles dont nous a vons parlé; on en verse euviron quatre poignées dans chacune; pour accélérer leur refroidissement, on les évente et on les ranne, puis on les étend sur une grande table couverte de nattes antour de laquelle sont rangés des hommes, des femmes et des enfunts. Chacun prend un tas de feuilles devant soi et s'occupe de leur enroulement, qui s'exécute de la manière suirante: on en prend une poignée, on frotte vivement les mains l'une contre l'autre par un 
mouvement circulaire gui s'opère en tenaut les doigts serrés et les pouces étendus. Ainsi presséc en tous sens, la poignée de feuilles prend la forme d'une boule et rend un jus rerdàtre (E). L'ourrier recommence à plusieurs reprises; tantôt il agglomère les feuilles, tantôt il les sépare et les laisse retomber isolément pour les reprendre de noureau; tout cela arec une prestesse étonnante. Enfin, il les remet dans la manne qu il agite circulairement, et les reporte au torréfacteur qui leur fait subir une denxième coction. On alterne ainsi la torréfaction et. l'enroulement jusqu'à trois ou ruatre fois, mais en diminuant graduellement la chaleur.

Pour compléter la dessiccation des feuilles, on les étend sur un tamis pourvu de trous de diverses grandeurs; ce tamis est placé au centre d'un panier élevé servant de séchoir, et représentant deux cònes tronqués superposés l'un à l'antre eu sens opposés $(\mathbf{F})$, de sorte que le milieu où est le tamis est beaucoup moins large que les deux bases extrêmes. Un feu de bois est allumé dans un fourneau différent de celui destiné à la première cuisson, attendu qu'il n'a point de bassine et qu'il est beaucoup plus petit: il faut laisser brùler le bois jusqu'à ce qu'il doune un brasier légèrement flamboyant, qui n'exhale ni odeur ni fumée. On place le panier sur ce petit fourneau de manière qu'il en occupe le centre; mais auparavant on a eu soin de bien le seconer rerticalement, de peur que les fenilles qui pourraient passer à travers les trous ne viemnent à tomber dans le feu et n'occasionnent une fumée susceptible de détériorer le thé. Ces précautions prises on laisse le panier sur lo fournean, car ancun danger n'est à redouter, attendu que les rebords circulaires du panier qui recouvrent le brasier en sont suffisamment éloignés. 


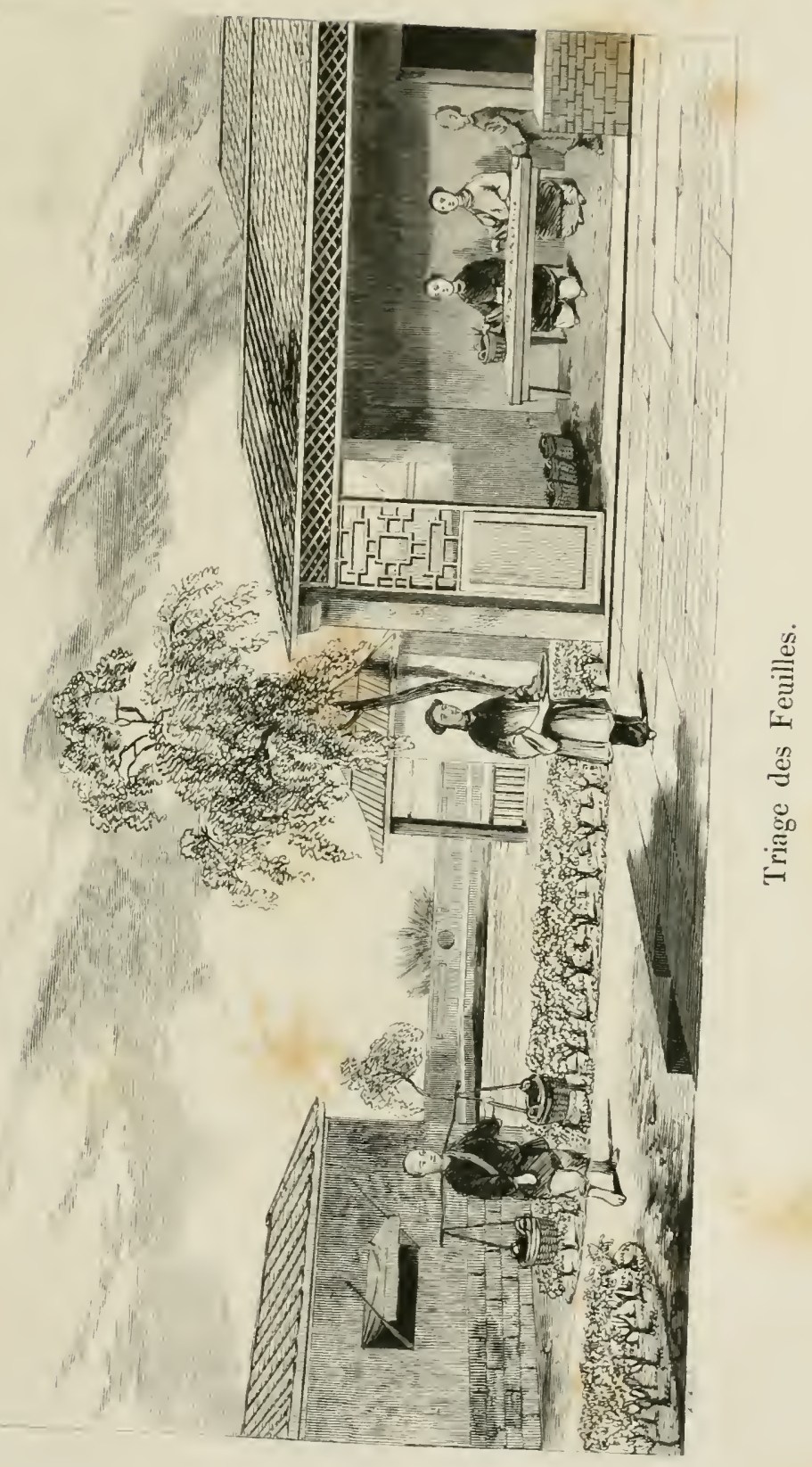



Quand les feuilles sout it moitié sèches et qu'elles n'ont pas perdu tout à fait leur flexibilité, on retire le panier du feu et on verse le contenu du tamis daus de grandes corbeille's à claire-voie rue l'on ne dépose jamais à terre, non plus que les cribles, mais sur des châssis.

Ce n'est que le lendemain qu'on procide au triage. Ilabitucllement cette opération est confiée ì des femmes et it des enfints; ils classent les fenilles suivant leur grandeur et leur finesse, séparant celles qui sont bien roulées le celles qui le sont moins, celles qui sont trop torréfiées de celles qui le sont conrenablement ${ }^{\mathrm{T}}$. Les plus jeunes et les plus tendres forment le pekoë, les deuxièmes en qualité le parr-chong; les suivantes le souchong, puis le congou; les plus grossières fournissent les dernières sortes.

Après leur assortiment, on range de nouveau les feuilles sur les tamis qui s'adaptent aux paniers ì sécher et on les expose à l'action d'un feu encore plus doux que précédemment; au bout de quelques minutes on les retire, on les vamne, et on les jette dans une nouvelle corbeille. Cette opération, qui a pour but d'arriver à une parfaite dessiccation des ihés noirs, est, de même que les premières cuissons, réitérée jusqu'à trois fois. Sur la fin, le feu ne doit plus flamboyer, mais être réduit à quelques tisons consumés. Afin que la chaieur nes'érapore nas, on recourre alors le panier d'une seconde corbeille; en ayant toujours soin de retourner de temps en temps les fenilles avec les mains. On reconnait qu'elles ont atteint leur dernier point de siccité, lorsqu'elies sont parfaitement crispées, rou-

1 On roil que le triage des fenilles suit toujours la torréfaction, au lieu de la précéder, contrairemeut aux assertions de la plupart des auteurs qui ont traite de celte matiere. 
DU THÉ.

lées, et qu'elles se brisent à la moindre pression des doigts.

Tout est alors terminé. On emballe le thé dans de grandes caisses hermétiquement fermées, après l'y avoir lassé avec les mains, puis avec les pieds chaussés de bas tris-propres.

'Telle est la méthode usitée généralement en Chine pour confectionner les thés noirs, sauf puclques légires différences de manipulation qui s'appliquent au pekoë et au pouchong. Les feuilles dı premier, que l'on cueille non encore épanouies et courertes de leur duret, sont aussitôt après leur récolte exposées tour à tour au soleil et à l'ombre; puis successirement soumises à l'action d'un feu fort doux, roulces et amollies, étendues sur de grands tamis; enfin, après aroir passé la nuit à l'air, clles sont triées le lendemain matin et subissent de suite une scule mais énergique torréfaction. Ce mode de. préparation diffire quelque peu de celui que nous venons d'exposer. Quant au pouchong, la seule différence qu'il présente sous ce rapport arec les autres thés noirs, c'est qu'après avoir été roulé il est enveloppé dans des carrés de papier et mis en cet état dans les paniers à sécher ${ }^{\mathrm{I}}$, pour y subir ensuite l'action d'un feu très-doux.

Maintenant e'est le lieu d'aborider une question qui a été discutie léjà en Augleterre par tous les écrivains !ni ont parlé de la Chine et de ses produits; question qui intéresse jusqu'à un certain point la seience et mêrne le

' Les Chinois ont un the iuconnu sur nos marchés el dont la fabrication test analogne au purchong : its l'appellent sychée ei ne le réserrent que pour leurs fètes ou pour des présents a leurs prètres. 11 est rouk daus du papier, c!n forme

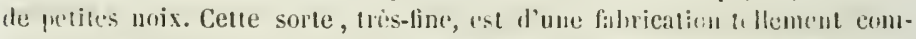
pliaquer, suivant les Chinois, que sur ceut torrifactemrs il y en a a peine un senl qui en connaisse les procédes. 
conmerce. Il est certain qu'il existe dans les thés noirs des parcelles de liverses plantes balsamiques. Quoignion ne sache pas positivement quelles sont celles qui sont entployées dans ce but, et que M. Bruce, ayaut interrogé ses Chinois à ce snjet, u'ait obtenu d'enx aucun renseignement, on at pu reconmaître fréquemment daus les caisses venues de Canton des fleurs d'Olea fragrans (l'olivier odorant) et de Cianellia sesanqua ${ }^{\text {}}$. Indépendamment de ces deux flemrs, les récits des royageurs et des missionnaires, joints aux fragments de végétaux trouvés dans les caisses venues de Chine, portent à croire que plusicur's autres plantes joucnt un rôle actif dans l'aromatisation des thés chinois, comme, par exemple, la fleur d'oranger', le jasmin d'Arabic (Nyclanthes-sambac), le magnolia, l'anis étoilé (Ilicium anasitum de Linnée), le V'etex pennata du mème, le Chlorantius inconspicuus de Schwartz, etc. Telles sont du moins les conjectures de nos botanistes contemporains les plus célèbres, Desfontaines, de Jussieu, de Mirbel, Richard, ete.

Ces rígétaux, que l'on présume associés à quelipues sortes de thés noirs, sont certainement pour'vus d'un parfum délicat cu' ils peuveut lui communiquer, mais eependant jamais de manière à détruire celui qui est jroprè à

I' Eolea fragrans, apjelé far les Chinois lanhoat, et le camelliu sesanqua, yu'ils disigneut sous le nom de Tcha-chou flenr de thè), ont éte connus de sir Georges Stamton, membre de l'ambassade anglaise à l'ékin, en 1793, et de Lellsom. Le camellia ressemble d'une maniere frappante a l'arbusle a thé ; ce n’est guère qu’i leur lloraison respective qu’il est jossible de se rendre comple de leur diflërence. Tous teux lleurissent an mois de técembre; mais le premier puelques jours avant l'autre, du muns dans uos elimats; it n'iflectionne que les terrains ingrats et impropres a tonte's antres flantationas. Sil

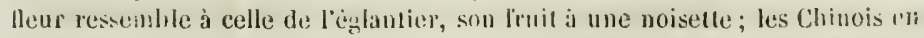
evtraient me huife qui, pomr la savenr et la limpiditi, le cide pen à notre huile doulive. Aussi la enlure de ect arbuste est-elle trés-dendue en Chine. 
la fenille chinoise et qui est tellement prononcé qu'elle ne s'en déponille jamais malgré sa plus grande vétusté.

Quoi qu'il en soit, on iguore encore absolument le procédé mis en usage par les Chinois pour effectuer le mélange dont nous parlons. Le font-ils immédiatement après la torréfaction on seulement à la veille de l'exportation? daus yuelle quantité relative ces plantes sont-elles mêlées an thé? quelles préparations leur fait-on subir préalablenent? Telles sont les questions qui restent encore à r’ésoudre. Dur reste, nous savons positivement que les produits des plantations de Jara et d'Assam ne contiennent ancun principe aronatique étranger au thé; ce qui les distingue éminemment de ceux qui nous arrivent de la Chine.

\section{\$2. - Torréfuction du Thé vert.}

'Toutes les feuilles de l'arbre à thé, ainsi que nous l'arons dit dans le jrécédent chapitre, concourent indistinctenent à la fabrication des thés verts, pourvu qu'elles soient cueillies au raz de leurs pétioles. Dès qu'elles sont récoltées, le torréfacteur en jette environ trois livres à la fois dans la bassine chauffée à rouge, les retournc en tous sens, d'abord arec les mains nues, puis, quand la chaleur devient trop ardente, avec deux petites fourchettes de bambou it six dents, d'environ un pied de longueur. Il s'en sert en sonlevant délicatement les feuilles, d'abord avee la main droite, puis avec la gauche, et par cet exercice continu les empèche de brûler ou de s'attacher au fond du vase. Au bout de trois minutes, elles ont acquis assez de flexi- 
hilité pour etre roulées sans se briser. Alors on les retire du fen, on les verse dans les mames ou dollahs dont il a été question pour les thés noirs; on les évente, puis on les macère avec les mains à pen près de la nême manière. Il en sort une grande quantité de jus, surtout si elles sont fraiches. Quclques planteurs les soumeltent is l'air peudant me muit, et ces derniires renferment natnrellement moins de prineipes aquenx.

Les feuilles pour le thé vert sont pétries avec les mains de manière ì leur donner, non pas une forme sphlérique comme pour le thé noir, mais elliptique ou plutòt conique. Ces petits cônes sont placés par rangées dans des mannes qu'on pose sur des châssis. Ils sont exposés au soleil pendant huit ou dix minutes, après ruoi on lesdéroule un par un. Au fur et ì mesure qui on les déplie, on étend les feuilles dans des mamnes et on les expose de nouveau au soleil, puis on les refaçonne en cône; et ainsi de suite jusqu’a trois fois consécutives. Si le temps est pluvieux et qu'il semble ne devoir pas s'éclaircir, on elfectue cette dessiccation en étendant le thé sur une claie et en le faisant chauffer lentement dans une éture. Mais les torréfacteurs de thé reert ont rarement recours à cet expédient, préférant, à l'exemple de leurs confrères les torréfacteurs de thé noir, la chaleur bienfaisante du soleil à toute autre chaleur artificielle.

La troisième fois que les feuilles ont été ployées en cônes, puis séchées, elles ont nécessairement perdu la plus grande partie de leur moiteur aqueuse; c'est le moment yu'on choisit pour les verser dans la bassine qui est incandescente; on les tourne et retourne en tous sens; puis, lorsqu'elles sont sur le point de brûler, on les jette dans 
un panier, et tandis qu'elles sont encore chaudes on en transvase de quinze à ringt livres environ dans un sac préparé ì cet effet, lequel sac est de toile épaisse et a environ quatre pieds de long sur deux de circonférence. On presse le thé dans ce sac arec beaucoup de force et en se servant des pieds et des lnas. De la main gauche l'ouvrier en tient louverture fermée au raz dles feuilles, et de la droite il bat le the a vigoureux comps de poings en le tournant en tous sens, et le resserrant à chaque fois. Lorsque l'ouvrier juge le thé réduit par cette pression au plus petit rolume possible, il noue élroitement ce sac qui n'est plus alors rempli qu'au tiers, et en retourue l'excédant sur le fond, ce rui dounle la toile; puis il en tord les deux bouts à direrses reprises. Le sac étant ainsi hermétiquement fermé, il l'élend à terre, saute dessus à pieds joints en se tenant suspendu à une trarerse de bois. Dans cette posture, il pèse de tout le poids de son corps, sur ce sac, le foulant tantôt d'un pied tantôt de l'autre, le retournant dans tous les sens, et l'ourrant de temps à autre pour le resserrer de plus en plus. Quand cette balle de feuilles est devenue aussi dure qu'un caillou, il en ferme l'orifice arec le plus grand soin et la met de côté pour ce jour-là. Le lendemain matiu, il ourre le sac, en extrait les feuilles avec précaution, pour ne pas les déformer. Quelque vigonreusement tassées qu'elles aient élé, elles n'adhèrent point les unes aux autres, attendu leur première dessiccation. On les met dans des corbeilles, puis on les passe an feu jusqu'à ce qu'elles soient crispées, recoquillées à peu près comme pour les thés noirs. Eıfin, ce thé est ensuite emballé dans des caisses ou dans des paniers de bambou garnis de feuilles du même arbre, et on le conserve ainsi pendant 


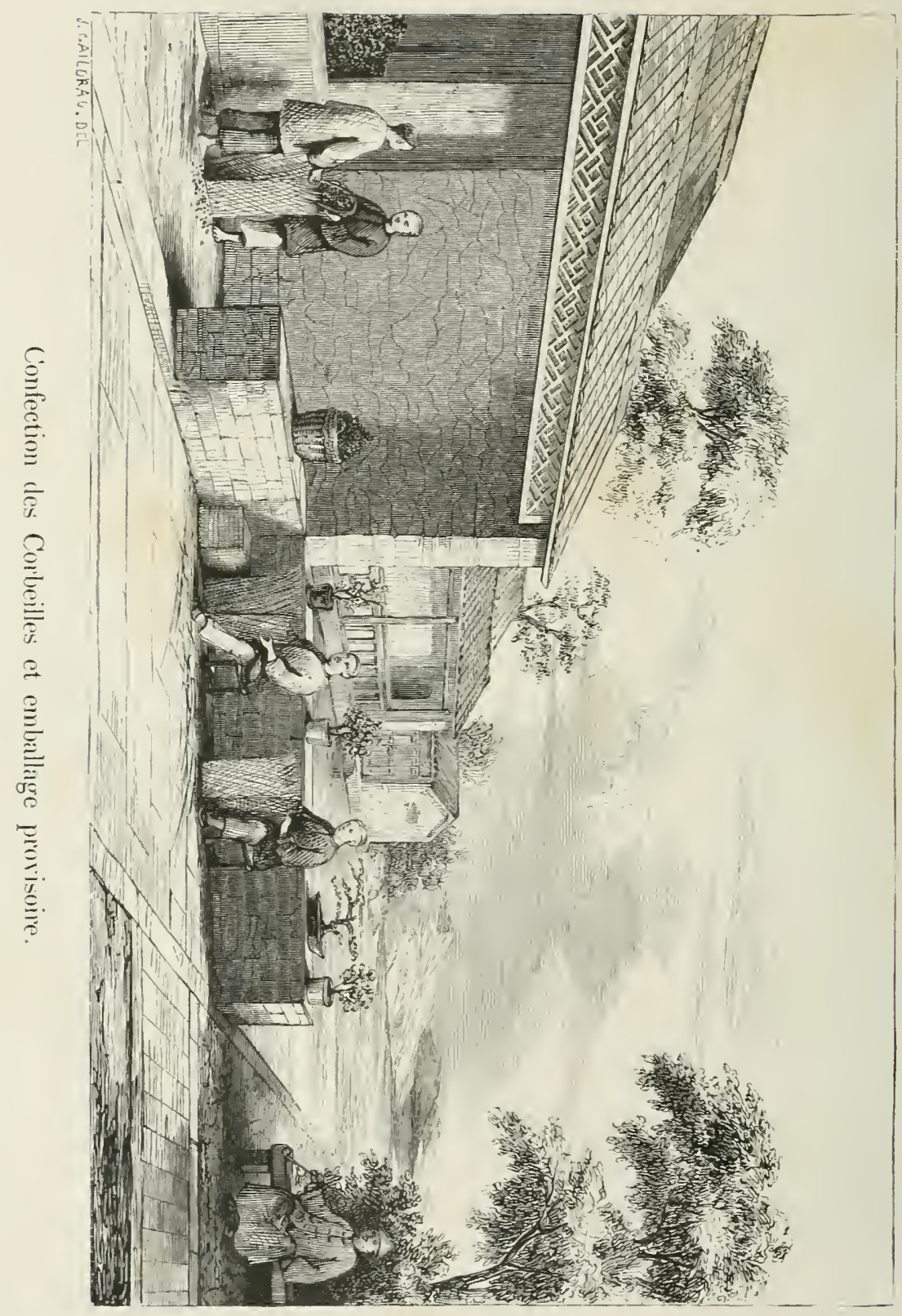




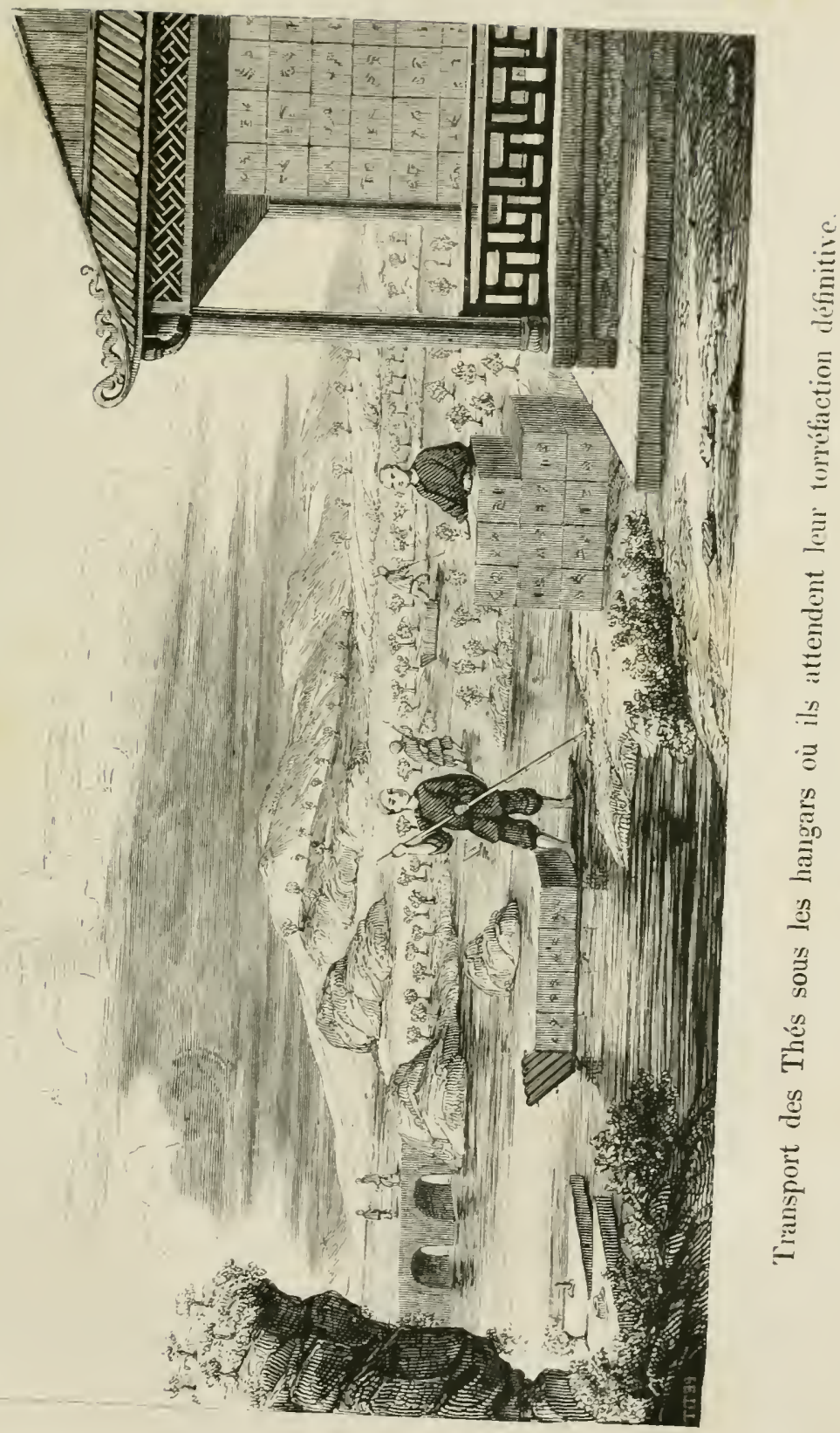



deux, trois et même six mois arant de lui faire subir la dernière préparation.

Pour y procéder, on ourre les caisses ou les paniers aux intervalles de temps que nous venons de désigner; on étend le thé dans de grandes corbeilles qu'on expose à l'air jusqu'à ce qu'il se soit assez amolli pour' être enroulé. Alors on fait rougir sur un feu de bois mne bassine de fonte pareille à celle dont on se sert pour le thé noir; on y jette enriron sept livres de feuilles, qu'on roule alternativement arec les deux mains pour ne pas rendre cette occupation trop fatigante; et comme la bassine est inclinée en avant (ainsi que nous l'avons décrit), les feuilles retombent continuellement rers le torréfacteur, qui les repousse toujours de bas en haut, en appuyant dessus arec la paume de la main et tenant les doigts en l'air, de crainte qu'ils ne viennent à toucher la fonte rougie.

Au bout d'une heure de ce travail donloureux, on jette les feuilles dans un gros crible sous lequel se trouvent perpendiculairement placés deux autres cribles, l'un moyen et l'autre fin. Par ce triple tamisage, le thé se trouve naturellement divisé en trois sortes : grosse, moyenne et fine. Le triage n'est encore qu'à son début. Les feuilles sont introduites successivement, en commencant par les plus larges, dans l'entonnoir d'une machine à vanuer dont la construction est aussi simple qu'ingénieuse. Cet entonnoir correspond à une auge ayant trois divisions formant trois cases fixes au fond de chacune desquelles est une trappe par où le thé tombe dans un panier placé audessous. A l'une des deux extrémités de l'auge et près de l'entonnoir se trouve placé un grand éventail qui se met en mourement au moyen d'une roue que l'ourrier tourne 
de la main droite tandis que de la gauche il fait fonctionner une coulisse pratiquée au fond de l'entonnoir et qui sert à regler la quantité de thé (jui doit tomber à la fois. L'air qu'agite violemment l'érentail chasse les parcelles et la poussière du thé à l'autre extrénité, oì elles sont arrêtées par me planche circulaire mobile que l'on avance on recule à volonté. Là elles tombent par une ourerture dans un panier préparé pour les receroir. Ces pellicules sont le résidu de la cuisson et forment les thés verts les plus communs. La qualité suirante, qui est la meillenre, parce qu'elle se compose des fenilles les plus tendres de l'arbuste, est soufflée presque au bout de l'auge et tombe dans un panier. Ce thé fort estimé s'appelle Young-Hyson (hyson junior). La (qualité qui suit est un peu plus lourde et ne s'envole pas aussi loin, elle tombe dans la même case et daus le même panier, qui sont l'un et l'autre partagés en deux par un compartiment. Ce thé est le hyson. Le suivant est plus pesant encore et tombe dans la rleuxième case, non loin de l'érentail; on l'appelle poudre ì canon, parce qu'il est roulé en petits globules. Enfin le thé le plus lourd tombe le plus près de l'éventail et presque sous l'orifice de l'entommoir dans la première case. C'est la grosse poudre ì canon ou thé impérial ${ }^{\text {; }}$; ses grains sont trois fois plus gros que cenx de la sorte précédente : ils se composent de plusieurs jeunes fruilles agglomérées ensemble et formant des petites boules compactes. Cette sorte est mise à part dans une caisse; on la coupe aree un instrument tranchant quand on veut la

${ }^{1}$ Les Chinois appellent cette sorte Tychen; les petites poudres i canon. Cheochen; l'hyson, chingcha; l'hyson-juniur. hyson-uchui; les vieilles feuilles, hyson-skin; les petits bouts, poocha; et la lelle poussière, chamoot. 


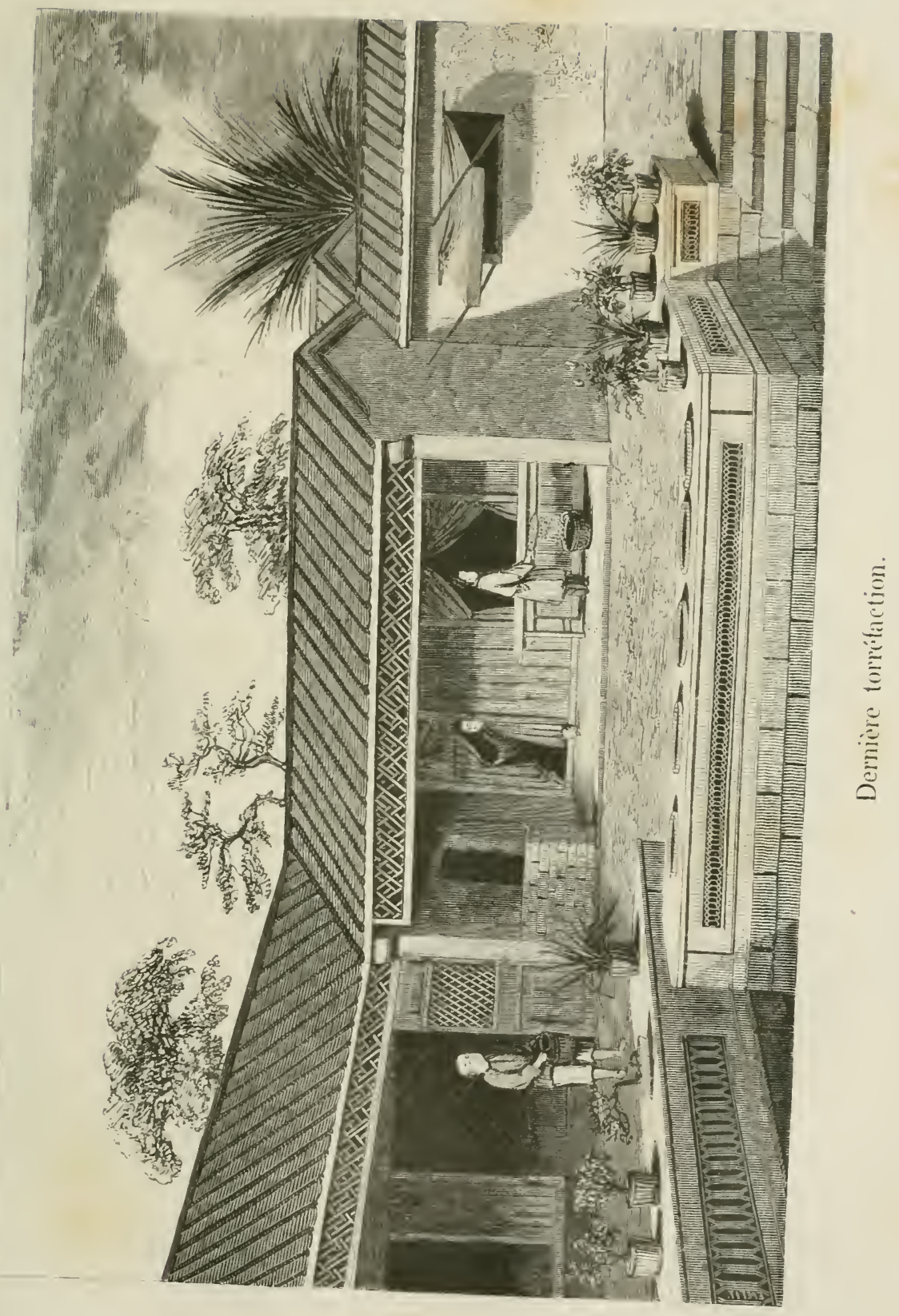



mélange ravec la poudre it canon proprement dite, ì laquelle elle ressemble et de goutt et de forme.

D'après cette description, que nons nous sommes efforcé de rendre aussi claire et aussi précise que nous l'a permis le texte anglais de M. Bruce, on peut se faire une idée de la patiente et laborieuse sollicitude qu'exige la préparation des diverses sortes de thés rerts. Cependant l'épreuve de la machine ì vanner pour les classer n'est point la dernière qu'elles aient ì subir : des femmes et des enfunts s'emparent des paniers, en déposent le contenu sur une table, puis s'occupent arec attention d'enlever les mauvaises feuilles, les téguments et débris de tiges et de branches qui peurent s'être mêlés au thé. Ce travail est fort long et fort emnuyeux, attendu que la manière plus ou moins consciencieuse dont il est fait influe puissamment sur la valeur et le prix des diverses sortes. Pour abréger quelque peu cette aride besogne, on passe encore les thés, depuis la poudre à canon jusqu’à la poussière, au sortir de l'entonnoir, dans des tamis pourvus de trous de diverses grandeur's. Nous l'avons déjil dit, quoique de bambou, ces tamis, sont aussi solides, aussi symétriquement percés que s'ils étaient de fil d'arehal.

Quand ces thés sont ainsi bien épluchés, bien épurés, on les remet encore dans des bassines rougies au feu; on les roule et on les trie de nouveau; enfin, on leur administre un troisième et semblable traitement. Nais cette dernière fois on ajoute, it la cuisson, pour sept livres de feuilles une demi-cuillerée à café d'une poudre dont roici la composition : $3 \Psi^{4}$ de sulfate de chaux et $1 \Psi^{4}$ d'indigo pulvérisé et passé à travers une mousseline très-fine. On roule le thé avec cette mixtion pendant une heure au 
linoins. Ce procédé a pour effet de domner an thé wne. nuance uniforme, d'ompeccher qu'il ne s'y trouve des grains d'un vert plus pâle ou plus foncé les uns que les autres; du reste, cette poudre n'ôte ni n'ajoute rien ¿ l'arôme du thé : l'indigo donne la couleur, et le sulfate de chaux la fixe. Les Chinois appellent Younglin la première de ces substances, et la seconde $A c c o^{\mathrm{I}}$.

A l'issue de leur dernière cuisson, les thés verts sont emballés tout chauds dans les caisses où on les tasse à l'aide des pieds et des mains ${ }^{2}$.

Les deux descriptions que nous venons de donner et dont nous garantissons la scrupuleuse exactitude, attendu (qu'ellesémanent de sources officielles, et jusqu'ici inconnues en France, démontrent victorieusement, s'il en était encore besoin, que les thés noirs et lis lliés verts proviennent des feuilles de la même espèce d'arbuste; mais que leur mode

' C'est sans donte de eette eomposition que parle Lettsom dans ce passage de con onvrage : “ Un de mes a mis m’informe qu“il possede une collection com"plète de toutes les opérations manuelles qu'exige la préparation du thé. "Sur l'un d'eux on roit plusieurs personnes occupées à Irier les feuilles, ut à "les faire sécher au soleil. Elle's ont auprès d'elles plusicurs paniers remplis " d"nile substance visqueuse verdàtre. On ne connaît ni la natmre uj la destiua" tion de celte substance. Cependant il est avéré à mes yeux qu'elle coneourt " vtilement a cette manipulation."

2 Voiei la méthode usitie au Brésil pour fahriquer les thés verıs: On verse. les lenilles dians une bassine très-évasée, en fer poli, ayant environ 1 mèt. de diamètre ot 30 cent. de profondeur: elle est placée sur un fourneau allumé avec dı bois. On les retire quand elles out aequis un eertain degré de sonpiesse. $\Lambda$ la siconde operation, qui a pour lut l'enroulement, on malaxe les finilles sur des nattes de hambou; ce travail dure une demi-heure environ. bans une troisième opération, on replace les fevilles dans les mêmes bassines ot on les agite sins cesse avee les mains, en les fitsant sauter et voltiger. La densiccation achevée, on retire le thé des bassines et on le erible dans des tanis de bambon. Diajrès cette deseription oflicielle, on peut concevoir que les thés du Brésil soient inférieurs à ceux de Chine, leur préparation étant souverainement distincte. 


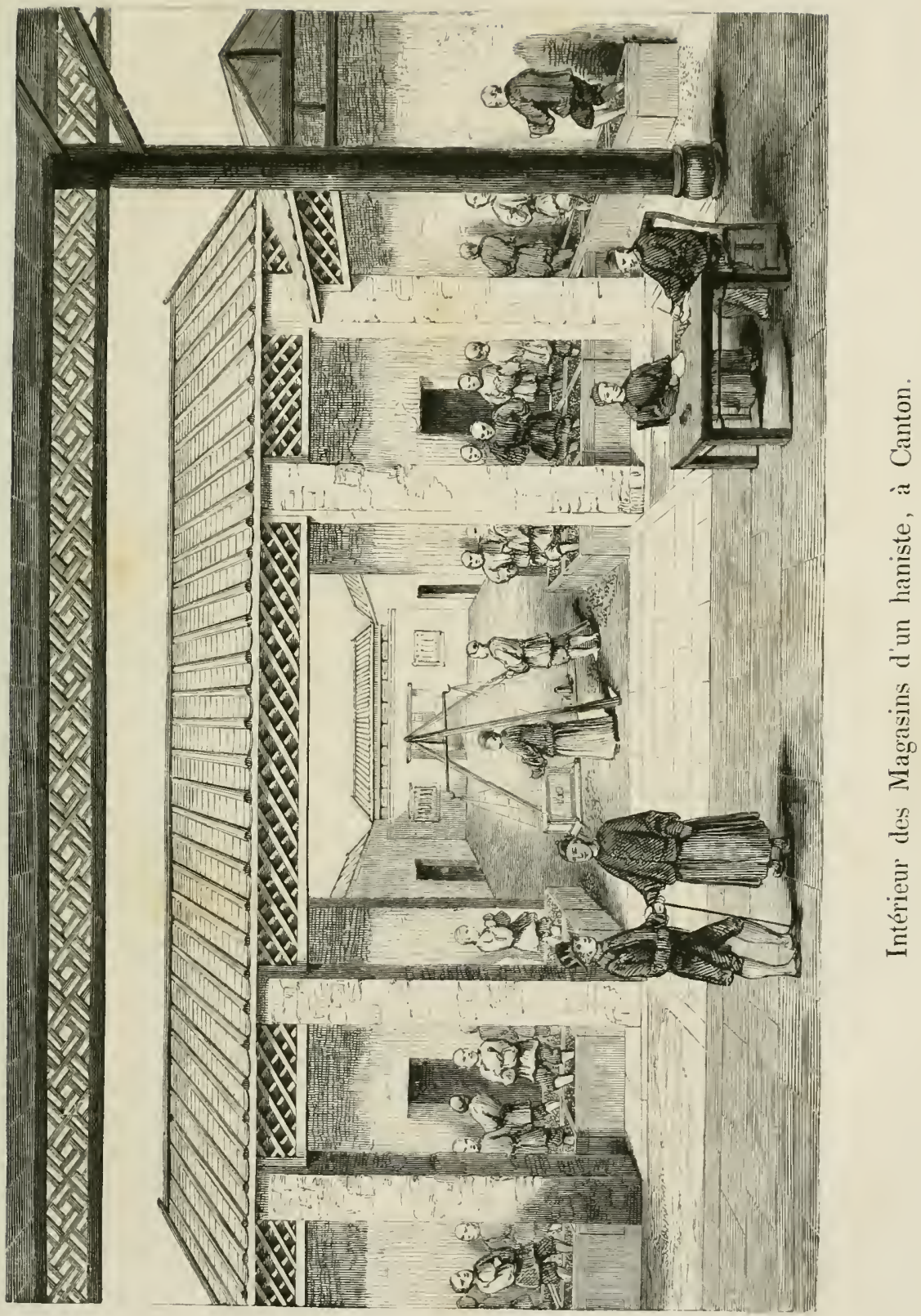



de préparation, presque entièrement distinct, établit leur différence de conleur, de goùt et de propriété. Les premiers ne sont bons à être employés qu'au bout d'une année et même plus; ear, à l'instar de nos vins, leur arôme se perfectionne et se veloute en vieillissant. Avant de les livrer à l'exportation, on les fait sécher encore sur un feu doux, pour leur oter tout prineipe d'humidité.

Les thés vorts étant moins torréfiés que les thés noirs, conservent davantage leur couleur et leur force primitive, nıais aussi ils résistent bien moins à l'action du temps; cependant, il ne faut pas s'en servir avant une année, afin qu'ils aient eu le temps de se dépouiller d'une partie de leur odeur herbacée, ainsi que de leurs principes narcotiques et styptiques. Tous les thés fins destinés à l'exportation sont mis dans des caisses vernissées, doublées de lames d'étain, de plomb, de feuilles sèches ou de papier peint, afin d'en clore tous les interstices et de les rendre imperméables à l'air extérieur; ces caisses sont en outre revêtues de nattes de bambon très-serrées, ou recouvertes en peau; mais ce dernier emballage ne se pratique que pour lès thés fins envoyés en Russie, et qu'on désigne sous le nom de thés de cararane.

Les sortes communes sont simplement déposées daus des paniers fermés, d'où on les retire pour les emballer dans des caisses au fur et à mesure de leur livraison.

Les nombreuses et délicates manipulations qu'exige le thé depuis sa culture jusqu'à sa conversion en denrée alimentaire, expliquent les difficultés que l'on a éprouvées pendant si longtemps, soit d'alsord pour l'acclimater, soit ensuite pour en extraire un article de consommation de 
première utilité. Mais l'activité et la persévérance infatigables qui caractérisent le gourernement anglais n'ont point reculé devant ces obstacles. Le magnifique établissement du Haut-Assam est un nouveau fleuron à ajouter à sa couronne industrielle. Créé depuis dix années seulenent, il a coûté des sommes immenses à la compagnie des Indes; mais, grâce à la convenance du terroir et à une direction aussi habile qu'intelligente, il est aujourd'hui en voie de dédommager largement ses fondateurs de leurs arances de fonds. Charque année, suivant les calculs de M. Bruce, surintendant de ces plantations, le chiffre des produits double, et si cette progression géométrique continue, il n'y a pas lieu de douter que d'ici à quelques années la colonie d'Assam ne soit en état de fournir à la métropole le tiers de sa consommation actuellè. La qualité de ses produits semble suivre la même loi progressive; ils ne le cèdent que peu à ceux de la Chine, et on se rendra facilement compte de ces rapides et importants résultats, si l'on considère que la haute administration de cet établissement, auquel sont attachés un grand nombre de Chinois, est parfaitement renseignée sur tous les procédés usités dans le céleste empire pour la culture et la préparation du thé. Il est vraisemblable que le succès toujours croissant de cette entreprise, aussi hardieque grandiose, ne restera pas le seul que l'on puisse citer. 


\section{CHAPITRE VII.}

Composition chimique du Thé.

\section{PAR M. E. PÉLIGOT,}

Professeur au Conservatoire des arts et mètiers.

Le thé, cette feuille privilégiée qui unit par un lien commercial toutes les contrées du globe, qui établit une similitude de goût entre les populations les plus éloignées par l'espace et par les mœur's, n'a fixé qu'à de rares intervalles l'attention des chimistes qui, depuis cinquante ans, dirigent les progrès de leur science vers la connaissance des produits régétaux que l'homme sait appliquer à ses besoins. L'oubli dans leqquel cette plante est restée jusqu’à ce jour est d'autant plus difficile à justifier, qu'il existe dans l'aspect, dans l'arôme, dans les propriétés nutritives ou médicales des diverses sortes de thé, des différences tellement grandes que chacun a pu les reconniaitre et les constater.

Quelles sont les causes de ces différences qui influent tant sur le prix et sur les usages de cette feuille ? C'est à la science ì répondre à cette question; et la science, interrogée, reste muette.

Plusieurs chimistes anglais, parmi lesquels il faut citer le célèbre sir II. Dary, Frank, Brande, ont néanmoins cherché à établir la nature et la proportion des principes 
constituants d'une substance si importante pour les relatious extérieures et pour l'alimentation de leur pays: Mais les résultats auxýuels ils sont arrivés sont trop contradictoires pour qu'il soit possible d'y ajouter foi; M. Steinhouse l ui-mème, qui a publié tout récemment une analyse partielle des thés les plus employés en Angleterre, est arrivé à des données numériques qui laissent encore heaucoup à désirer.

Je n'étais pas encore convaincu de l'insuffisance de ces divers travaux lorsque jentrepris, sur les vives instances de M. Houssaye, de résumer dans son livre les faits acyuis à la scienee sur la nature chimique du thé; anssi, en commencant mon travail d'historien et de critique, je lus tout d'abord arrêté par l'impossibilité de lui donner le moindre intérêt pratique. Je voulus alors établir tout au moins par quelques essais la nature et la quantité des éléments solides que contient l'infusion de thé préparée comme hoisson, dans les circonstances les plus habituelles. Mais, dès les premières expériences que je tentai pour connaître un peu la composition de cette feuille, j’arrivai à des résultats nouveaux, inattendus, qui me portèrentà la soumettre à un examen plus approfondi. Je fus ainsi conduit ¿ entreprendre surce sujet un travail assez étendu, et je m'y décidai d'autant plus volontier's qu'une heureuse occasion s'offrait à moi d'opérer sur des échautillons de thés albondants, nombreux, authentiques, que M. Ioussaye, qui avait provoqué ces recherches et qui pressentait leur importance, mit à ma disposition avec une libéralité et une bonne grîce dont je lui sais infiniment de gré. Je domnerai donc daus ce chapitre, outre le résumé des divers travaux qui ont été publiés sur le thé, les résultats pratiques de mes propres recherches, bien qu'elles ne soient pas encoro 
terminces, réservant les détails et les déductions jurement scientifiques pour le mémoire que je lirai prochainement sur ce sujet à l'Académie des Sciences.

De même que tous les végétaux, le thé offre une composition complexe, et contient un nombre assez considérable de principes mal définis, dont la séparation présente de sérieuses difficultés : de là le désaccord qu'on remar(que daus les analyses qui en ont été faites. D'après Frank, qui le premier a publié une analyse quantitative du thé, cette substance renferme :

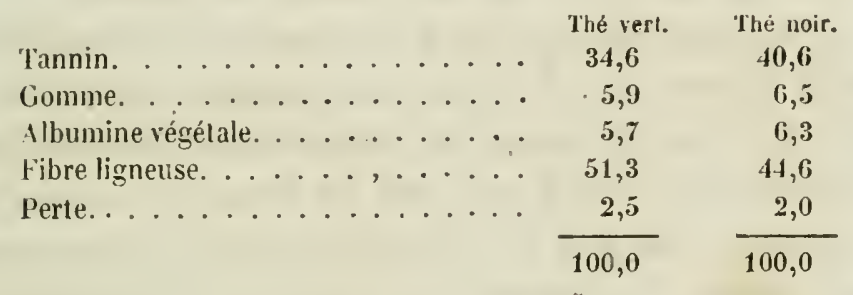

Ainsi que le remarque M. Berzélius, la proportion de tannin indiquée par Frank est heaucoup trop grande, car ce chimiste a pris pour tannin toutes les substances dissoutes par l'alcool qu'il a fait agir sur l'extrait aqueux; Davy, au contraire, a trouvé dans le thé sonchong 32,5 pour 100 d'extrait, dont dix parties seulement étaient absorbées par les membranes: d'où il conclut que lẹ $2 \mathbf{2}, 5$ parlies restantes ne consistaient pas en tannin ; de même, il nia trouvé que 8,5pour 100 de tannin dans le thé vert.

Outre les matières qui viennent d'ètre signalées, le thé coutient d'autres produits dignes d'une mention tonte spéciale, qui sont : $1^{\circ}$ une huile essentielle qui est la cause de son aròme, et qui exerce une grande influence sur sa valeur vénale : cette huile, qu'on peut isoler en distillant 
le thé aree de l'eau, est jaunâtre, épaisse, douée de l'odeur du thé, mais plus forte et étourdissante. Direrses sortes de thés chinois contiennent, sans aucun doute, outre l'huile essentielle qui préexiste dans la feuille naturelle, d'autres huiles essentielles empruntées à des régétaux odorants, tels que l'olea fragrans, la fleur d'oranger, etc., que les Chinois ajoutent au thé dans des circonstances qui ne sont pas comuues, ainsi que cela a été dit dans le chapitre ru de ce livre. Ces principes odorants sont, dans tous les cas, en trop petite quantité pour que le chimiste puisse ein fixer, soit la nature, soit la proportion exacte.

$2^{\circ}$ Ln principe azoté qui a été signalé il y a une douzaine d'années par M. Oudry. Ce principe, auquel on a donné le nom de théine, est identique arec la substance découverte en 1820 dans le café par Runge, la cafćine, et aussi arec celle que Th. Martius a extraite du guarana, médicament fort recherché des Brésiliens. Il est remarquable de rencontrer la théine dans les deux substances alimentaires qu'on emploie dans les conditions les plus semblables, dans le thé et le café, qu'on peut considérer comme à peu prés équivalents par leurs usages et par leur action sur notre économie.

$3^{\circ}$ Ln autre principe azoté, qui n'arait pas été signalé jusqu'à ce jour et qui se troure en abondance dans la feuille de thé, après qu'on en a extrait, au moyen de l'eau bouillante, tous les principes solubles qu'elle renferme. Au point de rue pratique, l'existence de cette matière offre peu d'intérêt; elle ell a beaucoup, au contraire, au point de rue seientifique, car il résulterait de mes expériences, encore incomplètes et inédites, que ce produit est identique aree le caséum qui forme la matière azotée du lait 
des animaux. Si ce fait est exact, il peut devenir d'une haute importance pour la question, si débattue aujourd'hui, de la préexistence dans les végétaux des matières azotées qu'on trouve chez les aninnux, ces matières devant concourir, par l'assimilation directe, ì leur nutrition.

Quoi qu'il en soil à cet égard, voici un tableau représentant la composition des deux sortes de thés que j'emprunte au 'Traité de chimie organique de M. Liebig. Ce célèbre chimiste ne cite pas l'auteur de ces analyses, qui est, je crois, un chimiste hollandais, M. Mulder; bien qu'elles soient inexactes sur plusieurs points, elles peuvent être considérées comme l'expression la plus fidèle de nos connaissances actuelles sur ce sujet.

100 parties de thé de Chine renferment :

\begin{tabular}{|c|c|c|}
\hline Huile essentielle. . . . . . . . & $\begin{array}{c}\text { Thé vert. } \\
0,79\end{array}$ & $\begin{array}{c}\text { Thé noir. } \\
0,60\end{array}$ \\
\hline Chlorophylle. . . . . . . . & 2,22 & 1,84 \\
\hline Cire. . . . . . . . . & 0,28 & $"$ \\
\hline Résine. . . . . . . . . & 2,22 & 3,64 \\
\hline 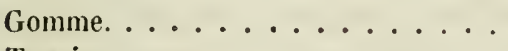 & 8,56 & 7,28 \\
\hline 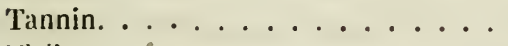 & 17,80 & 12,88 \\
\hline Théine. . . . . . . . . & 0,43 & 0,46 \\
\hline Matière extractivé......... & 22,80 & 19,88 \\
\hline Id. foncée........... & $"$ & 1,48 \\
\hline \multicolumn{3}{|l|}{ Matière colorante du thé séparée par } \\
\hline l'acide hydrochlorique....... & 23,60 & 19,12 \\
\hline 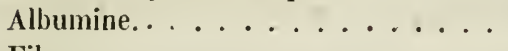 & 3,00 & 2,80 \\
\hline 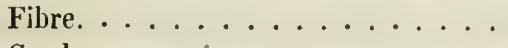 & 17,08 & 28,32 \\
\hline Cendres. . . . . . . . . . & 5,56 & 5,24 \\
\hline
\end{tabular}

J'aurai occasion, dans le courant de ce chapitre, de revenir sur quelques-uns des résultats énoncés dans ce tableau.

Au point de vue pratique, le thé contient deux parties essentiellement distinctes : l'une est soluble dansl'eau 
DU 'THÉ.

bouillante, l'antre ne l'est pas. Lal premiere contient l'huile essentielle, le tamnin, la gomme, la théme, la natière extractive, la plus grande partie des sels qui constituent les cendres; la seconde est fornice des autres substances énumérées dans les analyses que je viens de citer. J'ai entrepris la détermination de ces denx parties sur vingtsept sortes de thés, qui sont, d'après M. Houssaye, toutes celles yu'on troure habituellement dans le commerce en France et en Angleterre. Ces analyses ont été faites en épuisant complétement, au moyen de l'eau distillée bouillante, 10 grammes de chaque sorte. La feuille épuisée était soumise à une lente dessiccation, d'abord à la température ordinaire, ensuite à l'étuve à la température de 110 regrés centigrades : la différence entre le poids de la feuille ordinaire et cclui de la feuille épuisée et séchée a donné la quantité de matières solubles que contenait la première.

Il fallait d'ailleurs, pour arriver à des résultats précis, opérersur la feuille prise au mêne état de dessiccation avant et après son traitement par l'eau bonillante. Or, la feuillé, telle qu'elle arrive de Chine, n'esi jamais complétęment sćche, soit que la torréfaction ne lui ait enlevé qu'une partie de l'eau qu'elle contient lorsqu'elle vient d'être récoltée, soit qu'elle ait emprunté à l'atmosphère, pendant le royage, une certaine quantité d'humidité, soit enfin que ces deux causes concourent, ainsi que cela est trìs-vraisemblable, à son état de non siccité complìie. J'ai đlone déterminé la quantité d'eau que perd chacun de ces thés, et j'en ai tenu compte dans l'estimation de leurs produits solubles et unsolubles. Je crois inutile de rapporter ici tous ces nombres; je dirai senlement quo les thés noirs contiennent en moyenne 10, et les thés rerts 8 pour cent d'eau. Parmi 
ces derniers, la poudre a canon perd 6,6 d'eau pour eent a $120^{\circ}$; le hyson-skin 8,6. Parmi les thés noirs, le sonchong fin perd 11,7; le pekoë orange 8,6, et le assam 8,2. Ce sont les nombres les plus extrèmes que j’aie obtenus. Ces différences paraissent tenir surtout a l'état plus ou moins compact des diverses sortes de the's.

Je donnerai maintenant la proportion des matières solubles contenues dans les thés. J'ai trouvé que 100 parties des thés dont les noms suivent, contiennent:

THÉS NOIRS.

Parties solubles dans l'eau bouillante.

Les thés étant pris

Souchong fin. Id.

fin. .

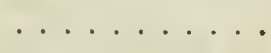

à l'étal sec à l'état ordinaire.

Souchong ordinaire.

45,7

46,0

40,3

Souchong or
Id.

41,8

40,7

40,3

37,3

Pekoë.

34,6

36,0

Id.

38,1

31,3

Pekoë orange.

48,7

34,5

Id.

46,8

44,5

Pouchong.

42,8

42,8

Congo.

40,9

39,0

Congo bon.

45,8

36,8

Id.

45,0

41,5

Campoy

45,0

40,7

Bohea.

44,4

37,1

Caper.

39,3

39,8

Assam.

45,4

35,8

Thé Java.

35,2

41,7

Pekoe ordinaire

41,5

32,7

38,0

THÉS VERTS.

Poudre à canon. ........ 51,9

48,5

$I d$.

50,2

46,9

Impérial

43,1

39,6

Id.

47,9

44,0

Hyson.

47,7

43,8 


\begin{tabular}{|c|c|c|}
\hline \multirow[b]{2}{*}{ Hrson fin } & \multicolumn{2}{|c|}{$\begin{array}{l}\text { Parties solubles dans l'eau bouillante. } \\
\text { Les thès étant pris }\end{array}$} \\
\hline & $\begin{array}{l}\text { A t'état sec. } \\
\qquad 46,9\end{array}$ & $\begin{array}{l}\text { A l'état ordinaire: } \\
\qquad 43,1\end{array}$ \\
\hline Schoulang. . . . . . . & 45,9 & 42,3 \\
\hline Hyson junior. . . . . . . . & 51,5 & 47,4 \\
\hline Hyson skin. . . . . . . . & 43,5 & 39,8 \\
\hline Tonkay............. & 42,2 & 38,4 \\
\hline
\end{tabular}

Brande a déterminé la proportion relative des matières solubles dans l'eau et dans l'alcool, contenues dans dix sortes de thés. Les nombres qu'il a obtenus pour la solubilité dans l'eau varient entre $\mathbf{3 1}$ pour le tonkay et $\mathbf{4 1}$ pour la poudre à canon. M. Liebig donne d'autres nombres empruntés à un auteur, qu'il ne cite pas, d'après lequel le hohea fournit $\mathbf{2 9 , 5}$ de matic̀res solubles; le congo du Cap, 29,0; le tonkay, 36,5; le hyson, 44,4.

Il n'est pas surprenant que les mêmes espèces de thés contiennent des quantités variables de produits solubles et insolubles; il est même impossible qu'il en soit autrement, ces quantités étant dépendantes de la préparation qu'on fait subir à la feuille, dans des cireonstances qui ne peuvent pas être deux fois identiquement les mêmes; néanmoıns , en comparant les nombres donnés par Brande et par M. Liebig avec ceux que j'ai obtenus, on voit que j'ai séparé du thé une quantité notablement plus considérable de produits solubles dansl'eau; aussi ilme parait évident que les premiers nombres ont été fournis par la feuille prise dans son état commercial: en opérant ainsi on a bien les prineipes solubles dans l'eau contenus dans la feuille de thé, mais on n'a point les principes solides et solubles dont la détermination surtout offre de l'intérêt. J.es nombres obtenus par Brande et ceux que cite M. Liebig s'accordent d'ail- 
leurs assez bien arec ceux que j’ai obtenus au moyen du thé pris dans son état ordinaire.

En incinérant un certain poids de thé, j’ai obtenu les quantités suivantes de cendies :

Souchong (thé noir). . . . 5,5 cendres pour 100 de thé.

Poudre à canon (thé vert). . . 5,5 -

Autre. . . . . . . 6,0

Pekoẹ (thé noir).

La plus grande partie des sels minéraux contenus dans le thé, qui consistent, comme dans la plupart des végétaux, en sulfates, phosphates et chlorures alcalins, sont solubles dans l'eau, et se retrouvent dans son infusion.

Les cendres sont un peu rougeâtres, et contiennent par conséquent une petite quantité d'oxyde de fer qui provient, sans doute, en partie, des vases de fer employés a la torréfaction de la feuille : il parait résulter, en outre, des renseignements qu'on possède sur la culture du thé en Chine, et de ceux (qu'a fournis M. Guillemin sur les plantations du Brésil, que cet arbuste se plaît surtout dans lesterrains argilo-ferrugineux. L'existence de l'ammoniaque dans les oxydes de fei naturels n'exercerait-elle pas quelque influence sur la forte portion d'azote que contient le thé?

Quelques auteurs ont prétendu que le thé rert devait sa couleur à la présence d'un sel de cuivre. Cette assertion est tout à fait inexacte; les cendres du thé vert ne contiennent pas la moindre quantité de ce métal.

L'infusion du thé offre les caractères suivants : elle est d'une couleur qui varie entre le jaune clair et le brun foncé, selon qu'elle á été faite avec du thé vert ou avec du thé noir. Lorsqu'elle est concentrée et chaude, elle est limpide; mais, en refroidissant, elle se trouble, et elle tient 
alor's en suspension une pourlre grise très-divisée, qui la rend comne laiteuse, et qui consiste en une combinaison de tannin et de théine soluble dans l'eau chaude et non soluble dans l'eau fròile. Ce composé n'a pas de saveur quoiqu'il soit formé de deux matières très-sapides, l'une astringente, le tannin, l'autre amère, la théine.

Lorsyu'on a séparé, au moyen du filtre, ce composí insoluble, ou lorsqu'on opère sur des liqueurs chaudes, l'infusion limpide donne, arec le sous-acétate de plomb, un précipité jaune-brun abondant, qui renferme plusieurs des produits solides du thé en combinaison avec l'oxyde de plomb.

J'ai trouré, en déterminant le poids et la composition de ce mélange, les proportions suivantes de matières organiques solubles précipitables par le sous-acétate de plomb:

Dans 100 parties de thé souchong sec, épuisées par.

l'eau bouillante............... . .

Dans 100 parties de thé hyson sec, traitées de la même manière. . . . . . . . . . . 26,8

Ces quantités sont fornées par un mélange de trois substances organiques distinctes an moins, qui sont: $1^{\circ}$ toute la matière colorante: la liqueur du sein de laquelle le précipité plombique s'est déposé est entièrement incolore; $2^{\circ}$ tout le tannin : on sait que ce corps forme arec l'oxyde de plomb une combinaison insoluble $; 3^{\circ}$ un acide particulier qui, lorsqu'il est isolé, donne, a rec le sous-acétate de plomb, un précipité jaune qui contient environ 70 pour cent d'oxide de plomb. On peut obtenir ce précipité directement de l'infusion du thé, en' la traitaut d'abord par la chaux éteinte, qui sépare le tannin et la matière colorante; la proportion de ces deux corps 
s'ílève, daus le thé vort, à 10 pour cent environ, d'après mes analyses. Lorsyu'on a sépitré au moyeu du filtre, ce précipité qui est d'un brun foncé, on sature l'exè̀s de chaux que la liquemreontien par l'acide acétique; elle fournit alors, au mojen du sous-acétate de plomb, ce composé jaune, qui renferme un acide dont la nature ne m'est pas encore suffisamment connue pour que je puisse le definir.

On voit d'ailleurs yue l'infusion du thé vert, qui contient évidemment moins de matière colorante que le thé noil', fournit cependant plus de substinces précipitables par le sous-acétate de plomb que le thé noir. On a déji vu que, pris sous le même poids, il renferme une plus grande quantité de matières solubles, ce qui tient à ce que, tout en prosenant du même arluuste, il est préjaré avec une feuille plus jeune ot par conséquent moins ligneuse; de plus;, il est orlinairement aromatisé au moyen d'une huile essenticlle étrangère qu'on n'ajoute pas au thé noir; enfin, il est plus compact, plus dense et en mêne temps plus sec que le thé noir, et comme, pour préparer l'infusion de thé, on prend ordinairement la feuille au volume au lieu de la prendre au poids, on est disposé à faire usage, jour la même quantité d'eau, d'un poids de thé vert plas considérable que de thé noir. Cetle réunion de cireonstances rend suffisamment compte, je pense, de l'action différente qu'exercent sur notre économie ces deux sortes de thés: les principes que contient leur infusion sont les mêmes; mais ils s'y trouvent dans des proportions un peu différentes, et comme ces proportions sont moins fortes dans le thé noir que dans le thé vert, celui-ci est plus actif.

Il me reste à parler de la substance la plus importante 
que renfurme le thé, de la théine. C'est à la présence de cette remarquable substance dans l'infusion de thé qu'il faut attribuer, à mon sens du moins, la plus grande part des vertus médicales, peut-être même nutritives, de cette feuille.

Divers procédés ont été proposés pour son extraction. Ainsi, on peut épuiser le thé par l'eau bonillante et précipiter par le sous-acétate de plomb les trois matières que j'ai mentiomnées; on ajoute à la liqueur filtrée de l'acide sulfurique ou de l'acide sulfhydrique pour séparer l'excès de plomb, puis on concentre par la chaleur cette liqueur qui laisse déposer, en refroidissant, des cristaux de théine.

On peut encore, comme a fait M. Mulder, traiter l'extrait aqueux du thé par la magnésie calcinée, évaporer le liquide à siccité et reprendre le résidu par l'éther; celuici dissout la théine et l'abandonne en s'éraporant.

Quel que soit le procédé employé pour son extraction, la théine offre les caractères suivants : elle cristallise en aiguilles fines flexibles et brillantes qui ressemblent à de la belle soie blanche; sa saveur est extrêmement amère; elle est peu soluble dans l'eau froide, car il faut 93 parties d'eau à la température ordinaire pour dissoudre une partie de théine : elle est beaucoup plus soluble dans l'eau cbaude, l'alcool la dissout moins bien que l'eau, et l'éther sulfurique moins bien que l'alcool; de telle sorte que 300 parties d'éther n'en dissolvent qu'une partie.

La théine est azotée, de même que les substances les plus actives du règne organiqué, les alcalis végétaux.

Elle contient 29 pour 100 d'azote, ce qui est une quantité tellement considérable comparée à celle que renferment 
les autres matières organiques azotées, qu'on n'en peut citer qu'un très-petit nombre qui en contiennent une aussi forte proportion. Elle possède à un faible degré quelquesuns des caractères des alcalis végétaux, tels que la quinine, la morpline, etc.

Ainsi elle se combine avec les acides, quoique difficilement, pour former des sels cristallisables; de même que la plupart des alcalis végétaux, elle est précipitée par la dissolution de támin, lors même qu'elle n'existe dans un liquide qu'en très-petite quantité; aucun autre réactif ne la précipite de ses dissolutions.

"Les expériences que l'on a faites sur l'action de la caféine, (théine) dans l'économie animale, dit M. Liebig dans son Truité de chimie organique, tendent à prouver que cette substance n'appartient pas aux substances narcotiques ou vénéneuses; toutefois on ne peut s'empêcher d'admettre qu'introduite dans le corps, elle accélère ou favorise les fonctions de certains organes.

"La quantité qu'en renferme le thé et le café est si petite, qu'en rérité on ne saurait lui attribuer aúcune part dans la uutrition ; d'un autre côté, comme ce principe est répandu dans les graines et dans les feuilles de deux familles végétales reconnues pour être très-favorables aux fonctions vitales, il est fort probable que ces plantes lui doivent leur efficacité. "

M. Liebig fait ensuite remarquer qu'un principe azoté qu'on rencontre dans la bile, la taurine, contient ses éléments constituants, c'est-á-dire le carbone, l'hydrogène, l'oxygène et l'azote, dans les mêmes proportions que la théine, plus une certaine quantité d'oxygène et d'eau.

«Bien que pour le moment, ajoute-t-il, ces rapproche- 
ments ne conduisent à aucune conclusion, ils présentent néannoins de l'intérêt, si l'on se rappelle ce fait observé par Lehmann, que la caféine (théine) introduite daus l'estomac, a pour effet d'augmenter la sécrétion de l'urée et celle dle la bile. "

On voit que $M$. Liebig refuse à la théine toute part dans la nutrition, en se fondant sur la trop petite quantité qu'on en a trouvée daus le thé ct daus le café. Il résulte, en effet, des analyses qu'il a citées que 100 parties de thé de Chine vert ou nöir ne contiennent pas tout à fait une demi-partie de théine.

Si cette proportion était exactement déterminée, l'opinion émise par M. Liebig serait à l'albri de toute objection ; mais il n'en est pas ainsi : cette détermination est inexacte; la quantité de théine qui existe dans le thé est notablement plus considérable.

J'étais arrivé, dès mes premiers essais sur le thé, à cette conclusion, lorsque $\ddot{j}$ ai eu connaissance d'un travail tout récent de M. le docteur Steiuhouse, sur la proportion de théine contenue dans diverses sortes de thé et sur un nonveau made de déterminer cette proportion. Ce mode consiste a décomposer l'infusion de thé par l'acétate de plonb employé en léger excès; on filtre à chaud pour séparer le précipité qui contient le tannin et la matière colorante; on évapore la liquem à sec, après l'avoir mélangée avec du sable; on la chauffe dans un appareil particulier, afin d'obtenir par sublimation la théine, en profitant de la propriété qu'elle possède d'être volatile saus décomposition à la température de 400 degrés environ.

En procédant ainsi, M. Steinhouse a retiré de 100 parties de 
Hyson vert. ........................ 1,05 de théine.

Congo (thé noir). . . . . . . 1,02 -

Assam (thé noir)................ 1,27 -

Tonkay ordinaire (vert). . . . . . 0,98 -

Il y a progris, comme on voit, puistuce ces nombres représentent plus que le double des quantités obtenues par M. Mulder.

Mais M. Steinhouse n'a pas retiré non plus de la feuille de thé toute la théine qu'elle renferme : sa méthode, préférable à celle de M. Multer, ne vaut rien comme méthede quantitative, et cela pour plusieur's motifs qu'il serait inutile de détailler ici.

Le procédé de M. Mulder, qui consiste ả éraporer l'infusion de thé arec de la magnésie caustique et à traiter le l'ésidu par l'éther, qui ne dissout que la théine, offre un double inconvénient: il produit un dégagement d'ammoniaque ou de sels ammoniacaux aux dépens d'une certaine quantité de théine qui se trouve décomposée; il laisse dans le produit épuisé par l'éther une autre quantité de cette substance, l'éther ne mouillant paṣ bien toutes les parties du résiclu. .

J'ai trouvé préférable de traiter d'abord par l'alcool le produit évaporé, puis ensuite par l'éther le résidu alcoolique desséché.

En procédant ainsi, ou bien en traitant par l'éther le résidu évaporé de l'infusion, dépouillée par le sous acétate de plomb d'une partie de ses produits solubles, privée ensuite de l'excès de plomb par le sulfate de soude, j'ai obtenu les quantités de théine suivantes: 
100 de thé vert poudre à canon. . . . . . . . . 2,34

100 d'un mélange à parties égales de souchong, poudre à canon, hyson, impérial, caper, pekoe. . $\quad 2,93$

100 thé hyson. . . . . . . . . 2, 2,

100 poudre à canon. . . . . . . . . . . 3, 3

Ces quantités sont plus que doubles de celles obtenues par M. Steinhouse, et j'ai la certitude qu'elles sont encore trop faibles.

Je suis encore à la recherche d'un procédé qui donne la totalité de la théine contenue dans le thé. Cette substance étant soluble dans l'alcool et dans l'eau, de mêne que les matières qui l'accompagnent, on ne peut point la séparer entièrement parl'emploi de ces dissolvants : l'éther ne la dissout qu'autant qu'elle est en excès par rapport à ces autres matières, de sorte qu'il en reste toujours beaucoup dans les résidus, ainsi qu'on peut le constater au moyen du tannin. Peut-être arriverai-je, par l'emploi de ce dernier corps, à sa complète séparation.

Pien n'étant plus important, pour l'histoire chimique ou physiologique du thé, que la détermination exacte de la nature et de la quantité des principes azotés contenus dans cette feuille, j’ai cherché, par des analyses faites arec le plus grand soin, à déterminer, $1^{\circ}$ la quantité d'azote qui se trouve dans les principales sortes de thé; $2^{\circ}$ celle qui existe dans l'infusion de thé préparée en épuisant la feuille de tous ses produits solubles au moyen de l'eau bouillante; $3^{\circ}$ celle qui reste dans la feuille ainsi épuisée ; $4^{\circ}$ celle qui se trourc dans l'infusion de thé destinée à servir comme boisson, cette infusion étant faite dans les conditions les plus habituelles; $5^{\circ}$ la nature et la 
proportion des principes azotés auxquels appartiennent les quantités d'azote constatées dans ces différents produits.

J'ai trouré, à l'aide des procédés d'analyse organique les plus récents et les plus précis, que $\mathbf{1 0 0}$ parties des thés suivants, desséchés à la température de 110 degrés, contenaient en azote :

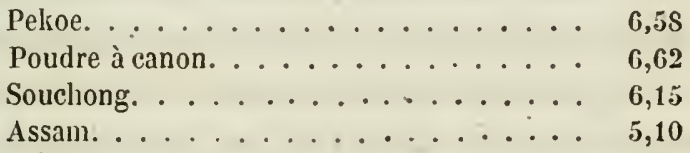

Ces résultats sont aussi remarquables (qu'ils étaient inattendus; car cette proportion d'azote est plus forte que celle qui existe dans aucun des végétaux qui aient été examinés jusqu'à ce jour. Or, cet examen a été fait par M. Boussingault, pour la plupart des plantes consommées comme fourrages par les animaux, et par MII. Boussingault et Payen, pour un très-grand nombre de végétaux employés comme engrais. On sait que la valeur comparative des fourrages et des engrais est en raison de la quantité d'azote qu'ils contiennent, et qu'elle peut être appréciée par la détermination de cet élément, essentiellement propre à l'entretien de la vie tant chez les animaux que chez les plantes.

Je dois d'ailleurs fäire remarquer que cette quantité d'azote, qui est plus que double de celle qui a été trourée dans les feuilles les plus azotées, appartient à une feuille prise, non pas dans son état naturel, mais après avoir été, pour aiusi dire, manufacturée.

On a vu, en effet, que le thé avant d'être livré à la 
consommation, subit toujours une torréfaction qui ramollit la feuille et qui permet d'en exprimer par la pression des mains un suc assez abondant, âcre et légèrement corrosif; la feuille est ensuite roulée en spirale et desséchée plus ou moins rapidement, selon qu'il s'agit de la fabrication du thé vert ou de celle du thé noir.

Or, il est raisemblable que ce suc n'est pas ou est peu azoté et que cette opération augmente, par suite, la quaistité d'azote qui reste dans la feuille; car j’ai déterminé l'azote des feuilles fraîches des arbres à thé cultivés dans les belles pépinières des MII. Cels, et j’ai trouvé dans ces feuilles, séchées à 100 degrés, 4,37 d'azote pour 100 de thé sec; cette quantité, quoique. plus faible que celle du thé chinois, est encore plus considérable que celle qui a été trourée dans aucune des feuilles analysées jusqu'à ce jour.

Très étonné du résultat de ces premières analyses, qui déroilent dans le thé l'existence de 20 à 30 pour 100 de matières azotées, je me suis mis, pour ainsi dire, à la poursuite de ces matières, en procédant par élimination, et en les cherchant successivement dans l'infusion de thé, dans la feuille épuisée et dans les prorluits qu'on peut isoler soit de cette infusion - soit de cette feuille.

A cet effet, j’ai épuisé compléternent par l'eau bouillante 20 grammes de poudre à canou non desséchée, et j’ai obtenu, en éraporant cette infusion à une douce chaleur, un résidu couleur chocolat qui pesait $9^{\text {gr. }} \mathbf{4} 3$. Ce qui fait 51,2 le produits solubles dans 100 de ce thé pris à l'état sec, et co qui confirme le nombre cité précédenment et obtenu par une méthodo toute différente. Ce résidu contenait 4,35 d'azote pour cent. 
La mème expérience faite sur le souchong a donné un résidu qui, à l'état sec, contient 4,70 p. 100 d'azote.

Ces quantités d'azote appartiennent-elles tout entirres it la théine contenue dans ces résidus? Je suis porté à le croire, car le précipité formé dans l'infusion par le sousacétate de plomb, qui consiste en une partie des produits solides qu'elle renferme elle-mênıe, n'est pas azoté, e dans les produits solubles qui y restent je n'ai pas trouvé d'autre matière azutée que la théine. A la vérité, je n'ai pu extraire de ce résidu que 7,03 pour cent de théine, tandis qu'il doit en contenir 12,6 ; mais j'ai dit comment il ne m'était pas possible de séparer tonte cetle matière des substances qui l'accompagnent dans le thé.

Quant à la feuille épuisée par l'eau, elle contient le complésnent de l'azote total de la feuille non infusée; 100 de feuilles éprisées sèches contiennent 4,30 d'azote pour le thé poudre ì canon, et 4,4 pour le thé souchong; cet élément s'y trouve non pas à l'état de théine, car ces feuilles paraissent être entièrement dépouillées de cette substance, mais à l'état d'un produit qui, d'après un examen encore insuffisant, semble être identịue aree la caséine. Comme cette dernière substance ne contient que 15 pour cent d'azote, les feuilles épuisées et sèches n'en contiendraient pas moins de 30 pour cent; le thé, dans son état ordinaire, ell contiendrait 15 pour eent environ. Cette caséine paraît être dans les feuilles en combinaison avec le tannin; ce qui rend compte de son insolubilite dans l'eau pure, tandis чu'elle est dissoute par l'eau faiblement alcaline.

Le thé renferme donc, tant dans son infusion que dans ses feuilles épuisćes par l'eau, une quantité d'azote et, par suite, de substance azotée beaucoup plus considérable qu'on 
ne l'avait supposé jusqu'à ce jour. Il n'est pas douteux que, lorsque cettefeuille est consommée dans son ensemble, avec ou sans infusion préalable, comme le consomment, assure-t-on, quelques populations indiennes, elle constitue un aliment plus riche en principes azotés, et par conséquent plus nutritif qu'aucun autre produit végétal. Mais doit-on admettre que l'infusion de thé préparée comme on la prépare ordinairement, c'est-à-dire arec peu de thé et beaucoup d'eau, agit comme boisson autrement que sur notre système nerveux, en produisant une surexcitation qui peut tenir lieu, pendant un certain temps, de nourriture véritable ? Peut-on considérer cette infusion, abstraction faite des propriétés spéciales des substances qui la composent, comme équivalant, par son poids et par celui de son principe azoté, à d'autres substances liquides d'une incontestable efficacité comme aliments? Peut-on, par exemple, la comparer au lait ou au bouillon de viande? La solution de ces questions se trouve subordonnée à des éléments trop divers et trop incertains pour qu'on puisse la considérer comme prochaine. J'ai cherché néanmoins à déterminer quelques-uns de ces éléments, apportant ainsi ma pierre à cet édifice qu'on appelle la physiologie, œuvre dont la construction est si lente et si difficile.

J'ai fait du thé, comme on le fait ou comme on doit le faire habituellement, et j'ai déterminé le poids des principes solubles contenus dans cette boisson.

J'ai donc fait infuser pendant 10 à 12 minutes, dans une théière préalablement échaudée, en métal anglais ou en porcelaine, 10 grammes de thé rert (poudre à canon): j'ai employé pour l'infusion 500 centimètres cubes d'eau bouillante qui représentent trois tasses de thé environ. 
L'infusion contenait 3 grammes de produits solubles; soit 33,3 pour 100 de thé. La même expérience, répétée avec 20 grammes du même thé et un litre d'eau, a donné 6,33 gr. de produits solides dissous par l'eau; soit 31,7 pour 100 de thé. 20 grammes de souchong, traités de la même manière, ont fourni $4,55 \mathrm{gr}$. de produits solubles; soit 22,7 pour 100 de thé.

On voit que l'infusion ordinaire de thé ne renferme qu'une partie des produits solubles contenus, dans la feuille, car on a trouré dans la poudre à canon, prise dans son état ordinaire, 48,5 , et dans le souchong, 40,3 pour 100 de ces produits.

Dans une autre expérience, j'ai fait deux infusions successives dı même thé, chacine pendant 10 minutes; c'était du souchong : la première contenait 19,4 de principes solubles pour 100 de thé, et la seconde 4,8; en tout $2 \%, 2$.

J'ai ensuite déterminé l'azote contenu dans ces infusions; dans les produits solubles éraporés à siccité de la poudre à canon, il y avait 4,81 d'azote pour 100 .

Dans ceux du souchong. . . . . . . 4,79
Dans la première infusion du souchong. . $\quad . \quad 4,80$
Dans la seconde infusion. . . . $\quad 3,89$

Les trois premiers de ces nombres représentent environ 15 de théine dans 100 de résidu sec, d'où il résulte que l'infusion, par exemple, faite avec 20 grammes de poudre à canon, qui a fourni 6,33 de produits solubles, renferme à peu près 1 gramme de théine. Ces quantités sont-elles suffisantes pour qu'on puisse considérer le thé comme un aliment réel? C'est une question que je ne saurais décider. 
Il est d'ailleurs essentiel de rappéler que l'infusion de thé n'est habituellement consommée qu'avec du sucre employé en quantité quatre fois plus considéral)le au moins que le the lui-même, de sorte que la proportion de produils solides dans le thé sucré derient égale, dans le cas que je viens de citer, ì 32 grammes environ.

En comparant l'infusion de thé dans cet état arec le bouilnn, on arpive aux chiffres suivants.

D'après les analjses du bouilion de la Compagnie hollindaise faite par les meinbres de l'Institut composant la commission dite de la gélatine, un litre de ce bouillon contient :

Matières organiques so!ubles. . . . 15 grammes.
Matières inorganiques (stl marin). .
Résidu sec. . . . . . . .
24 grammes.

La quantité d'azote contenue dans ces $\mathbf{1 5}$ grammes de produits organiques n’a pas été déterminée; je pense que cette quantité peut être égale à 8 d'azote eniviron dans 100 de ces produits sees, ce qui ferait $1,2 \mathrm{gr}$. d'azote dans un litre de bouillon.

L'infusion de the faite avec 20 grammes de thé pour un litre d'eau et ensuite sucréc, donne en produits solides:

Résidı sec dı thé. . . . . . 6,33 grammes.

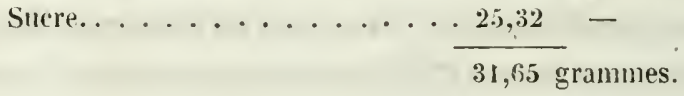

Ce mẹlange contient 3 décigrammes d'azote et $1 \mathrm{gr}$. environ de théine. 
Ainsi, si le résidu du bouillon est plus riche, en azote, le résidu de l'infusion de thé contient un poids plus considérable de matières solides. Il faut d'ailleurs remar(puer que le bouillon, comme l'infusion de thé, varie beaucoup dans sa composition, et que celui de la Compagnie hollandaise contient une quantité de produits solubles plus forte que celle qui existe daus la plupart des bouillons de ménåge.

Ces faits semblent conduire déjà à celte conséquence que le thé ne doit plus désormais être considéré comme une boisson exclusirement excitante; il est possible que cette hoisson soit en nutre nourrissante, à cause de la proportion et de la nature des substances qui la composent. Soulever cette question, ce n'est pas la résoudre, assurément; mais cest diéjà beaucoup, à mon sens, que d'être autorisé à la soulever.

ll est à désirer que des expériences physiologiques viennent nous apprendre bientôt ce qu'il faut penser du rôle que le the joue dans l'alimentation, surtout quand on considère l'énorme quantité qu'on en prend dans quelques pays. Les Anglais, lorsqu'ils consomment par an 18 millions de kilogrammes de thé associé à 72 millions de kilogrammes de sucre au moins, acceptent-ils cette boisson comme un moyen d'attendre des aliments plus substantiels, ou bien l'acceptentils comme l'équivalent de ces aliments euxmêmes? Le problèrre à résoudre peut être posé, je pense, en ces simples termes. Il est curieux d'aillenrs de faire cette remarque, par laquelle je termine ce trop long chapitre, qu'en associant, conme ils foṇt habituellement, l'infusion de thé an sucre et au beurre, ils réalisent instinetivement, sans le savoir, les conditions qu'un de lenrs plus labiles chimistes, le docteur Prout, a assignées à tout ali- 
ment parfait, à tout aliment pouvant, de même que le lait qu'il a pris pour type, suffire à lui seul à la nutrition; ces conditions sont l'existence de trois matières : l'une azotée comme le caséum ou peut-être la théine; l'autre neutre, non azotée, comme le sucre de lait ou le sucre ordinaire; la troisième de nature grasse, comme le beurre. 


\section{CHAPITRE VIII.}

Propriétés médicales et hygiéniques.

\section{PAR LE DOCTEUR TROUSSEAU,}

Il n'est pas toujours facile, quand une substance est réellement active, de se prémunir contre les exagérations, d'ailleurs si naturelles, de ceux qui l'ont employée avec quelque avantage, ou contre celles des personnes qui en ont éprouvé de mauvais effets.

Le thé est véritablement dans ce cas : vanté par les uns avec un fanatisme qui n'a pas toujours été justifié, proscrit par les autres avec un acharnement aveugle, il a pris enfin place à côté du café dans l'histoire hygiénique et médicale des hommes.

Il ne saurait entrer dans notre plan de nous appesantir ici sur des considérations d'économie politique, qui ont trouvé tout naturellement leur place dans les chapitres précédents de cet ouvrage. Aussi resterons-nous dans le cercle que nous nous sommes tracé; toutefois nous croyous utile de reporter l'attention du lecteur au chapitre $\mathrm{I}^{\mathrm{er}}$, 
pour mieux faire comprendre les canses d'erreur que nous avons dù rencontrer à chaque pas lorsque nous avons voulu apprécier, avec un esprit dégagé de toute prévention, la valeur des assertions un peu exagérées des écrivains qui, dans le Royaume-Uni et dans les Indes orientales, ont publié sur le thé les travaux les plus complets.

Nous arons lu arec attention tous les ourrages des auteurs recommandables qui ont étudié le thé au point de rue de l’hygiène et de la médecine. En première liğne nous placerons les docteurs John Coakley Lettsom, Thomas Short, W. Newnham, auteur d'un Essai sur les affections de l'utérus; G.-G. Sigmond, professeur de matière médicule à la Société royjale de botanique de Londres. Nous arons nous-même fait des expériences pour constater les propriétés du thé pris, soit comme boisson alimentaire, soit comme médicanıent, et nous nous efforcerons de nous affranchir de toute préoccupation pour exposer, arec autant de fidélité que possible, l'histore hygiènique et médicale du thé.

Notre travail sera divisé en deux parties distinctes :

$\mathbf{1}^{\circ}$ L'influence du thé sur l'homme sain, lorsque l'habitude de la substance n'a pas encore été acquise ; son influence comme boisson alimentaire;

$2^{\circ}$ Nous étudierons l'influence du thé comme médicament.

\section{$\mathbb{S} 1^{\mathrm{er}}$. - DE L'INFLUENCE DU THÉ SÉR L'HOMNE SAIN.}

Il importe arant tout de diviser les thés en deux sortes distinctes. Et bien que, d'après ce qui a été établi au chapitre III, le thé vert et le thé noir prócèdent d'un seul et 
même arbre, et que la manipulation de la feuille imprime lit différence de couleur, cependant on ne peut se dissimuler qu'entre l'action du thé noir et celle du thé vert il n'y ait une différence inmense. Le thé noir, de quelque espèce qu'il soit, a moins d'énergie que le thé vert; il faut done le considérer comme type d'action. Nous verrons plus tardce qu il peut y aroir de particulier dans l'action du thé vert.

\section{Influence du thé noir.}

Le the se prend en infusion, et de cette manière il conserve tout son parfum. Si l'infusion est prompte, elle est remarquahle par la finesse de sa saveur, par la netteté de l'arôme, et par un sentiment d'astringeice qui n'a rien de désagréable. Si l'infusion a été longtemps prolongée, elle a perdu de son arôme, mais il s'est développé un goùt nouveau qui ressemble à celui des feuilles séchées de la plupart des végétaux qu'on soumet à l'ébullition. Eu mèıe temps l'infusion prend de l'astringence; elle happe à la langue et derient un peu amère. Si au lieu de faire infuser le thé, on le fait bouillir, l'amertume, l'astringence et le goût de feuilles séchées se prononcent encore darantage, et au lieu d'une boisson agréable, on n'a qu'un breuvage qui ne flatte nullement le palais.

Dans cette circonstance, le goût, cette sentinelle avancée de la digestion, ne trompe pas. Il démontre dans la boisson l'existence de principes nouveaux, principes qui ne sonit peut-être pas malfaisants, mais qui, à coup sûr, domnent au thé des qualités nouvelles et autres que celles que nous recherchons ordinairement ${ }^{\mathrm{I}}$.

1. Voir au chap. vir, analyse de M. Péligot. 
L'impression que le thé produit sur les organes du goût, fort importante sans doute pour ceux qui n'y cherchent qu'un plaisir des sens, n'intéresse que très-secondairement le pliysiologiste et le médecin. Les phénomènes qui désormais vont se passer offrent un intérêt beaucoup plus grand.

\section{Excitation générale.}

Parmi ces phénomènes, il en est d'immédiats qui évidemment appartiennent au calorique qui est ajouté à la boisson, et qui agit sur la membrane muqueuse de l'estomac. Il en est d'autres qui sont secondaires et qui appartiennent entièrement au thé, indépendamment de la température à laquelle il a pu être ingéré.

Nous savons tous quelle est l'influence des boissons chaudes, de celles mêmes qui ne contiennent d'ailleurs aucun principe excitant spécial.

Chez l'homme débilité par des causes déprimantes, telles que la diète, le froid, les passions tristes, elles rendent immédiatement une énergie nouvelle, caractérisée par l'accélération du pouls; de plus, elles donnent un sentiment de force et une aptitude plus grande aux mouviements de la vie animale et de la vie organique. Si la boisson a été prise en quantité un peu considérable, il peut s'établir pour un inslant une sorte de fièvre, qui se termine le plus souvent par une sueur critique.

\section{Excitation persistante.}

Mais cette excitation est essentiellement temporaire; après quelques minutes, un quart d'heure, une demi- 
henre, au plus, elle cesse et l'homme tómbe dans une débilité plus grande qu'auparavant. Cela tient à ce que le calorique, seule cause de stimulation dans la boisson dont nous venons de parler, est par lui-meme essentiellement diffusible, et ne pent, par conséquent, que donner ì l'économie un coup de fouct qu'elle oublie presque immédiatement:

Au contraire lorsque nous prenons une infusion chaude de thé, nous éprouvons d'abord la même influence que celle que produisent les boissons quelconques qui cèdent du calorique à l'économie; mais bientôt se font sentir les phénomènes propres au thé, c'est-à-dire une continuité d'excitation qui se soutient pendant plusieurs heures, tandis que celle qui était sous la dépendance du calorique ne durait quelquefois pas plus d'une minute.

Le sentiment de faiblesse qui suit ordinairement l'ingestion des boissons chaudes non stimulantes, ne se fait plus sentir alor's, dès que l'excitation produite par le calorique est dissipée; it est remplacé au contraire par un sentiment de bien-être et de recomfort qui n'est pas sans analogie arec celui que donne une boisson alconlique, conme le vin, le grog, le porter, ou la bière. Bientôt surviennent des signes de stimulation nerveuse caractérisée jar une mobilité, plus grande, une aptitude notable ì concevoir, une heureuse disposition aux travaux de l'esprit el du corps, et une dịstribution plus régulière de la chaleur animale. Ces phénomènes s'observent surtouit quand on a pris des thés noirs; et lorsqu'ils ont duré une, deux ou tröis hemres, ils se dissipent pour ne laisser après eux ni faiblesse ni málaise.

"Chez quelques personnes très-irritables, il peut s'y 
joindre d'autres phénomènes qui bien rarement appartiennent au thé noir, et qui an contraire s'observent trèscommunément après l'usage du thé vert.

\section{Action du Thé vert.}

Lettsom a parfaitement indiqué cette action dans son ourrage..Une heure au plus après l'ingestion de la boisson, et lursqu'on a observé les symptômes que nous avọns vus appartenir au thé noir, surviennent des troubles nervenx caractérisés par des bâillements, des agacements, une irritabilité insolite, des pincements dans la" région de l'estomac, des palpitations de cœur, des tremblements légers dans les membres, un sentiment de resserrement daus les tempes, une eertaine propension à la tristesse; et lorsque cette scène est terminée, il reste une faiblesse assez notable, et souvent un sentiment incommode de brisement et presque de courbature. Ces aceidents, trèscommuns chez les personnes qui prennent rarement du thé vert, disparaissent graduellement lorsqu'on s'est fait une habitude de cette boisson; pourtant il est eneore un certain nombre de constitutions qui ne peurent s'y aceoutumer. Et il faut dire que cenx mèmes qui font tous les jours usage du thé noir ne peuvent pas impunément prendre du thé vert le soir; leur sommeil en est presque toujours profondément troublé. On remarque, en effet, quant an sommeil, que le thé noir ne le dérange que très-exceptionnellement, tandis que le thé vert pris le soir eause ordinairement de l'insomnie à ceux mêmes qui én boivent le matin à déjeuner. Mais les tempéraments roloustes et peu irritables finissent par 's'habituer an thé 
vert; et comme le gout en est plus agréable, du moins pour le plus grand nombre, il a fini par s'introduire dans la plupart des familles où les individus qui la composent out une vigoureuse organisation. Oi prend ordinairement de l'infusion faite avec un mélange de the noir et de thé vert dans des proportions variables.

Certaines constitutions exceptionnelles s'accommodent; il est vrai, du thé vert, et nous voyous des gens prendre matin et soir de fortes infusions de ce thé, nonseulement sans en ètre incommodés, mais encore en y trouvant un grand bien-être. C'est ainsi que, pour le vin, le plus grand nombre des tempéraments s'arrange bien de uos vins légers de France coupés d'eau, tandis quue heaucoup de personnes boivent aux repas des vins riches en alcool, et mème de l'eau-de-vie, du rum, ou des liqueurs encore plus fortes, trouvant seulement dans des stimulauts aussi énergirues le moyen d'exciter leurs organes engourdis ou de réveiller leurs sensatious blasées.

Il y a aussi certains individus qui ne peuvent jamais s'habituer aı thé, même au thé noir, au même titre que d'autres ne peurent jamais supporter de liqueur's alcooliques; et, chez eux, les accidents nerveux qui suivent ordinairement l'ingestion de cette infusion peuvent aller jusqu'ì un véritable délire, jusqu’à la manie. Ainsi Lettsom raconte l'histoire d'une mélancolie qui, développée sous l'influence de l'usage et de l'abus du thé, cessa lorsque le malade s'abstint de cette boisson.

Il ne faut pas prendre pour un des accidents qui dépendent de l'influence du thé ce sentiment de faiblesse et de défaillance indiqué par Lettsom, et qui s'observe quelquefois immédiatement avant le dìner, lorsque l'on a pris 
du the ì déjeuner. Ce sentiment est assez eommun, et loin d'être un motif d'accusation contre le thé, il absout au contraire cette liqueur. Il tient, en effét, à l'activité qu'il imprime aux fonctions digestives et assimilatrices; et l'on concoit aisénent que si la digestion a été beaucoup plus rapide, le sentiment de défaillance qui survient lorsque l'estomac est vide et qu'il demaude de nouveaux aliments, se fasse sentir plus promptement et avec plus de force que si la digestion avait été lente et laborieuse.

Aux personnes qui éprouvent un accident de ce genre, il n'y a pas d'autre conseil à leur donner que de prendre entre les deux repas quélque chose de légèrement alimentaire.

\section{Influence du The sur la digestion.}

Ceci nous conduit tout naturellement à examiner l'influence du thé sur la digestion. Cette influence est heureuse, et il est peu de personnes chez qui le thé ne favorise l'élaboration des aliments.

On doit dire même que chez les grands mangeurs le thé devient une sorte de nécessité, une condition qui leur permet d'engloutir sans danger une grande masse d'aliments.

Les individus sobres n'ont sans doute que rarement besoin de ce secours pour accomplir l'acte digestif; mais, il faut le dire, nos liens sociaux, la nécessité et lés convenances qui retiennent chez enx les hommes et les femmes daus l'organisation actuelle de la société', et beaucoup d'autres causes encoie qu'il serait superflu d'indiquer ici, rendent, chez le plus grand nombre, les digestions habi- 
tuellement paresseuses, et une boisson légèrement stimulante devient nécessaire. Le thé est celle que l'on peut prendre, nou-senlement avec le plus de plaisir, avee le moins d'inconvénients, mais encore avec le plus d'avantages réels.

Obésité produite par le Thé.

C'est ici le lien de discuter un des plus grands reproches que l'on fasse au thé. Il dispose, dit-on, à l'obésité. Qui ne voit au contraire qu'un pareil reproche est tout à l'avantage du thé? L'obésité, qu'on ne s'y trompe pas, ne peut pas être considérée comme uno maladie, mais bien comme l'exagération de l'état,normal. Cet état est chez les animaux et chez l'homme l'indice d'une excellente santé et de l'accomplissement facile de toutes les fonctions : done, si le thé est capable de la produire, il faut en conclure rigoureusement que cette boisson peut imprimer aux fonctions, et notamment aux fonctions digestives, une aetivité et une aptitude remarquables. Que des hommes abusent maintenant des bienfaits du thé, et yu'ils en profitent pour assouvir, non pas leur faim, ce qui serait fort naturel, mais leur gourmandise et les inille caprices de leur sensualité, c'est une chose qu'it faut déplorer; mais alor's il faut attribuer à l'intempérance ei ì la. gloutomerie l'obésité que, le thé farorise, en ce sens seulement qu'il aide à supporter sans dommage la gloutomerie et l'intempérance. Ainsi le reproche que l'on fait au thé d'engraisser les Chinois, les Hollandais et les Anglais, doit retomher seulement sur ceux qui so servent du thé pour assonvir la brutalité de leurs instincts. 


\section{Du The considéré comme aliment.}

Mais ce n'est pas assez de considérer le thé conmue boisson purement excitante; et bien que, à ce titre, il jouisse de propriétés précielises, ainsi que je viens de l'établir, il se recomnande encore comme alinent proprement dit.

Les belles analyses de M: Peligot ont prouvé que le thé contient, ontre le principe aromatique dont nous avons parlé, une matière azotée qui entre dims l’infusion, au moins dans la proportion de quatre pour cent. Sans doute, il n'est pas permis en bomne physiologie de prétendre que tout principe azoté est par cela nême alimentaire; mais tout au moins pourons-nous affirmer, en nous fondant sur l'analogie, que și ce principe azoté, d'ailleurs. altaquable par les sucs gastriques, s'unit, dans l'aliment, à d'autres principes azotés ou non azotés; aromatiques ou non aromatiques, mais susceptibles également d'être convertiś en chyme, la réunion de ces éléments divers contpose un aliment parfait.

Ainsi il est douteux que le thé pur soit un aliment, bien qu'il soit riche en azote, de la même maniìre que la gélatine pure, si bien aromatisée qu'elle puisse ètre, n’e̊st pas un aliment, ou tout au moins ne suffit pas ä l'entretien de la vie; majs qu’à la gélatine on ajoute les principes aromatiques et sapides de la viande, elle devient à l'instant même alimentaire, et elle devient surtout un excellent aliment si on y ajoute encore de la fécule, bien que la fécule ne soit pas azotée. Le thé a sur la gélatine l'avantage de renfermer en imême temps et le principe azoté et le principe aromatique, et, à ce titre, il pourrait nieux 
que la gélatine servir à l'entretien de la vie; toutefois il sc placerait peut-etre à côté de la.gélatine aromatisée. Nais nous ne prenons pas de thé pur, nous y ajoutons une quantité considérable de sucre, uin peu de crème; et, de cette manière, une infusion de thé contient certainement plus de principes alimentaires que le meilleur consommé, attendu que le sucre, bien que non azoté comme la fécule, levient, par sou union à un principe azoté, un aliment riche et substantiel. Combien l'aliment ne sera-t-il pas plus substantiel encore si nous y ajoutons un peu de pain beurré?

L'analyse chimique de M. Peligot vient done expliquer ce que l'expérience journalière avait dès longtemps constaté. Nous sarions tous que les forces, l'embonpoint, se conservaient à inerveille, bien qu'on ne prît à déjeuner Iue deux ou trois tasses de thé sucré avec un peu de pain beurré; nous sentions, par la conservation de nos forces, que cet aliment nous substantait, qu'il suffisait à la réparation des pertes. Certes, mie hoisson exclusivement stimulinte, comme le vin ou l'alcool, produit bien un effet temporaire; mais la restauration des forces ne persiste pas; tandis qu'après l'ingestion du thé auquel on ajoute un peu de pain, le sentiment de réfection persiste comme après un bon repas.

Son influence sur les actes reproducteurs.

Je ne terminerai pas ce qui concerne la partie physiologique du thé sans parler d'une propriété qui lui a été généralement attribuée; je veux parler de celle d'exciter aux actes reproducteurs. 
On dit que les peuples qui font usage du thé multiplient d'une manière extraordinaire, et l'on cite pour exemple la Chine, l'Angleterre, la Hollande; tandis que ceux qui au contraire font usage du café voient leur nombre diminuer rapidement, ainsi les Italiens, les Tures, les Arabes. Ces propositions générales, appuyées de faits assez superficiellement observés, trou vent faclement crédit quant on ne les analyse pas; mais on s'aperçoit bientốt qu'elles reposent sur des données ássez peu positives.

En prenant la Grande-Bretagne pour exemple, nous voyons que la population est particulièrenıent dense daus l'Irlande, la partie du Royaume-Uni qui consomme le moins de thé; que la Hollande, où l'usage du thé est unirersel, est moins peuplée que la Belgique, où les habitudes frangaises persistent encore; que la Pologne, où le thé reste la boisson de la noblesse et des classes aisées, est plus peuplée que la Hoscovie, où l'uságe du thé est aussi général qu'en Angleterre.

Il est évident que l'abus du café rend moins apte à l'exercice des actes reproducteurs; mais l'usage du thé ne semble avoir réellement aucune influence directe sur les orgạnes de la génération.

\section{Influence sur les dents.}

Le thé exerce, dit-on, une fàcheuse influence sur les dents. "C'est à l'usage constant de cette boisson que les Hollandais doirent la rapide altération de leurs dents. » On ne sait vraiment comment des hommes sérieux croient et répètent de pareilles assertions. Si l'on est forcé de convenir ąu'eiı général les habitauts de la Hollande ont la 
bouche en assez. mauvais état, on ne pourra pas contester que les Anglais, qui font peut-être abus du thé, ont en général les dents, sinon bien faites, du moins fort saines, et certes meilleures que celles des habitants de Paris.

\section{Influence dangereuse du Thé.}

Nous ne savons, en vérité, s'il faut se donner la peine de réfuter les singulières assertions de quelques auteurs qui disent que le thé peut produire des accidents extraordinaires, et quelquefois mème agir à la facon des poisons. "Ainsi, dit-on, certains ouvrier's employés dans des ar" rière-boutiques à mêler des thẹs, ont été pris d'étour" dissements, d'hémorragies; un négociant a été frappé " d'apoplexie et de convulsions après a voir longtemps flairé "des thés! » Peut-on croire que des faits aussi exceptionnels puissent jamais amener une conviction sérieuse? On parle d'un négociant qui tombe frappé d'apoplexie après avoir flairé des thés; mais cent mille négociants ont flairé des thés toute leur vie sans en ressentir aucun mal, et celui dont on parle faisait peut-être ce métier-là depuis trente ans saus èn avoir été incommodé. Autant vaudrait dire que la lecture de la Bible peut donner des attaques d'apoplexie, parce qu'un père de famille sera frappé après la lecture du soir. Et puis, en admettant mème que le thé fut la cause de l'accident, comment ne voit-on pas qu'il faudrait accuser, non pas la boisson, non pas l'arôme du thé, mais une disposition toute exceptionuelle? N'aronsnous pas des personnes qui sont prises de véritables iecidents d'empoisonnement après a voir mangé des moules, des huitres, du poisson, du gibier, des fräises, du cres- 
son, etc.? En faut-il conclure que ces dirers alinents sont des poisons?

Résumé de la premic̀re partie.

Pour nous résumer, noüs dirons done que, en général, le thé agit comme excitant; qu'il est en neême temps alimentaire; qu'il exerce sur les facultés de l'entendement et de la digestion une influence beureuse, et que l'abus seul peut en être peruicieux.

\$ 2. - DES USAGES DU THĖ EN MÉDECINE.

Nous distinguerons, en étudiant les propriétés médicales du thé, celles qui sont incontestables, nous dirons mệme incontestées, et celles qui ne sont admises que par un petit nombre de sarants qui ont ou mieur observé, ou été aveuglés par une prérention favorable.

En parlant des usages du thé comme boisson alimentaire, nous avons vu qu'il favorisait, qu'il activait les fonetions digestives. C'est aussi dans certaines maladies de l'estomac et des intestins qu'il sera particulièrement conseillé; mais ici il faut faire une distinction attentive. Si le thé est employé par une personne qui en fasse usage tous les jours, on comprend qu'il n'aura plus la même influence que si on l'administre chez un malade qui n'y soit pas habitué. L’habitude, en effet, émousse l'action d'un remède; et tel qui, ne buvant que de !'eau à ses repas, s'enivrerait avec un verre de vin pur, ou en serait tout au moins trèsvivement excité, n’éprouvera à la long̣ue rien d'anormal s'il prend une grande quantilé de vin à ehaque repas; de 
sorte que le thé qui, pour une personne qui n'y est pas liabituée, devient un médicament dans l'acception du mot, perd cette qualité dès qu'il s'applique à un individu qui en fait tous les jours usage.

Disons encore que, dans certains cas, il peut devenir très-nuisible; nous nous expliquerons pltis bas sur ce fait.

Nous supposerons done un individu qui ne soit pas habitué au thé, à cette seule condition le thé sera uin médicament.

Dans les fatigues d'estomac, les parësses de digestions qui succèdent aux maladies aiguës, ou qui se manifestent après des excès de table, de veilles, le thé pris ou pendant ou après le repas, est un des moyens les plus énergiquement curatifs que possède la thérapeutique. Il doit être donné chàud et sucré, à moins de contre-indication particulière. Il sera moins utile et le plus souvent nuisible aux personnes qui auront une.constipation.opiniâtre, des flatulences, des romissements.

Il sera conseillé avec quelque avantage aux femmes enceintes dont les digestions seront habituellement laborieuses, en ayant soin de faire prendre de temps en temps un peu de magnésie an niomeit où la malade se met au lit.

Dans lẹs diarrhées qui suçcèdent à la dyssenterie, au choléra, ou quii persistent șans fièvre inprès des maladies aiguës, l'usage du thé est très-convenable; mais, dans ce cas; il faut prolonger le temps de l'infusion, afin que l'eau puisse dissoudre le principe astringent que la feuille ne cède qu'avec lenteur: le thé sera moins agréable, il est vrai, mais ses propriétés thérapeutiques seront augmèntées.

On peut établir en thèse générale que, rarement applicable aux maladies du canal alimentaire dans l'enfance, te 
thé réussit mieux à une époque un peu plus avancée, et notamment dans la vieillesse. Les hommes qui abusent des plaisirs de la table, et surtout des boissons alcooliques, finissent par perdre leurs facultés digestives, ainsi que nous l'avons indiqué déjà. Mais, par une fatảité déplorable, l'excitation à laquelle ils se sont habitués leur devient en quelque sorte nécessaire: si, un seul jour, -ils cessent de boire, ils tombent dans une hypocondrie, dans un dégoût de la vie, dans un anéantissement de forces musculaires qui ne serait pas sans péril si l'on n'y portait secours. L'usage du thé est, dans ce cas, un remède souverain: cette boisson excite le système nerveux, lui rend toute son énergie, dissipe la tristesse et l'hypocondrie, et met ceux qui n'y sont pas habitués dans un état plus agréable et beaucoup moins fàcheux que l'ivresse. Elle permet aux malades de se déshabituer lentement des spiritueux, rend à l'estomac sa puissance digestive; et, quand bien même l'abus du thé remplacerait chez le malade celui des boissons fermentées, il y aurait encore tout à gagner, et les inconvénients seraient bien minimes, comparés à ceux qu'on aurait ètités.

Nous avons dit plus haut que, chez les bureurs de thé dont l'estomac devenait malade, cette boisson pouvait être pernicieuse, et que la paresse de l'estomac et les difficultés de la digestion ș'augmentaient par l'usage du thé. Je dois ici une explication. On concoit d'abord que, lorsqu'il existe une irritation vive de l'estomac et des intestins, une boisson fortement stimulante doive plutôt augmenter que diminuer le inal, et que, par conséquent, il faille interdire le thé, ou tout au moins diminuer considérabblement la quantité que l'on permet au patient. Mais il existe souvent 
chez les buveurs de thé un état de l'estomac qui eṣt bien différent de l'irritation, je veux parler d'une atonie profonde, conséquence de l'habitude de stimulation dont la membrane nuqueuse a été l'objet. Brown a parfaitement établi que, lorsqu'un stimulus était sans eesse mis en rapport avec une partie.excitalle, si l'action n'excédait pas certaines limites, il en résultait d'abord une stimulation légère, mais que, an bout de peu de jours, la même dose de stimulus ayant ce qu'il appelle épuisé l'incitabilité, le tissu stimulé ne répondait pas avee une énergie réactionnelle plus énergique qu'il ne le faisait auparavant au, contact des aggents ordinaires de stimulation, de sorte qu'en augmentant tous les jours la dose de stimulus, on finissait par accontumier un organe à supporter, sans paraitre le sentir, des influences qui eussent produit les effets les plus puissants quand la partie n'avait encore rien perdu de son incitabilité.

Un exemple rendra plus évidente cette vérité.

Un buveur d'eau prend un verre de vin et s'enivre; il persiste pendant plusieurs jours, et l'effet disparait. Il augmente la dose de la liqueur alcoolique de manière à ètre en pointe de vin. Bientôt, pour obtenir le même effet, il faudra doubler, tripler, décupler la quantité de vin. Plus tard, le vin ne suffisant plus, il faudra recourir au rum, à l'eau-de-vie, au gin, à l'arack, et l'estomac ne semblera pas plus stimulé par ces liqueurs brûlantes qu'il ne l'était le premier jour par un peu de vin de Bordeaux ou de Bourgogne.

De même pour le thé. Mais on comprend qu'il est un terme où s'arrête la folie des hommes et la tolérance des organes. Quand l'estomac a abusé des thés les plus éner- 
giques, son excitabilité est usée et nẹ répond plus à aucune stimulation, et ses fonctions sont entrarées. Le moindre bon sens indique que, dans un cas semblable, loin d'insister dans cette voie funeste, le médecin doit rompre arec ces mauvaises hahitudes, interdire le thé, et recourir à l'autres moyjens capables de faire perdre à l'estomac cette sorte d'insensibilité.

Les propriétés sudorifiques du thé sont utilisées daus certaines maladies; ainsi, dans la goutte atoniyue, dans le rhumatisme non fébrile, dans les affections catharrales légères qui sliccèdent à l'impression subite d'un froid vif, lo thé, dans certaines circonstances, en excitant vivement le système circulatoire, provoque la sueur, qui sert de crise; par là, l'économie se débarrasse des principes morbifiques qui auraient pú déterminer dés désordres locaux plus ou moins graves.

La hécessité, la convenancé de la sueur existe dans un grand nombre de maladies, et le thé nous offre un moyen facile et assez sur pour olitenir la transpiration; et si nous comparons cette boisson à celles qu'on est dans l'usage d'employer pour arriver au même but, on ne peut s'empêcher de lui donner la préférence. Sa saveur agréable fìt-elle le seul motif de notre choix, celui-ci se trouverait suffisamment justifié; car lors même qu'une maladie accomplit ses périodes en peu de jours, les patients ne supportent qu'arec dégocit les tisanes diverses que l'on a l'habitude de leur prescrire, à plus forte raison lorsque l'affection est chronique. Le thé comme sudorifique a, sur' les autres médicaments de la même classe, le grand avantage de né pas causer une débilitation qu'il est urgent d'éviter dans un grand nombre de cas. 
Tous les thés produisent les effets que nous avons indiqués jusqu ici, mais il cn est qui appartiennent plus spécialement aux thés verts; ceux-ci provoquent ordinairement la sécrétion urinaire, et impriment au système nerveux une modification puissante, qui peut et doit être ntilisée dans quelques circonstances.

C'est i cette propriété diurétique des thés verts que l'on attribue le peu de fréquence de la pierre et de la gravelle dans la Chine et an Japon. Cette opinion mérite d'être discutée.

A n'en pas douter, les diurétiques ont une incontestable utilité dans le traitement de la pierre et de la gravelle, et trop de faits déposent dans ce sens pour que nous veuillons les révoquer en doute; mais, parmi les diurétiques, ceux qui exercent sur la composition de l'urine une influence chimique évidente sont bien autrement utiles que ceux qui n'ont d'action qu'en augmentant la quantité de fluide secrété. Or, le thé vert èst dans la dernière de ces deux catégories.

Les auteurs qui ont avancé que le thé vert guérissait la pierre et la gravelle se sont surtout fondés sur un fait : savoir, que les Chinois et les Japonais sont à peu près exempts de ces deux infirmités.

D'abord, si l'on jette un coup d'œil critique sur la médecine des Japonais et des Chinois, on verra qu'elle consiste dans des pratiques tellement ridicules, qu'on ne peut guère dans notre Europe lui comparer que l'homœopathie; et puis la Chine et le Japon sont jusqu'à présent restés tellement en dehors des relations et des investigations des savants, qu'il est téméraire d'affirmer et absurde de croire ce que l'on a dit de la pierre et de la gravelle. 
maladies donl la constatation n'est ni simple ni facile. Maintenant promenons nos regards sur les peuples de l'Europe; nous voyons que, suivant les relevés de nos savants les plus recommandables, la Hollande est le pays qui renferme le plus de calculcux.

L'Angleterre est ensuite la partie de l'Europe où la gravelle s'observe le plus souvent. Or, je remarque que ce sont précisément les deux contrées où l'usage dı thé est le plus répandu; de sorte qu'il faudrait au contraire conclure de ces observations que le thé est favorable à la production de la pierre.

Conclusion que je regarde comme peu fondée, il est vrai, mais qui l'est au moins autant que la conséquence opposée. Il me semble raisonnable de ne pas se prononcer sur une question semblable, jusqu'à ce que l'on ait pu apprécier l'influence que les mille conditions de climat, d'alimentation, de tempérance, etc., peuvent avoir sur la production des affections calculeuses.

I'ai dit plus haut que le thé vert, par cela mème qu'il modifie puissamment le système nerveux, avait été utilement employé dans quélques maladies connues sous le nom de névroses. Je l'ai essayé dans l'asthme avec quelque succès; et j'ai vu se calmer des accès contre lesquels avaient échoué des moyens ordinairement très-puissants. 


\title{
CHAPITRE IX.
}

\author{
Classification.
}

Les classifications adoptées jusqu'ici dans les divers ouvrages français qui ont traité du thé, n'ont paru à l'auteur ni assez complètes ni assez explicites pour donner au négociant, au détaillant ou au consommateur la facilité de reconnaitre les différentes sortes et les qualités de cette feuille.

Il a donc tâché de placer ici, sans toutefois prendre de marche ascendante ou inrerse, toutes les espèces connues en Europe, en ajoutant à leurs noms, qui sont purement arbitraires, le nom chinois, et son étymologie fabuleuse ou poétique.

La description de chaque thé a été basée sur les premières qualités, car ces sortes se subdivisent pour la plupart en un grand nombre de variétés; et par la conclusion de cette analyse, on a tâché de mettre l'acheteur dans la possibilité de choisir lui-même le thé qui convient à son gout comme à sa constitution, en résumant le degré de force et d'activité qui se trouve dans chaque sorte, d'après le tableau renfermé au chapitre VII.

L'auteur fait observer seulemeñi que les thés qui seront choisis suivant la désignation attachéc à chaque espèce, doivent être bons, mais que ce n'est qu’à l'infusion qu'on 
peut s'assurer positivement de leur mérite, et classer leur valeur; car, de toutes les denrées connues, c'est la seule peut-être qui, en satisfaisant l'œil dı connaisseur, peut tromper son goût. On jugera de l'exactitude de cette observation, en réfléchissant à la susceptibilité de l'arôme de cette plante, qu'un peu d'humidité, un emballage mal soigné, ou même un maurais emmagasinage, peurent altérer; l'apparence de la feuille reste la même, mais son goût a changé, et le parfum n'existe plus.

Tous les thés noirs donnent à l'infusion une couleur jaune orange plus ou moins foncée, plus ou moins limpide, mais qui devient louche et terne en refroidissant.

\section{THES NOIRS.}

\section{PEKOE OU PAK-HO.}

Littéralement : duvet blanc.

C'est le plus fin, le plus aromatisé, et le plus cher des thés noir's.

En France, où l'usage du thé n'est encore répandu que parmi les classes aisées, le pekoe y est très-connu, très-apprécié, et notre marché est mieux approvisionné que celui de Londres pour les qualités qu'on y importe. Nais c'est la Russie surtout qui achète et consomme les premières sortes dont elle ra s'approvisionner à Kiakhta, et à la célèbre foire de Nidjni-Nowgorood. Ces thés viennent tous des provinces septentrionales de la Chine, et sont expédiés par caravane a travers la Tartarie chinoise, dont elles sont limitrophes; 
et, soit en raison du mode de transport, du soin extrême qu'on apporte aux emballiges, ou du sol où on les récolte, ils ont un parfum supéricur à ceux qui nous viennent de Canton; aussi leur prix en Russie s'élève de 20 a 80 roubles la livre russe. Les Anglais n'emploient ce thé qu'en le mélangeant arec d'antres thés noirs, pour leur donner du parfum, et encore en mettent-ils fort peu.

Le pekoë a la feuille très-allongée, d'un noir argenté, et couverte d'un léger duvet blane et soyeux; ses extrémités sont tachetées de noir, de gris et de blanc. Dans celui qui nous rient de Canton, on trouve sourent des petits bâtons venant de la tige des feuilles; mais dans celui de Russie, dont les feuilles sont presque toutes argentées, il ne s'en rencontre pas.

Ce thé est la première récolte de l'arbuste, lorsque les . feuilles sont encore en bourgeons; de là lui vient ce parfum si délicat que les Chinois augmentent encore en y mêlant quelques fleurs de l'olea fragrans, dont on trouve fréquemment des graines parmi le pekoë. Comme ce thé se torréfie très-légèrement pour n'en point altérer le parfum, il est plus susceptible que tout autre de se détériorer par le voyage, l'humidité, ou par le temps.

Son goût à l'infusion ressemble un peu à celui de la noisette fraiche.

PEKOE D'ASSA.M (COLONik anglaise).

La feuille de ce thé est à peu près la même que.celle du pekoë de Chine, elle est seulement un pen plus large et moins allongée; mais son infusion diffère entièrement de saveur, de parfum et de goût, étant bien inférieure à 
celle que fournit le pekoë chinois désigné généralement sous le nom de pekoë à pointes blanches.

ORANGE PEKOE.

Nous ne désignons ce thé que par le nom qu'il porte sur les caisses qui viennent de Cantọn, et que les Anglais lui ont donné en raison, sans doute, de sa couleur, qui est d'un noir foncé mélangé de jaune orange. Il est très-menu; son odeur est agréable, quoiqu'elle ne paraisse pas naturelle, car on trouve parmi les feuilles beaucoup de petites graines semblables à celles de l'olea fragrans, dont cependant il n'a pas le parfum. On le boit rarement seul; mais en le mélangeant avec du souchong, il lui donne de 'la force et produit une boisson assez agréable, mais un peu stimulante. Cette sorte n'est apportée sur nos marchés d'Europe que depuis dix à douze ans.

C'est ce thé qui, mélangé avec du congo, se vend à Londres sous la dénomination assez connue de Howqua Mixture (mélange d'How'qua).

Sa couleur à l'infusion est beaucoup moins transparente que celle du souchong.

\section{HUNG NUEY, OU PEKOE NOIR}

Cette sorte est fort rare sur notre marché, et surtout en bonne qualité; la meilleure s'apporte en Angleterre. Sa feuille est inégale en grosseur; elle est frisée à la manière de l'orange pelioë; on y tronve quelques parcelles blanches, des petits bâtons et des pétioles rougeâtres.

Son arôme à l'infusion se rapproche du bon congo. 
CoNGo ( KOONG-HOO).

Littéralement : travail, assiduité ou persévérance.

Le congo, qui est presque inconnu sur notre marché, est de tous les thés noirs celui qui mérite le plus de fixer notre attention.

En Chine, où ses propriétés bienfaisantes sont avérées, il formẹ à lui seul la boisson journalière des habitants du pays.

En Angleterre, où le chiffre de la consommation du thé dépasse annuellement 30 millions de demi-kilogrammes, le congo y figure ì lui seul pour plus des deux tiers, d'après les relevés officiels des importations de la GrandeBretagne. Anciennement la Compagnie des Indes avait établi des primes pour les meilleurs lois qui lui étaient offerts; mais depuis l'abandon de cet usage, on y importe souvent des qualités communes, qui cependant conservent leur goùt de congo bien distinct.

En Russie, où on lui a donné le nom si heureusement significatif de "thé de famille, " on le trouve sur toutes les tables. Il y est certainement d'une qualité supérieure à cẹlui qui nous vient de Canton, mais son prix est beancoup plus élevé.

Le congo se récolte sur Ie même arbre qui a produit le pekoë, et se cueille immédiatenent après lui; seulement il faut que l'arbre ait atteint l'âge de six ans. Ses feuilles sont minces, courtes, plus petites que celles du souchong; sa nuance est d'un noir grisâtre. C'est ainsi que le désignent les essayeurs experts de la Compagnie des Indes. Les qualités inférieures sont plus foncées. 
Le congo superfin est plein d'arôme et de saveur; son parfum a quelque analogie arec celui du pekoë; aussi l'appelle-t-ou souveut pekoë noir. Il est sans contredit un des plus sains et des plus agréables que produise l'arbuste à thé; et je ne mets point en doute qu'on ne lui accorde chez nous la préférence qu'il a trouvée chez tant d'autres peuples, dès que nous aurons pu apprécier son mérite incontestable par un plus fréquent usage.

Il domne à l'infusion un goùt saroureux aupuel se joint une sorte d'amertume agréable et presque impossible à décrire.

\section{SOUCHONG, OU SEAOU-CHUNG.}

Littéralement : sorte petite et rare.

Ce thé est fait avec les feuilles de l'arbusie qui a produit le pekoë et le congo, mais c'est la seconde récolte et lorsqu'elles sont arrivées à leur maturité.

Le souchong jouit d'une grande réputation en Chine. Sa feuille est un peu plus large que celle du congo; elle est mince et tant soit peu concassée, ce qui dénote sạ qualité, car les feuilles jeunes, tendres et bien torréfiées se brisent plus facilement que les antres. C'est le plus fort des thés noirs, et lorsqu'il est mêlé avec dı pekoë il for'me une boisson d'un arôme exquuis.

pouchong (PAOU-Chusg ou PADREA).

Ce thé est supérieur au souchong et très-estimé par les Chinois. Les feuilles en sont larges, longues et bien roulées; elles sont mélangées d'une assez grande quantité de 
pétioles. II s'apporte presque toujours en petits payuets enveloppés de papier d'un jaune clair; ces paquets pèsent environ 200 grammes chacun.

Lettsom écrivait (en 1799) que ce thé n'était apporté que par les officiers de la Compagnie des Indes, et dans des boîtes fort riches toujours destinées pour présents.

L'origine de son nom nous vient de l'usage habituel qu'en faisaient les missionnaires catholirjues, qui sans doute étaient bons dégustateurs.

L'arôme de ce thé est très-fin, suave et délicat. Il est fort léger, et il faut en mettre un peu plus que d'une autre sorte si on reut obtenir une bonne infusion; il dome a l'éau à peu près la même nuance que le bon souchong.

\section{NING-YONG, SORTE DE POCCHONG.}

Les feuilles de ce thé sont extrêmement larges et peu roulées. Il est beaucoup plus torréfié que le souchong, et ressemble en apparence an thé noir de Java; du reste, il rs! incommu sur notre marché, et ce n'est que de temps à autre qu'on le troure sur celui de Londres. Le prix en est peu élevé. Il est droit en goùt, mais il en faut une forte dose pour obtenir une boune infusion.

\section{HOU-LONG.}

Ce thé n'est point comnu en France, et on en trouve fort peu en Angleterre, où il ne s'apporte que pour être offert en présent. Cette sorte ressemble beaucoup au pouchong; les feuilles sont larges et très-peu torréfiées; les Chinois disent eux-mèmes qu’il est fort difficile que ce thé 
arrive en bonne qualité sur le marché d'Europe, malgré les précautions qu'on prend pour l'expédier. Il vient, comme le pouchong, enveloppé dans des feuilles de papier, et ces paquets sont mis soigneusement dans des petites boîtes d'étain renfermées dans des doubles caisses.

\section{CAMPOY, OU KIEN-POEY.}

Littéralement : Thẻ choisi séché au feu.

Il est rare sur notre marché, et surtout en borme qualité. Cette sorte est formée des feuilles les plus délicates et les mieux choisies de la treisième récolte. Elles sont plus larges et plus épaisses que celles du souchong, auciuel il ressemble beaucoup à l'infusion par sa couleur; mais son goût est moins aromatique et plus faible; c'est pour cette dernière raison qu'il est peu gonté des consommateurs. Cependant c'est un bon thé quand il est bien choisi, et, en Angleterre, on l'ordonne comme boisson rafraîchissante.

\section{CAPER (SHWANG-CHE).}

Thé composé de plusieurs sortes.

Cette sorte de thé a des feuilles courtes, frisées, dont la plupart sont ramassées en petites boules rendues compactes au moyen d'une substance glutineuse dont elles sont enduites. Elle n'a jamais été apportée en France pourla consommation. En Angleterre, où ce thé a été fort recherché pendant queliues aniées, on ne l'y trouve plus que très-rarement, en raison des mauraises qualités qu'on y importait. En septembre 1826, à la suite d'un discours 
que fit M. Nicholson sur ce sujet, on en jeta cent mille kilogrammes dans la Tamise.

Sa liqueur dépose au fond de la tasse un sédiment sablonneux mélangé de parcelles métalliques qui provient sans doute de la substance qui forme les boules.

Il faut le laisser infuser longtemps pour en obtenir la saveur.

\section{BOHEA, OU WOO-E.}

Tire son nom d'une rangée de collines très renommées dans la province de Fokien, oủ il se récolte.

Autrefois tous les thés noirs étaient désignés sous ce nom, qui dérive de celui d'un canton de la province de Fokien d'où on les tire principalement. Aujourd'hui cette sorte seule a conservé cette désignation. On peut la classer en deux espèces différentes: le bohea de Fokien et le bohea de Canton. Ce thé est le plus commun de ceux qui viennent en Europe, cependant le bohea de Fokien est d'une qualité moins grossière que celui de Canton. Mais on n'importe guère que de ce dernier, en raison, sans doute, de son bas prix; sa consommation, qui en Angleterre s'était généralisée parmi les basses classes, a tellement diminué d'année en année, qu'elle disparaittia probablement de ce marché, comme du nôtre où il est presque inconnu. Les Chinois font entrer dans sa composition des feuilles de toutes sortes, qu'ils préparent comme du vrai thé, et auxquelles ils mêlent une petite quantité de feuilles naturelles; elles sont larges, plates, inégales, d'une couleur brun-clair et verdâtre, toujours mêlées de poussière et de petits fragments de pétioles. 
L'infusion a peu de force, encore moins de saveur, et parfois un goùt de fumée; elle laisse aussi une sorte de sédiment noir au fond de la tasse.

\section{THES VERTS.}

\section{HYSON, OU HE-CHUN.}

Litlėalement: heureuse fleur du printemps.

Cette étymologie est beaucoup plus juste et plus naturelle que celle qu'on lui a longtemps appliquée, en disant que son nom dérivait de celui d'un négociant de l'Inde qui, le premier, aurait apporté ce thé en Europe. C'est de tous les thés verts le plus généralement estimé, car la Compagnie des Indes a jusqu'à présent donné des primes pour les deux meilleurs lots choisis dans ceux qu'elle achète amnuellenent, de même qu'elle le faisait autrefois pour le congo, et ce motif d'émulation a soutenn la qualité de ce thé, surtout à cause du renom qu'il donne aux négociants chinois qui obtienment ces primes. C'est la première récolte du thé vert; sa feuille est longue, étroite, charnue, bien tournée en spirale, d'un vert argenté, ou, pour mieux dire, couverte d'une sorte de fleur comparable à celle d'un fruit sur l'arbre. Ainsi ce thé ne doit pas être reluisant comme le vendent quelques marchands qui lui donnent cette apparence factice en le frottant avec du talc pour qu'il soit plus flatteur à l'œil, ce qui ôte peu de chose à sa qualité mais ajoute beaucoup à son poids. L'hyson, en qualité supérieure, est ordinairement très-lourd, quoique 
très-sec et facile à lriser. Il est très-sensible à l'action de l'air; il a du reste ceci de commun avec tous les thés verts: cette espéce n'ayant pars, comme les noirs, subi de torréfaction prolongée, ils sont bien plus aptes que ces derniers ¿i se détériorer par l'air, le temps ou l'humidití.

Il faut, pour en obtenir la saveur, le faire infuser longtemps; alor's sa feuille s'ouvre entièrement el devient trissouple: si elle restait crispée, le thé ne serait pas de bonne qualité. Il teint l'eau d'une nuance jaunc-citron limpide, et la parfume d'une odeur agréable. Son gout est, comme celui de tous les bons thés verts, ın peu âcre lorsqu'on le prend scul.

Tous les thés rerts, de même que les thés noirs, domnent à l'üfusion cette même nuance plus ou moins foncée.

\section{HYSON JUNIOR (YC-TSEEN).}

Avant les pluies.

L'hyson junior est formé de petites feuilles très-délicates qui se cueillent de bonne heure dans la saison, ainsi que son nom l'indique : "Arant les pluies. » Cette récolte est peu abondante, et rend ce thé trop rare pour l'avoir naturel, surtout depuis quelques années où les Américains en ont fait de si fortes demandes que, ne pourant y sitisfaire loyalement, les Chinois coupèrent les feuilles d'autres thés, et les passèrent à travers des tamis de certaine dimension, pour remplir d'une manière quelconque les commandes qui leur étaicnt faites. Les inspecteurs de la Compannie des Indes s'aperçurent de la fraude et n'en expédièrent pas une seule caisse en Angleterre. Quand ce 
thé est naturel, la feuille est très-petite, délicate, bien crispée, d'un vert jaunâtre, et d'un parfum très-doux ressemblant un peu à la violette.

\section{HYSON-SCHOULANG.}

C'est encore une variété du hyson de première qualité; sa feuille est la même, mais son arôme diffère entièrement des autres sortes. Lettsom dit que "pour lui donuer ce goût suave, on y mêle des fleurs de l'olea fragrans. „ Mais comme nous avons ru plus haut que cette fleur sert à parfumer le pekoë dont le goût est tout à fait différent, il est probable que c'est le mode de préparation dont on se sert qui lui donne ce parfum; toutefois ce moyen nous est inconnu. Ce qu'il y a de certain, c'est que l'hyson schoúlang est un thé qui se prépare pour quelques marchés seulement, car on est obligé de le commander une année à l'avance pour en obtenir de véritable. Son goutt a peu d'analogie arec les autres thés verts, en raison du parfum étrange qui y domine.

HYSON SKIN,

Littéralement : rebut.

Les Chinois l'out ainsi nommé par allusion sans doute à la peau d'un animal, à la pelure d'un fruit, etc., skin signifiant aussi peau, écorce, enveloppe, enfin rebut, cette traduction indique donc d'où ce thé tire sa source. En préparant l'hyson, on en retire toutes les feuilles jaunes, communes, et qui ne sont pas roulées, pour former le hyson 
skin qui se vend très-bon marché, et se consomme dans les ports de mer par les matelots et les gens des classes laborieuses. Son goût est un peu ferrugineux.

\section{POUdR: A CANON (CHOU-CHA).}

Littéralement : Thé perlé.

Ce thé n'est autre chose que le hyson soigneusement trié et formé des feuilles les mieux roulées en petites boules très-serrées. Ce triage se fait en le torréfiant, ainsi qu'il est indiqué au chapitre VI, et l'on voit que ce sont les feuilles les plus fines et les plus petites qui se roulent le micux et le plus promptement. Leur choix forme cette sorte de graine ronde qui lui a valu le nom de "petites perles de thé. $)$

Il a donc plus de parfum que le hyson, et renferme une substance plus active, parce que la feuille étant plus fortement roulée, le suc qu'elle contient se comprime davantage et se conserve mieux que dans les autres thés verts, qui ne sont roulés qu'en longueur seulement. Ce thé est très-lourd, d'un vert un peu plus foncé que le hyson, et ses globules doivent être très-réguliers et sans poussière, car ce thé se concasse moins facilement que le hyson.

Il faut qu'il infuse longtemps pour déployer ses feuilles, et il donne à l'eau une belle teinte d'un vert doré.

\section{IMPÉRIAL.}

Cette sorte se forme, comme la poudre à canon, du triage de l'hyson, et se fait de la même manière; 'seulement les grains en sont beaucoup plus gros, parce que les 
feuilles sont plus larges, mais elles doivent être roulées eai boules aussi serrées et aussi dures. Elles sont d'un vert argenté, et contiennent un principe moins actif que la poudre à canon.

Il est presque inutile de dire que ce thé, désigné sous le nom d'impérial, n'est pas le même que celui dont il est parlé au chapitre $\mathrm{V}$, lequel est destiné pour la cour de Pékin, et ne se trouve jamais dans le commeree.

Kompher dit seulement "que le thé impérial préparé pour l'exportation se cueille en février, quand les fẹuilles sont en bourgeons, et que le meilleur croît sur les montagnes. ')

Mais comme cette récolte ne serait pas assez aboudante pour fournir aux demandes des deux continents, le the qui vient sous le nom d'impérial n'est autre que celui que j’indique ci-dessus. Il réclame une infusion aussi longue que la poudre à canon.

TONKAY, OU TEN-KE.

Thé croissant sur le bord d'un ruisseau.

Ce nom bizarre lui vient probablement de celui d'une petite rivière qui arrose la partie de la province de KianHan, où il se récolte. C'est la dernière cueille de la saison d'été. Cette sorte est moins commune que le hysou skin, quoi qu'elle se compose aussi du second triage de l'hyson; mais en général les feuilles sont larges, jaunâtres, mal roulées, car on apporte peu de soin à leur préparation; en un mot, c'est le bohea des thés verts. Cependant il forme 
plus des deux tiers des importations de thé vert de la Grande-Bretagne, parce qu'en raison de son bas prix les détaillants le mêlent avec d'autres thés verts. Son infusion est d'une coulemr brun clair tirant sur le jaune terne, et elle a souvent un léger gont de poisson. 


\section{CHAPITRE X.}

Manière de préparer la boisson du Thé.

Quoique le thé ne se prenne généralement qu'en infusion et que ce procédé soit fort simple, il est indispensable d'y apporter les soins que nous allons indiquer pour obtenir toute la saveur de cette plante, dont l'arôme est si subtil et si délicat, qu'un degré plus ou moins élevé de chaleur, de l'eau plus ou moins pure peuvent en altérer le goût naturel.

Il faut verser de l'eau bouillante dans la théière pour l'échauder; on reverse ensuite cette eau dans les tasses pour le mème motif. Après avoir égoutté la théière on y met le thé. Quand l'eau est bien bouillante, on la verse jusqu'à moitié du vase environ, c'est-à-dire de manière à couvrir entièrement les fenilles. On referme la théière et on laisse infuser six à huit minutes, au bout desquelles on ajoute l'eau nécessaire pour le nombre de tasses qu'on veut faire. On laisse encore infuser deux minutes avant de verser le thé dans les tasses qu'on a eu soin de vider; on y met le sucre, on verse le thé et on y mêle environ deux petites cuillerées à bouche de crême froide qui n'aura pas été bouillie. Il faut huit grammes de thé pour deux tasses; c'est environ une forte cuillerée à.café par 
chacque tasse; si l'on veut en faire quatre tasses, douze grammes suffiront; il en faudra trente pour douze tasses.

Comme il serait par trop embarrassant de peser charque fois ces diverses quantités, nous nous servons ici de l'évaluation approximative de cuillerée; toutefois cette désignation ne se rapporte qu'au thé mélangé de noir et de vert. Les persoines qui ne prennent que du thé noir, et surtout du pekoë ou du pouchong observeront que ces thés ont les feuilles très-larges, qu'ils sont fort légers et qu'ils remplissent la cuillère sans former le poids nécessaire pour une bonne infusion; il faut donc en mettre davantage pour atteindre à peu près les quatre grammes. C'est exactement le contraire pour les thés verts : ils sont plus lourds, plus compactes, et le même volume pèse par conséquent presque le double de celui des thés noirs; ainsi done, il faut en diminuer la dose proportionnellement

C'est une condition rigoureuse que l'eau versée sur les feuilles soit très-bouillante; de là dépend la finésse et l'arôme de cette boisson. Le thé préparé avec de l'eau chaude seulement ne se déroule point et ne donne qu'une infusion pâle et sans saveur.

Cette précaution est du reste économique; il est facile de comprendre que pour obtenir une bonne infusion, il faut moins de thé avec de l'eau bouillante qu'avec de l'ean chaude, attendu que la première dégage beaucoup mieux les principes aromatiques des feuilles.

Il faut toujours avoir soin, lorsqu'on veut servir consécutivement plusieurs tasses, de ne vider la théière qu'à moitié, et de la remplir d'eau immédiatement. Au moyen de cette précautıon, le thé destiné au second tour achève 
de s'infuser pendant qu'on boit les premières tasses qui seront ainsi toutes égales en force et en goût. Si l'on faisait du thé pour un plus grand nombre de personnes que la théière ne contiendrait de tasses, il faudrait épuiser entièrement l'infusion au premier tour, et remettre dans la théière vidée à peu près la moitié de la dose primitive. La qualité de l'eau est extrêmement essentielle pour faire du bon thé; la plus pure et la plus douce est la meilleure. On doit encore avoir soin que le vase dont on se sert pour faire bouillir l'eau soit exclusivement consacré à cet usage, car, dans nos cuisines on se sert indistinctement des mêmes bouilloires pour les décoctions de tilleul, de graine de lin, de camomille, etc. Ces végétaux laissent après eux un mélange d'odeurs dont le thé, plus encore que toute autre substance, est susceptible de s'imprégner.

L'eau, comme je l'ai dit, dọit être versée dans la théière aussitôt qu'elle est arrivée à son plus haut degré d'ébullition; si elle séjournait plus longtemps sur le feu, elle risquerait de prendre un goût terreux et fade qui se communiquerait à l'infusion.

Les théières d'argent ou de métal sont supérieures pour infuser le thé à celles de porcelaine, attendu qu'elles sont de meilleurs conducteurs du calorique et qu'elles ont la propriété de s'imprégner davantage de l'arôme du thé.

Le soin et l'excessive propreté que les Chinois mettent dans la manipulation du thé démontrent assez combien cette plante est susceptible de s'imprégner des moindres odeurs; et l'on ne saurait trop recommander aux consommateurs d'éviter de mettre leur thé dans un endroit qui contiendrait des objets odoriférants, de quelque nature qu'ils puissent être. Les seules boîtes propres à con- 
server le thé sont en plomb, ou dloublées de plomb et en fer blanc; seulement, avant de se servir de ces dernières, i) faut prendre le soin de les aromatiser, en y faisant infuser du thé, afin de leur ôter l'odeur que leur clomne la térébenthine dont on se sert pour la soudure de ces boîtes. 


\title{
CONCLUSION.
}

\author{
Dans les grandes affaires on doit moins s'appliquer \\ à faire naître les occasions qu'à profiter de celles \\ qui se présentent.
}

Max. de La Rochefoucault.

Le sujet traité dans cet ouvrage se lie naturellement à une question d'une haute portée et qui commence aujourd'hui à fixer l'attention sérieuse du gouvernement et du pays; nous voulons parler de l'opportunité d'établir des rapports de commerce avec l'Indo-Chine. Déjà nous avons publié dans ce but deux petites brochures, l'une en 1839, intitulée: Réflexions sur notre commerce avec la Chine comparativement avec l'Angleterre, et projet d'améliorations pour l'importation des thés et marchandises de l'Indo-Chine en France; et l'autre en 1840, ayant pour titre : Lettre ì messieurs les députés sur l'opportunité d'établir des relations commerciales avec la Chine ${ }^{I}$.

Dans la première de ces brochures, nous énumérions avec toute la puissance de logique que donne une conviction fondée sur des faits et des chiffres, les immenses

- Se trouventchez l'auteur, rue de la Bourse, n* 3. 
avantages qui résulteraient pour notre pays s'il ouvrait des relations commerciales directement avec la Chine, au lieu d'abandonner ce riche débouché an monopole exclusif des Anglais et des Américains ${ }^{\text {I }}$.

N'envisageant d'abord que la spécialité des thés, nous faisions remarquer que le développement de la consommation de ce produit en France ne s'accomplissait que lentement, bien qu'on ait vu cependant dans le tableau des statistiques, au chapitre II, que nous sommes à cet égard plus avancés que ne l'était la Grande-Bretagne au bout des cinquante premières années de l'introduction de ce végétal exotique; car le thé n'a réellement pris rang dans notre consommation domestique que depuis environ

' Pour donner une idée de l'activité des rapports commerciaux de la GrandeBretagne avec la Chine, avant li dernière guerre, il suffit de dire que le chiffre de ses importations s'est élevé en 1837 à 200 millions, et celui de ses exportatious à 220 millions, non compris l'opium que les possessions anglaises de l'Inde fournissent au céleste empire. Ce seul article s'èlevait, en 1838 , à plus de 67 millions. I.es exportatious de l'A ngleterre en Chine et de la Compagnie des Indes consistent en cuivre, en fer, en plomb, elı étain, en verreries, en poteries, én joaillerie, en calicots imprimés, en cotons lilès, en laines, en draps de toutes sortes, en poivre, etc.

Les importations de la Chine sont en tlıé, en sucre, en porcelaine, en soieries de toutes sortes, en nankins, en casse, en camphre, en cannelle, etc. Le commerce des Américains avec les Chinois šélève, terme moyen, chaque année, à 7 millions de dollars pour les exportations $(37,100,000$ fr. $)$, et à 6 millions et demi de dollars pour les importations $(3 i, 450,000$ fr. ). Pour les importations, elles consistent en lingots d'or ou d'argent, en graine de Turquie, en laines, cotons anglais et pelleteries; les secondes en thés, nankins, soies écrues et filées, camplire, etc. Si on met en regard de ces chiflres le total des importations et des exportations françaises dans la mème année 1837, on est affeclé d'une pénible surprise. car les premières ne s'élèvent qu'à 591,595 francs, et les secondes à 2 millions. Il est vrai que, depuis 1837 , notre commerce avec la Chine a subi une notable extension, et qui ne tend qu'à s'accroître; une grande partie de nos envois consiste en argenı; le reste se compose de draps et quelques objets de fabrique de Paris. Les retours sont en thés, soies écrues et unies, nankins, cannelle, camphre, musc, rhubarbe, anis, porcelaine, rotins, et quelques objets de fantaisie. Les thés composent la moitié, à peu près, des chargements. 
vingt-cinq ans, et encore u'en faisons-nous presque point usage comme boisson alimentaire.

Les quelques petits navires expédiés en Chine, à de longs intervalles, des ports de Bordeaux, de Nantes et du Havre, vont rarement à Canton, parce qu'un bàtiment de trois cents tonneaux paie le même droit qu'un de mille. Ils s'arrêtent donc presque toujours à Nacao, et ils stationnent dans cette rade jusqu'à ce.que leur chargement de retour soit effectué. Les achats sont généralement faits par l'intermédiaire des comptoirs anglais, qui exigent d'énormes commissions s'élerant sourent à 15 p. 100.

La concurrence formidable de l'Angleterre et des ÉtatsUnis, jointe au peu de notions exactes que nous possédons sur' les marchés de l'Indo-Chine, empêche nos armateurs d'y envoyer des marchandises en quantité suffisante pour solder en échange leurs cargaisons. Ils sont donc obligés de payer comptant, soit en or, soit en argent, à moins qu'ils ne recourent aux maisons de batique anglaises, qui ne leur prệtent leur crédit qu'à des conditions souvent exorbitantes.

Pour le retour, ils ne peurent rapporter qu'un trèspetit nombre de sortes de marchandises, à cause de notre législation de douanes, qui en interdit l'importation.

Ce concours de circonstances explique suffisamment la cherté du thé dans notre pays; et cette cherté, combinée avec l'indifférence qu'on a apportée jusqu'ici à propager le goût de cette boisson, a dû nécessairement en liniter l'usage anx classes aisées.

En demandant qu'on se rapprochàt commercialement de la Chine, ce n'était pas seulement la cause du thé que nous avions en vue de défendre, mais celle beancoup plus 
importante de notre marine marchande et de notre industrie manufacturière, et pour ue pas laisser plus longtemps à nos roisins le privilége exclusif d'approvisionner l'une des plus riches contrées de l’Asie de produits que nous pouvons lui fournir aux mêmes prix qu'eux. Nous avions résumé dans cet écrit les différentes canses qui arrêtaient l'essor de nos armateurs, et qui empêchaient des expéditions plus fréquentes dans les mers de Chine; et nous proposions quelques modifications temporaires dans notre législation actuelle, afin qu'il leur fùt permis de payer leurs chargements en marchandises, etc., etc.

Telle était la substance de notre premier travail, qui ohtint l'assentiment de quelyues hommes spéciaux et de plusieurs écononistes distingués.

Encouragé par ces suffrages, nous crûmes devoir faire paraitre notre second ménoire, complément indispensable du premier.

Les graves événements dont l'Indo-Chine était devenue le théâtre lui domaient un caractère manifeste d'importance; les débats des Anglais avec les Chinois avaient dégénéré en une guerre ouverte; le sang avait coulé. Cette rupture déclarée, quelle qu'en fùt l'issue, offrait à notre pays la perspective de jeler dans ces lointains parages les bases d'une concurrence conımerciale à nos voisins. Dans ceite conjoncture, il importait, suivarıt nous, que le siége du consulat géméral fût transféré de Manille à Canton ${ }^{\mathrm{I}}$, et que quelques changenents que nous indiquions fussent apportés dans la nomination et le traitement de nos agents consulaires. Nous terminions en demandant que notre

1. Canton était alors le seul port unvert au commerce européen. 
factorerie fût graduellement organisée sur le même pied que celles de l'Angleterre et des États-Unis, pour donner à notre commerce appui et protection, et relever le prestige de notre pavillon dans ces mers éloignées, où, il y a un siècle à peine, il éclipsait celui même de la GrandeBretagne.

'Telles étaient les vues déreloppées dans notre seconde brochure, et sur lesquelles nous appelions l'examen du pouvoir législatif. Ces vues, qui ne pouvaient manquer .obtenir l'adhésion de tous ceux de nos concitoyens qui ne sont point indifférents aux besoins de notre commerce maritime, ne devaient que deux ans plus tard recevoir un commencement d'application.

Grâce, en effet, au dénouement de la lutte des Anglais avec les Chinois, le céleste empire est un marché désormais acquis à l'Europe et à l'Amérique. Le triomphe des armes britanniques est peut-être un bienfait dans l'avenir pour la patrie de Confutzée, arrachée de son immobilité séculaire, et qui, au frottement continuel de notre civilisation, se dépouillera insensiblement de ses préjugés et de sa défiance pour adopter nos arts et nos découvertes. C'est une destinée providentielle de la Grande-Bretagne que, tout en poursuivant avec une ténacité, une énergie indomptables, ses plans égoïstes de domination commerciale, elle sert presque toujours à son insu la cause du progrès et de l'humanité!

Les Chinois, nous le croyons, sont appelés, d'ici à un certain nombre d'années, à fournir une nouvelle preuve de la justesse de cette réflexion. Donés d'une remarquable aptitude pour l'ag̣riculture, le négoce, les travaux manuels; d'un génie sagace, patient et laborieux, ils recon- 
naîtront inévitablement tòt ou tard la supériorité de nos arts et de nos inventions, et comprendront, par suite, la nécessité de se mettre, sous ce rapport, au niveau des autres nations. Aux yeux des peuseurs, les canous anglais ont hrisé les digues qui reudaient le plus grand empire de l'Asie impémétrable à la civilisation occidentale.

Ce rapprochement de la Chine avec l'Europe sera sans doute d'abord timide, circonspect, réservé; mais il se transformera insensiblement en une franche et indissoluble alliance commerciale. La première ne tardera pas à comprendre qu'il y a une solidarité naturelle entre les natious comme entre les individus, et que la Providence, en domnant à chaque pays quelque chose dont les autres manquent, a évidemment voulu qu'elles dépendissent les unes des autres, et que cette réciprocité d'échanges de leurs produits fût tout à la fois le lien des sociétés et le principe de tout progrès matériel et intellectuel.

Envisagé sous ce point de vue élevé, le succès de l'expédition anglaise est un érénement qui, à bon droit, a appelé l'attention de l'Amérique et des principaux états de l'Europe. La France surtout n'en est pas restée spectatrice inerte, et les mesures pleines de tact et d'habileté qui, déjà, ont été prises à ce sujet, sont les préliminaires de ce qu'un gouvernement sage et éclairé fera sans doute pour établir notre influence commerciale dans l'Indo-Chine. Mais, pour concourir d'une manière plus efficace à l'accomplissement de cette graude cuvre, il faudrait emprunter d la législation anglaise le mode d'enquête auquel elle a recours pour obtenir les renseignements les plus sûrs et les notions les plus précises sur toutes les questions qui intéressent chaque genre d'industrie. Ainsi, en sup- 
posant aujourd'hui que le gouvernement envoie en Chine une mission diplomatique à laquelle il adjoindra des agents commerciaux pris dans les différentes branches de la production française, il serait à désirér qu'il nomıât, premièrement, une commissinn spéciale choisie dans l'administration, dans les conseils et chambres de commerce; parmi les manufacturiers, les négociants et les armateurs; cette commission serait en rapport direct, d'une part, avec ces derniers; de l'autre, avec le gouvernenent et même les Chambres, s'il en était bssoin, et elle leur fournirait tous les documents propres à éclairer la question. Elle présenterait au choix du ministre les candidats qu'elle jugerait réunir les qualités nécessaires pour devenir d'excellents agents commerciaux eu Chine. Expédiés et rémunérés aux frais du trésor, ces agents étudieraient aree soin, sur les lieux, les bésoins, les goùts et les habitudes des Chinois; ils recueilleraient les informations les plus exactes sur les produits nationaux qu'il conviendrait de leur exporter. A leur retour en France, ils seraient tenus de consigner les résultats de leurs investigations respectives dans un rapport collectif dressé et rédigé par l'un d'eux. Cette pièce serait soumise à l'examen de la commission, qui appellerait ensuite devant elle ces agents pour les interroger individuellement sur chacune des spécialités qu'ils auraient été chargés d'explorer. Ces enquêtes verbales, dont on est trop sobre encore dans notre pays, sont éminemment propres à éclairer une question neuve et compliquée d'intérêt matériel; elles constatent toujours des faits ignorés ou peu comnus : or les faits, en matière commerciale surtout, sont la base de toute détermination sage et prudente. 


\section{LISTE}

JES PRINCIPAUX AUTEURS QUI ONT ÉCRIT SUR LE THÉ.

Ricc I (Mathieu), de la Compagnie de Jésus; Mission catholique en Chine. .................... 1590

Leinsciotren, Hollandais; De l'île du Japon. . . . . . . . . 1599

Baunin, Francais; Pinax theatri botanici. . . . . . . . 1597

Rhodes (Alexandre d $\bullet$ ), de la Compagnie de Jésus; Sommaire de divers voyages apostoliques. . . . . . . . . . 1653

JoxQUEr, médecin français; Éclaircissements sur quelques plantes imparfaitement désignées par les Arabes et les botanistes modernes........................ 1612

Paul (Simon), IIollandais; De l'abus du tabac et de l'herbe du thé. ........................ 1635

Tulpius (Nicolas), médecin hollandais; Observations médicales. 1640

Oleırius (Adam), royageur hollandais; Voyages en Chine. . . 1633

Morisset, médecin français; Apologie du thé. . . . . . . 1648

Kırcher, jésuite; De la Chine illustrée. . . . . . . . 1657

Ma ppus, Hollandais; Du thé, du café et du chocolat. . . . . . 1675

Dufour; De l'usage du thé, du café et du chocolat, traduit de l'anglais en latin par J. Spon. . . . . . . . . 1685

Pechlin; Theophilus bibaculus. . . . . . . . . . 1684

BlegNy, nuédecin français; Le bon usage du thé, etc. . . . . 1680

Commens; idem. . . . . . . . . . . . . . 1687

République des lettres, février 1685 , tome III.

Petrut (Pierre); Poëme latin sur le thé. . . . . . . . . 1685

Bentekoe (Cornelius), médecin hollandais; Traité sur l'excellente boisson du thé. .................... 16i8

Berries (Juniper), Anglais; Histoirénaturelle du thé, du café, etc. 1683 
Cossurz, Allemand ; Économie de la nature avec démonstration du thé, etc. . . . . . . . . . . . . . . 1687

Lecomte, jésuite; Histoire de la Chine. . . . . . . . . . 1697

Rena u dot; Anciennes relations de la Chine et des Indes. . . 1712

KoEMPFER, voyageur hollandais; Amœnitates exoticæ. . . . . . 1712

LEMERY ; Traité des aliments. . . . . . . . . . . . . . 1712

Cuningham; Des diverses espèces de thé. . . . . . . . . 1718

Lettres curieuses et édifiantes des Jésuites.

Sновт, médecin anglais; Dissertation sur la nature et les propriétés du thé. . . . . . . . . . . . . . 1730

Du Halde, jésuite; Description générale, etc. . . . . . 1735

LEFÈYre; De la nature et de l'usage du thé. . . . . . . . 1737

LINÝE; Dissertatio potûs thex. . . . . . . . . . . 1763

JACQuis (L'abbé); Dela santé utile à tout le monde. . . . . . . 1763

Buchoz, médecin du roi de Pologne; Dissertation sur le thé, ete. 1775

Dictioxyaire de l'Excyclopédie, årticle Thé. . . . . . 1765

Le Bègue de Presles; Le conservateur de la santé. . . . . . 1763

Osbers, navigateur suédois; Voyages en Chine. . . . . . . 1771

Fougeroux; Mémoire sur le thé adressé à l'Acad. des Sciences. 1775

Thunberg, naturaliste suédois; Flora japonica. . . . . . 1784

Staunton; Récit authentique de l'ambassade anglaise en Chine. 1797

LETTSOM, médecin anglais; (Histoire naturelle du thé). . . . . 1799

Barkow; Voyage en Chine. . . . . . . . . . . . . . . 1804

Vextexat, botaniste français; Flore française.

$\begin{array}{ll}\text { Poirel, idem. } & \text { idem. } \\ \text { Desfontaines, idem. } & \text { idem. }\end{array}$

ViREY, membre de l'Institut; (L'usage du thé vert, etc.). . . . 1815

Newriar ; Observations sur les propriétés médicales et diététiques du thé. . . . . . . . . . . . . . . . . . 1827

A BEL ; Ambassades de lord Amherst en Chine . . . . . . . 1817

Dictionvaine de médecine, article Thé, par MII. les professeurs Richard et Mirbel.

SignOND, professeur de thérapeutique à la Société médico-botanique de Londres; (Du thé, de ses effets médicinaux et moraux).

Auber (Peter); Esquisse de la Chine, de son gourernement, de ses lois, etc. . . . . . . . . . . . . . . . . . . . 1834 
Matheson, négociant anglais demeurant à Canton; Du commerce britannique avec la Chine, etc. ......... 1836 Phisiologie du thé, par un auteur anonyme. Londres. . . . 1827 Journal de la Société asiatique du Bengale, année. . . . . . 1839 BruCE, surintendant des plantations du Haut-Assam ; Rapport à la Compagnie des Indes. . . . . . . . . . . . . . 1839

Carpena, vicaire apostolique du Saint-Siége; Manuscrit. . . . 1839

Medнunst, missionnaire anglais; Ltat de la Chine. . . . . . 1840

Davis; Description générale de l'empire de Chine et de ses habitants........................ 1841

Robert Mudde; De la Chine, de ses ressources particulières, etc. 1840 Tradescant LAY; Les Chinois comme ils sont, leur caractère social, moral et littéraire. . . . . . . . . . 1841 
-

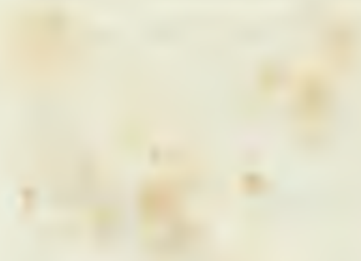




\section{TABLE DES MATIERES.}

Pages.

DU THÉ.

Chapitre Ier. - Histoire du thé et son introduction en Europe. . . . 4 4

Chap. II. - Tahleaux statistiques des importations du thé dans les divers états de l'Europe et de l'Amérique. . . . . . . . . . 20

Chap. III. - Origine du thé. - Sa description botanique. . . . . . 37

Cuap. IV. - Des cultures du thé. . . . . . . . . . . 47

Cirap. v. - De la récolte des feuilles. . . . . . . . . 60

Crap. VI. - De la torréfaction du thé, et de l'enroulement des feuilles. 67

$\$$ Ier. - Torréfaction des thés noirs. . . . . . . . . 69

\$ 2. - Torréfaction du thè vert. .............. 76

Crap. VII. - Sur la composition chimique du thé, par M. Eug. Péligot, professeur au Conservatoire des arts et mètiers. . . . . . . 85

Cinap. VIIL. - Propriétés médicales et hygiéniques, par le docteur Trousseau, médecin de l'hôpital Necker, professeur de thérapeutique à la Facultè de Médecine à Paris, etc., etc. . . . . . . . . 109

$\$$ Ier. - De l'influence du thẻ sur l'homme sain. . . . . . . . 110

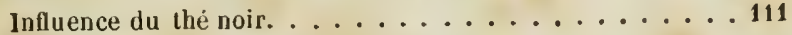
Enets secondaires. - Excitation générale. ...... 112

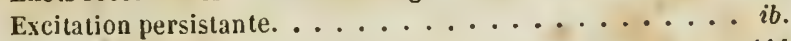

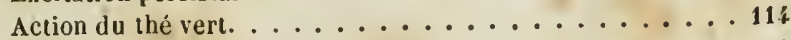
Influence du thé sur la digestion. ...................... Obésité produite par le thé. ............ 117 
- Influence sur les dents. . . . . . . . . . . 120

Inlhence dangereuse du the. . . . . . . . . . . . 121

Résumé de la première partie. ............ 122

\$2. - Des usages du thé en médecine. . . . .......

Chap. IX. - Classification. . . . . . . . . . . . 128

Cuap. X. - Manière de préparer la boisson du thé. . . . . . . 14 14

Conclusion. . . . . . . . . . . . . . . . 149

Liste des principaux auteurs qui ont écrit sur le thé. . . . . . 155 



